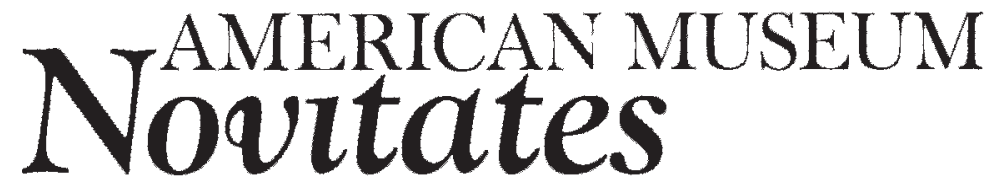

PUBLISHED BY THE AMERICAN MUSEUM OF NATURAL HISTORY CENTRAL PARK WEST AT 79TH STREET, NEW YORK, NY 10024 Number 3687, 56 pp., 28 figures, 2 tables

June 25, 2010

\title{
The Genus Hadruroides Pocock, 1893 (Scorpiones: Iuridae), in Peru: New Records and Descriptions of Six New Species
}

\author{
JOSÉ A. OCHOA ${ }^{1}$ AND LORENZO PRENDINI ${ }^{1}$
}

\begin{abstract}
We review the taxonomy of the Hadruroides Pocock, 1893 (Iuridae: Caraboctoninae), scorpions of Peru, describe six new species from the north of the country, and report new records of other poorly known species. The description of these species raises to 16 the number of described species in the genus, 13 of which occur in Peru. Four species inhabit dry forest in northern Peru: $H$. charcasus (Karsch, 1879); H. chinchaysuyu, n. sp.; H. geckoi, n. sp.; H. leopardus Pocock, 1900. Three species occur in inter-Andean valleys along the Cordillera: $H$. bustamantei Ochoa and Chaparro, 2008; H. carinatus Pocock, 1900; H. mauryi Francke and Soleglad, 1980. Six species inhabit desert along the Pacific coast: H. aguilari Francke and Soleglad, 1980; H. graceae, n. sp.; H. juanchaparroi, n. sp.; H. lunatus (L. Koch, 1867); H. tishqu, n. sp.; H. vichayitos, n. sp. Most species of Hadruroides have restricted distributions, except $H$. charcasus and $H$. lunatus, which are apparently more widely distributed. We consider it necessary to reassess all previous records of the latter two species, because we suspect several are based on misidentifications.
\end{abstract}

\section{INTRODUCTION}

Hadruroides Pocock, 1893, is a small genus of Neotropical iurid scorpions, currently comprising 10 species (Maury, 1975; Francke and Soleglad, 1980; Lourenço, 1995; Sissom and Fet, 2000; Ochoa and Chaparro, 2008), included in subfamily Caraboctoninae Krae- pelin, 1905, together with Caraboctonus Pocock, 1893, a monotypic genus endemic to Chile (Francke and Soleglad, 1981; Prendini and Wheeler, 2005; Francke and Prendini, 2008). Hadruroides has been reported from Bolivia, Chile, Colombia, Ecuador, Peru, and Venezuela (Karsch, 1879; Pocock, 1900; Mello-Leitão, 1945; Esquivel de Verde, 1968;

\footnotetext{
${ }^{1}$ Scorpion Systematics Research Group, Division of Invertebrate Zoology, American Museum of Natural History, Central Park West at 79th Street, New York, NY, 10024-5192 (jochoa@amnh.org; lorenzo@amnh.org).
} 
TABLE 1

Currently recognized species of the scorpion genus Hadruroides Pocock, 1893, with countries and departments or provinces from which they have been recorded

Hadruroides aguilari Francke and Soleglad, 1980

Hadruroides bustamantei Ochoa and Chaparro, 2008

Hadruroides carinatus Pocock, 1900

Hadruroides charcasus (Karsch, 1879)

Hadruroides chinchaysuyu, n. sp.

Hadruroides galapagoensis Maury, 1975

Hadruroides geckoi, n. sp.

Hadruroides graceae, n. sp.

Hadruroides juanchararroi, n. sp.

Hadruroides leopardus Pocock, 1900

Hadruroides lunatus (L. Koch, 1867)

Hadruroides maculatus (Thorell, 1876)

Hadruroides mauryi Francke and Soleglad, 1980

Hadruroides tishqu, n. sp.

Hadruroides udvardyi Lourenço, 1995

Hadruroides vichayitos, n. sp.

\author{
Peru: Lima \\ Peru: Ayacucho, Huancavelica \\ Peru: Cajamarca \\ Peru: Lambayeque, Piura, Tumbes? \\ Peru: Tumbes \\ Ecuador: Galápagos \\ Peru: Cajamarca \\ Peru: Ancash \\ Peru: Trujillo, Ancash \\ Peru: Lambayeque \\ Peru: Lima \\ Ecuador: Manabí, Guayas \\ Peru: Cusco \\ Peru: Ancash (Isla Santa) \\ Ecuador: Azuay, Loja \\ Peru: Piura
}

Kinzelbach, 1973; Maury, 1975; Cekalovic, 1983; Sissom and Fet, 2000), but is actually restricted to Ecuador, Peru, northern Chile, and several offshore islands, including the Galápagos (Cekalovic, 1966; Maury, 1975; Francke and Soleglad, 1981; Ochoa, 2005; unpubl. data). Species of Hadruroides inhabit inter-Andean valleys, Pacific desert, and dry forest habitats.

In the present contribution, we describe six new species of Hadruroides from northern Peru, collected during recent fieldwork, and report new records of other poorly known species. The description of these species raises to 16 the number of described species in the genus. Thirteen of these occur in Peru (table 1; figs. 1, 2).

\section{MATERIAL AND METHODS}

Most of the material reported here was collected during the course of several field expeditions to Peru in recent years, especially 2004 and 2008. Specimens were collected during the day by turning rocks or stones, and at night by ultraviolet (UV) light detection (Stahnke, 1972). Point-locality records were georeferenced in the field with a portable Garmin GPS V.

Material is deposited in the following collections: American Museum of Natural History, New York (AMNH); Natural
History Museum, London, U.K. (BMNH); Cátedra de Diversidad Animal I, Facultad de Ciencias Exactas, Físicas y Naturales, Universidad Nacional de Córdoba, Argentina (CDA); Field Museum of Natural History, Chicago (FMNH); Museo Civico di Storia Naturale "Giacomo Doria," Genova, Italy (MCSNG); Museo de Historia Natural, Universidad Nacional de San Antonio Abad del Cusco, Peru (MHNC); Museo de Historia Natural, Universidad Nacional San Agustín, Arequipa, Peru (MUSA); Museo de Historia Natural, Universidad Nacional Mayor de San Marcos, Lima, Peru (MUSM); U.S. National Museum of Natural History, Smithsonian Institution, Washington (USNM); Museum für Naturkunde der HumboldtUniversität, Berlin, Germany (ZMB); Zoologisches Museum der Universität Hamburg, Germany (ZMH).

Morphological terminology follows Vachon (1974) for trichobothrial nomenclature; Vachon (1952) and Prendini (2000) for pedipalp carinae, abbreviated as follows: internomedian (IM), dorsointernal (DI), dorsomedian (DM), dorsoexternal (DE), externomedian (EM), ventroexternal (VE), ventromedian (VM), ventrointernal (VI), dorsal patellar process (DPP), ventral patellar process (VPP); Stahnke (1970) for other characters; and a modified version of Prendini (2004) for metasomal carinae including carinae on ster- 


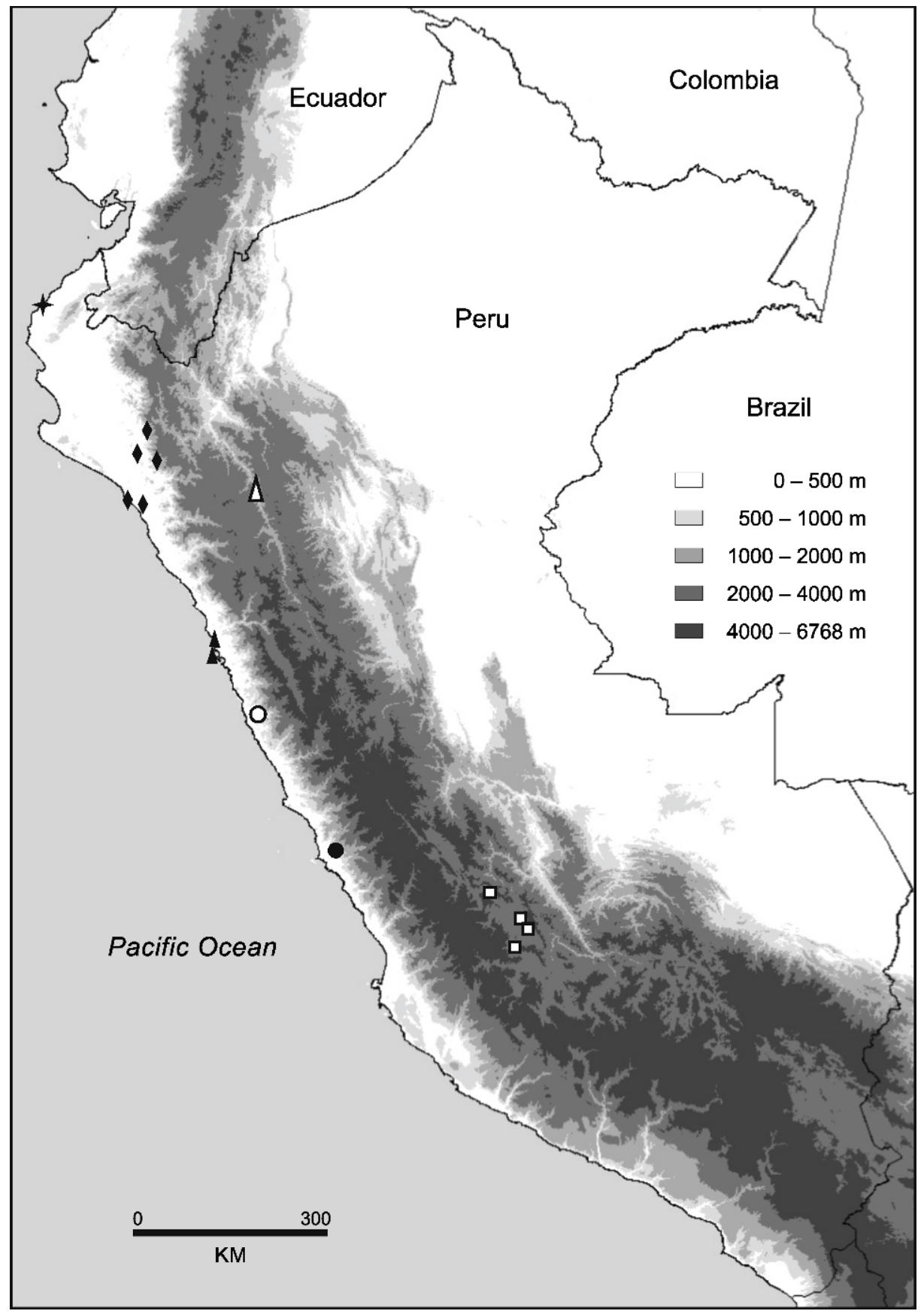

Fig. 1. Map of Peru, plotting known locality records of Hadruroides Pocock, 1893. Hadruroides aguilari Francke and Soleglad, 1980, solid circle. Hadruroides bustamantei Ochoa and Chaparro, 2008, squares. Hadruroides geckoi, n. sp., open triangle. Hadruroides graceae, n. sp., open circle. Hadruroides leopardus Pocock, 1900, diamonds. Hadruroides tishqu, n. sp., solid triangles. Hadruroides vichayitos, n. sp., star. 


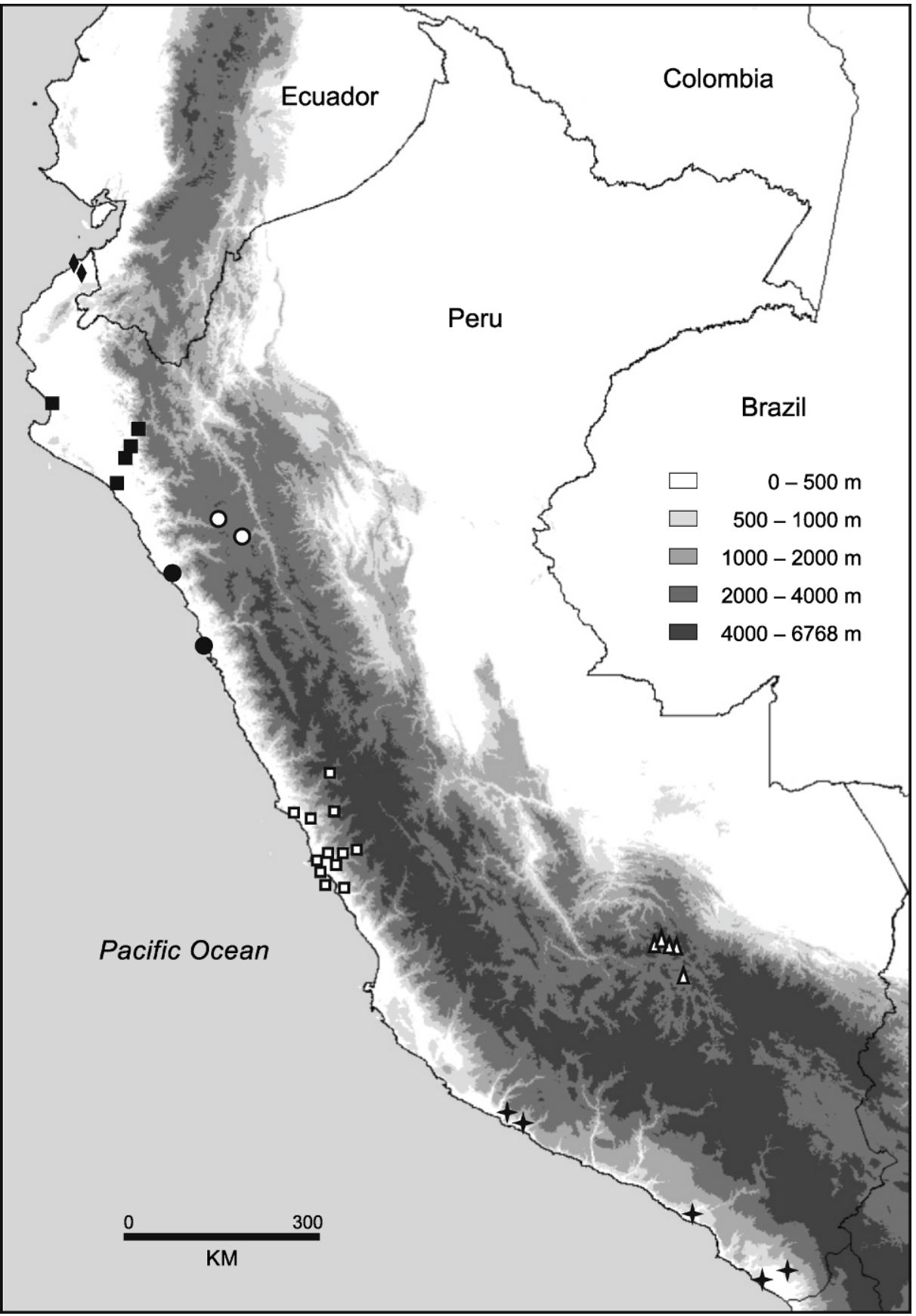

Fig. 2. Map of Peru, plotting known locality records of Hadruroides Pocock, 1893. Hadruroides carinatus Pocock, 1900, open circles. Hadruroides charcasus (Karsch, 1879), solid squares. Hadruroides chinchaysuyu, n. sp., diamonds. Hadruroides juanchaparroi, n. sp., solid circles. Hadruroides lunatus (L. Koch, 1867), open squares. Hadruroides mauryi Francke and Soleglad, 1980, open triangles. Undetermined Hadruroides species, stars. 
nite VII and tergites, abbreviated as follows: dorsolateral (DL), lateral supramedian (LSM), median lateral (ML), lateral inframedian (LIM), ventrolateral (VL), ventrosubmedian (VSM), ventromedian (VM); terminology for leg carinae follows that used for the pedipalps.

Measurements (in $\mathrm{mm}$ ) were recorded and illustrations produced using a Nikon SMZ1500 stereomicroscope fitted with an ocular micrometer and camera lucida. Photographs under UV and visible light were taken using a Microptics ML-1000 digital-imaging system. Distribution maps were generated using DIVA-GIS Version 5.4 (http://www.diva-gis. org/) by superimposing georeferenced pointlocality records on a digital elevation dataset from the CGIAR Consortium for Spatial Information (CGIAR-CSI; available at http:// srtm.csi.cgiar.org).

\section{SYSTEMATICS}

\section{FAMILY IURIDAE THORELL, 1876}

\section{SUBFAMILY CARABOCTONINAE KRAEPELIN, 1905}

Hadruroides Pocock, 1893

Telegonus: L. Koch, 1867 (part): 235.

Hadrurus: Thorell, 1876 (part): 186; Karsch, 1879 (part): 135, 1881: 290; Boeris, 1889: 125.

Caraboctonus: Pocock, 1893a (part): 92.

Hadruroides Pocock, 1893b: 306, 309, 329, 330, type species by original designation: Hadrurus charcasus Karsch, 1879 (= Hadruroides charcasus [Karsch, 1879]); Kraepelin, 1894: 182, 206; Laurie, 1896: 130; Kraepelin, 1899: 188; Pocock, 1900: 474; Birula, 1917a: 163, 189; Birula, 1917b: 44, 48, 51; Mello-Leitão, 1945: 119; Bücherl, 1964: 61, 1967: 115; Williams, 1970: 31; Bücherl, 1971: 328; Stahnke, 1974: 122; Maury, 1975: 10, 11; Francke, 1977: 75; Francke and Soleglad, 1981: 235, 256, figs. 9, 13, 27-33, 58; Francke, 1985: 8, 17, 20; Sissom, 1990: 130, 131; Nenilin and Fet, 1992: 14; Lourenço, 1994: 157, 1995: 74-76, 1997a: 601, 602, 1998: 135; Kovařík, 1998: 135; Lourenço, 2000: 25; Sissom and Fet, 2000: 411-413; Lourenço and Dastych, 2001: 55, 56; Soleglad and Sissom, 2001: 31, fig. 34; Acosta and Ochoa, 2002: 19; Soleglad and Fet, 2003a: 2, 5, 12, 2003b: 8, 111; Fet et al., 2004: 18, 23, 24; Prendini and Wheeler, 2005: 482; Fet and Soleglad, 2005: 12; Ochoa, 2005: 65, fig. 17; Dupré, 2007: 5, 14; Ochoa and Chaparro, 2008: 5; Francke and Prendini, 2008: 210; Fet and Soleglad, 2008: 255; Soleglad et al., 2009: 1 .
Diagnosis: The genus Hadruroides comprises small- to medium-sized scorpions, varying from ca. $30 \mathrm{~mm}$, e.g., $H$. leopardus Pocock, 1900, and $H$. graceae, n. sp., to ca. $80 \mathrm{~mm}$ in total length, e.g., H. charcasus (Karsch, 1879) (Maury, 1975). The most important diagnostic characters for the genus are as follows: cheliceral movable fingers, internal surface with two subdistal teeth and one prominent basal tooth; carapace anterior margin slightly convex, with three pairs of lateral ocelli; sternum subpentagonal, with Yshaped sulcus; pedipalp chela smooth, acarinate in most species, except $H$. charcasus, in which granular carinae are present on internal surface; chela movable finger, median denticle row with six or seven median subrows of denticles and variable number of accessory denticles; neobothriotaxic major Type C trichobothrial pattern (Vachon, 1974): femur with three trichobothria $(i, e, d)$; patella with 20: one internal $(i)$, two dorsal $\left(d_{1}, 2\right)$, three ventral $\left(v_{1-3}\right), v_{3}$ situated on external surface, and 14 external trichobothria ( $e_{1-3}, e s t, e m_{1-3}$, $\left.e s b_{1,2}, e b_{1-5}\right)$; chela with 26 trichobothria: 14 on manus $\left(E t_{1-5}, E s t, E s b, E b_{1-3}, V_{1-4}\right)$ and 12 on fixed finger ( $D t, D b$, et, est, esb, eb, dt, dst, $d s b, d b, i t, i b)$; leg telotarsus with ventromedian row of spinule clusters (setaceous tufts); metasomal segment $\mathrm{V}$ with complete, granular VL and VM carinae; telson slightly concave dorsally, with short aculeus; hemispermatophore lamelliform, with elongated crest, accompanied externally by medial slit and one free lobe, truncal flexure absent, internobasal reflection of the sperm duct absent.

Hadruroides appears to be most closely related to Caraboctonus. The two genera exhibit several similarities, e.g., trichobothrial pattern, ventromedian row of spinule clusters on telotarsus, dentition of chelicerae and pedipalp chela fingers. They may be distinguished by means of the ventral carinae of metasomal segment V: in Caraboctonus, the VL carinae are restricted to the posterior half of the segment and the VM carina is absent, whereas in Hadruroides, both VL and VM carinae are present and complete (except in $H$. tishqu, n. sp., in which the VL and VM carinae are restricted to the posterior two-thirds of the segment). The two genera may be further distinguished on the basis of pedipalp chela 
finger dentition: internal and external accessory denticles, flanking the median denticle row in Hadruroides, are absent in Caraboctonus. Furthermore, the hemispermatophore of Hadruroides exhibits an elongated crest and a medial slit, both absent from the hemispermatophore of Caraboctonus, which instead exhibits a digit-shaped process.

Distribution: The genus Hadruroides is endemic to Ecuador, Peru, northern Chile, and several offshore islands, including the Galápagos (table 1). Thirteen of the 16 described species occur in Peru (figs. 1, 2). Four species inhabit dry forest in northern Peru: $H$. charcasus (fig. 4E), H. chinchaysuyu, n. sp. (fig. 4B); H. geckoi, n. sp. (figs. 3B, 4C); H. leopardus Pocock, 1900 (figs. 3A, 5B). Three species occur in inter-Andean valleys along the Cordillera: H. bustamantei Ochoa and Chaparro, 2008 (fig. 3D); H. carinatus Pocock, 1900 (fig. 4A); H. mauryi Francke and Soleglad, 1980. Six species inhabit desert along the Pacific coast: $H$. aguilari Francke and Soleglad, 1980; H. graceae, n. sp. (fig. 4D); H. juanchaparroi, n. sp. (figs. 3C, 5A); H. lunatus (L. Koch, 1867) (figs. 3G, 5C); H. tishqu, n. sp. (figs. $3 \mathrm{E}, 5 \mathrm{E}) ; H$. vichayitos, n. sp. (figs. 3F, 5D). We exclude $H$. maculatus (Thorell, 1876), which is restricted to the central coastline of Ecuador, from the list of Peruvian species. Two other Hadruroides species are endemic to Ecuador: $H$. galapagoensis Maury, 1975; H. udvardyi Lourenco, 1995 (table 1). Most species of Hadruroides have restricted distributions, except $H$. charcasus and $H$. lunatus, which are apparently more widely distributed. We consider it necessary to reassess all previous records of the latter two species, because we suspect several are based on misidentifications. Other records of Hadruroides from the coastal desert of southern Peru and northern Chile (Ochoa, 2005; unpubl. data) correspond to new species related to $H$. lunatus (fig. 2), the descriptions of which are in preparation by the authors.

\section{PERUVIAN SPECIES OF HADRUROIDES}

\section{Key to Identification of the Species}

1. Adult pedipalp chela robust, internomedian, dorsointernal, and dorsal marginal carinae well developed and comprising strong granules (fig. 4E) . . . . . . . . . . H. charcasus Pedipalp chela smooth, acarinate (figs. 8E, $11 G) \ldots \ldots \ldots \ldots \ldots \ldots \ldots 2$

2. Sternite VII acarinate ........... 3

Sternite VII with two or four carinae (figs. 7C, $D, 27 C) \ldots \ldots \ldots \ldots$

3. Metasomal segments I-IV elongated; segment II longer than wide; segment V ( $\hat{\delta})$ approximately three times longer than wide, length:width ratio: $3.18 \ldots \ldots$. . . H. aguilari Metasomal segments I-IV relatively short (fig. 20E); segment II as wide as long; segment V $(\hat{\delta})$ approximately twice longer than wide, length:width ratio: 2.04-2.59 (figs. 19G, 23B) . . . . . . . . . . . 4

4. Pigmentation reduced to faint spots on carapace and tergites (fig. 24B), absent on metasomal segments; segment V, VM and VL carinae reduced to posterior two-thirds of segment (fig. 23B); telson, ventral surfaces smooth $(\hat{\delta},+$ ) (fig. 23A, C) . . . H. tishqu

Pigmentation pronounced on carapace, tergites, and metasomal segments (fig. 20C, D); segment V, VM and VL carinae complete (fig. 19G); telson, ventral surfaces smooth or sparsely granular anteriorly ( $\hat{\delta})$, granular (). . . . . . . . . . . . . . 5

5. Tergites I-VI with rectangular dorsosubmedian spots of pigmentation (fig. 20C); sternite VII and metasomal segment I, ventral surfaces unpigmented; hemispermatophore broader basally with relatively long crest ... H. lunatus

Tergites I-VI with irregular dorsosubmedian spots of pigmentation (fig. 20D); sternite VII and metasomal segment I, ventral surfaces with several spots of pigmentation surrounding insertion of setae (fig. 20E); hemispermatophore slender with short crest (fig. 21) ...

H. juanchaparroi

6. Chela fixed finger (adult $\delta$ ) curved, creating distinct proximal gap with movable finger when fingers closed (figs. $8 \mathrm{C}, 11 \mathrm{H}, 27 \mathrm{H}$ ) . . . . . 8 Chela fixed and movable fingers (adult $\delta$ ) straight, no proximal gap evident when fingers closed (fig. 15I) . . . . . . . . . 7

7. Metasomal segment IV, ventral surface densely granular (fig. 15C); segment $\mathrm{V}$ with 7-8 ventral setae and 6-8 lateral setae; pedipalp chela length:width ratio: 5.00-5.41 (o) , 4.46$5.12(+$ ( ) . . . . . . . . . . H. graceae

Metasomal segment IV, ventral surface smooth; segment V with 12-18 ventral setae and 3-5 lateral setae; pedipalp chela length:width ratio: 3.93-4.54 (す) ), 4.23-4.64 (+)............... H. leopardus

8. Metasomal segments, VSM carinae absent on segments I-III, present on IV . . . . . . 12 


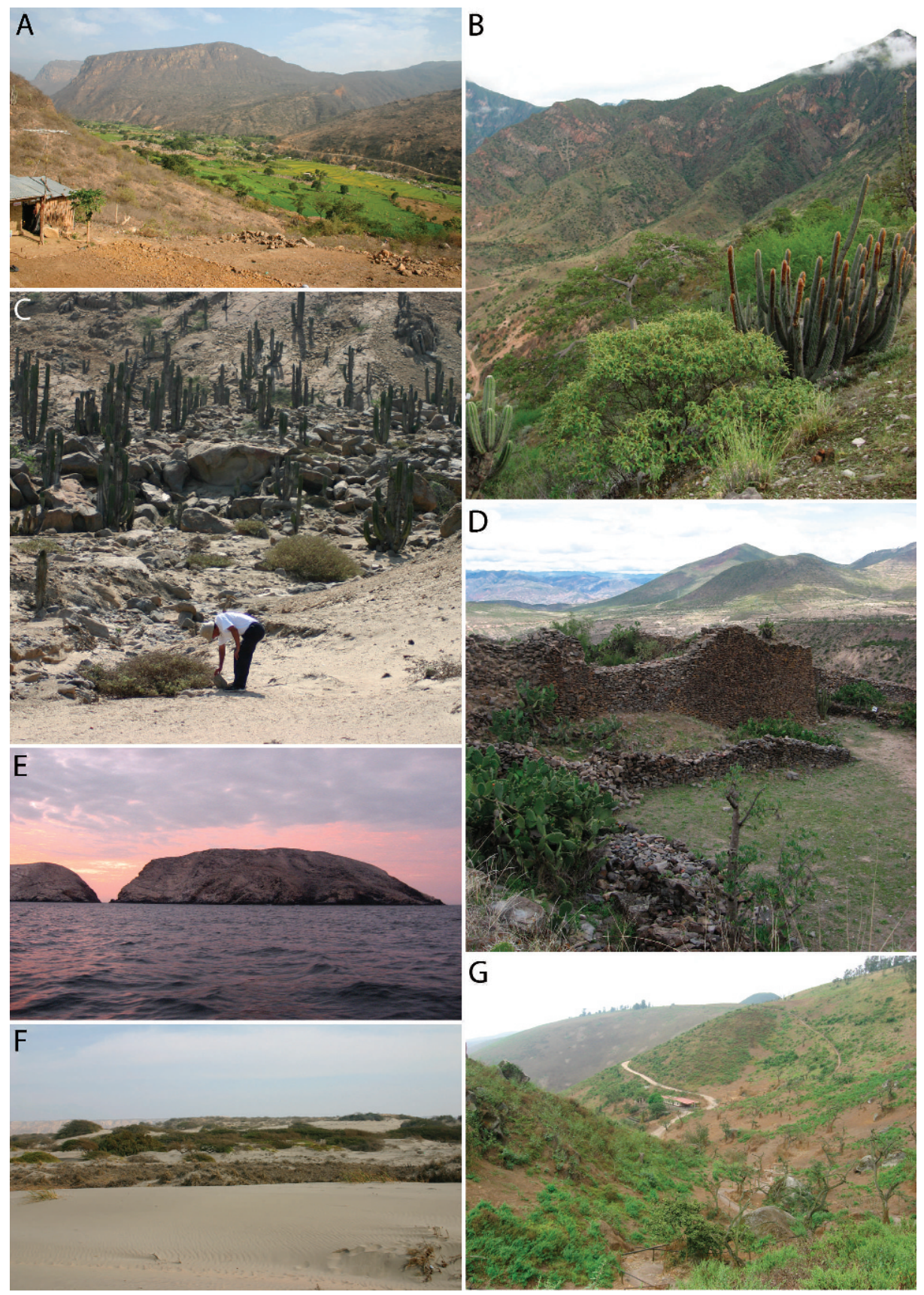

Fig. 3. Hadruroides Pocock, 1893, habitats in Peru. A. Puchaca Alto (Lambayeque Department), habitat of Hadruroides leopardus Pocock, 1900. B. Balsas (Cajamarca Department), habitat of Hadruroides geckoi, n. sp. C. Cerro Campana (La Libertad Department), habitat of Hadruroides juanchaparroi, n. sp. D. Wari (Ayacucho Department), habitat of Hadruroides bustamantei Ochoa and Chaparro, 2008. E. Isla Santa (Ancash Department), habitat of Hadruroides tishqu, n. sp. F. Playa Vichayitos (Piura Department), habitat of Hadruroides vichayitos, n. sp. G. Lomas de Lachay (Lima Department), habitat of Hadruroides lunatus (L. Koch, 1867). 

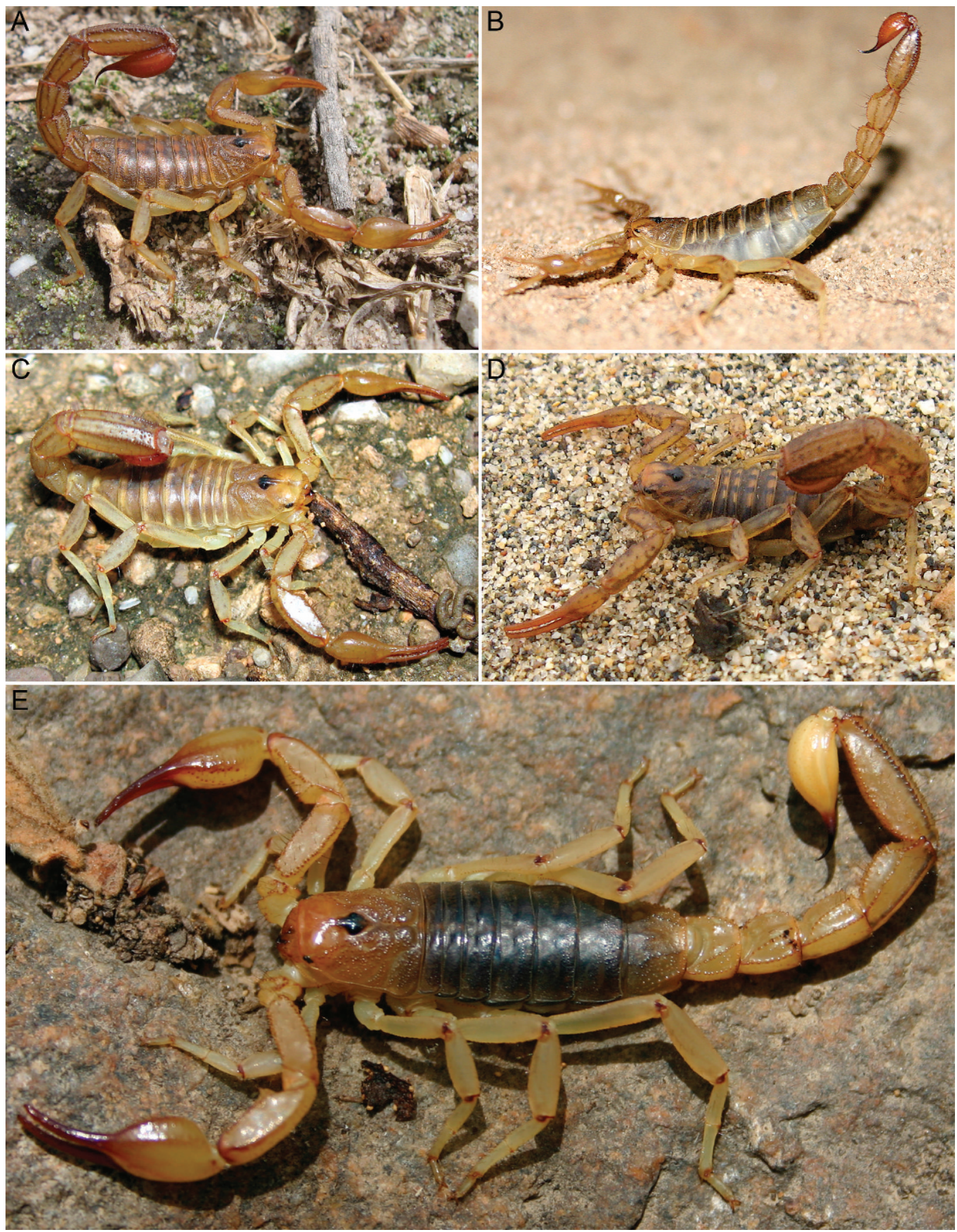

Fig. 4. Hadruroides Pocock, 1893, habitus in life. A. Hadruroides carinatus Pocock, 1900, §ิ. B. Hadruroides chinchaysuyu, n. sp., +. C. Hadruroides geckoi, n. sp., ô. D. Hadruroides graceae, n. sp., ô. E. Hadruroides charcasus (Karsch, 1879), के . 

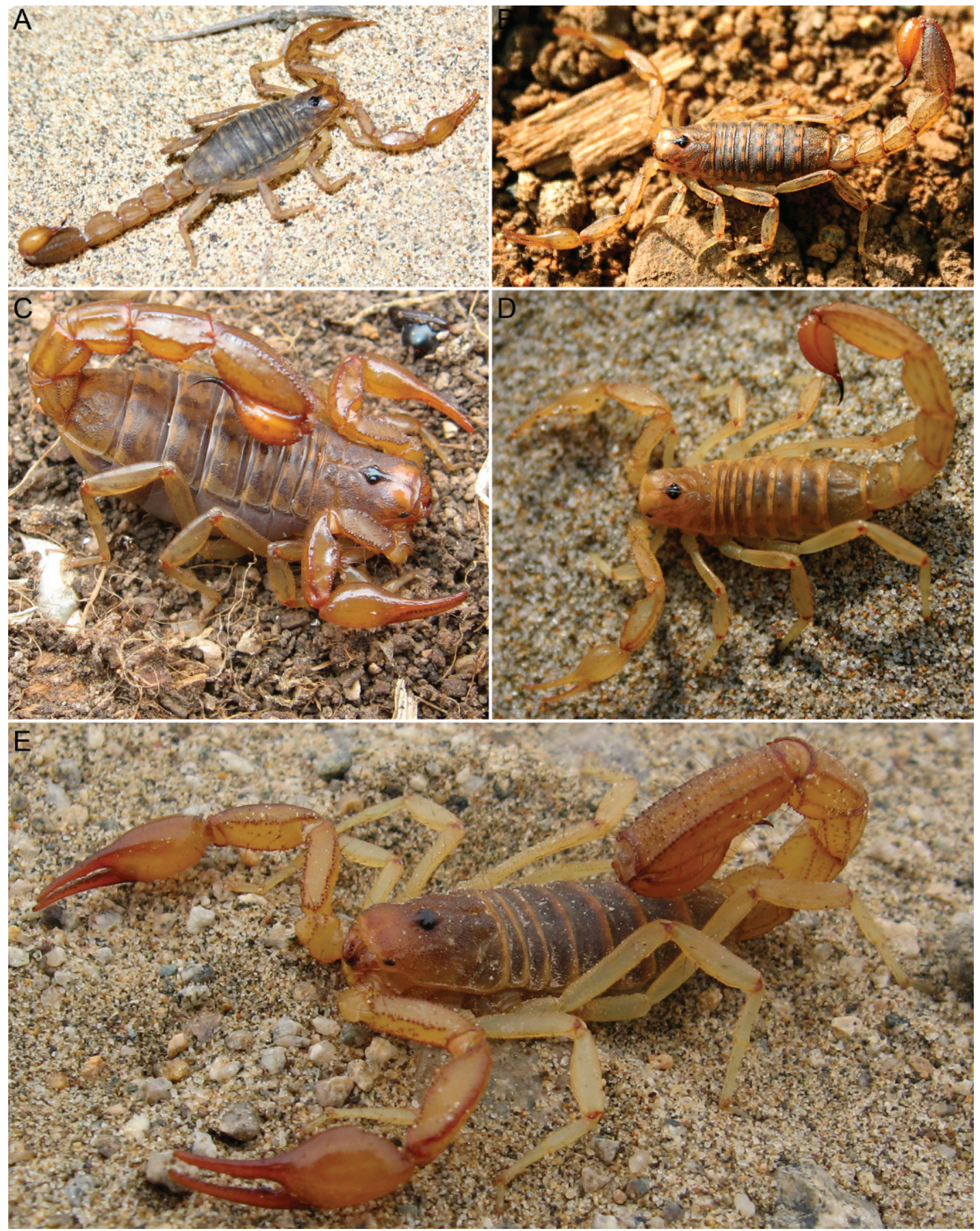

Fig. 5. Hadruroides Pocock, 1893, habitus in life. A. Hadruroides juanchaparroi, n. sp., ô. B. Hadruroides leopardus Pocock, 1900, §ิ. C. Hadruroides lunatus (L. Koch, 1867), ․ . D. Hadruroides vichayitos, n. sp., §ै. E. Hadruroides tishqu, n. sp., $\hat{o}$. 
- Metasomal segments, VSM carinae present on segment I and, usually, II and III, absent on IV .................. 9

9. Pigmentation pronounced on carapace, tergites, and metasomal segments (figs. 8I, 9C, $12 \mathrm{~F}, \mathrm{D})$; VSM carinae present on metasomal segments I-III; pedipalp chela fixed finger (adult $\hat{\delta})$ strongly curved, creating well developed proximal gap with movable finger when fingers closed (fig. $11 \mathrm{H}) \ldots \ldots \ldots 10$

- Pigmentation absent, except for small, faint spots on carapace and tergites (fig. 12G); VSM carinae obsolete on metasomal segment I, absent on segments II and III; pedipalp chela fixed finger (adult $\hat{\delta}$ ) slightly curved, creating weak proximal gap with movable finger when fingers closed (fig. $27 \mathrm{H}) \ldots \ldots$ H. vichayitos

10. Sternite VII, VL and VSM carinae well developed; metasomal segment V, DL carinae smooth; telson, ventral surface ( $(+)$ smooth; hemispermatophore lamina apically rounded ............ H. carinatus

- Sternite VII, VL carinae distinct, VSM carinae obsolete (fig. 7C); metasomal segment V, DL carinae sparsely to densely granular (figs. $8 \mathrm{~A}$, $\mathrm{D}, 11 \mathrm{~A})$; telson, ventral surface $(+)$ granular (fig. 8B); hemispermatophore lamina apically acuminate (figs. 9E, 13) . . . . . . . 11

11. Metasomal segment V elongated ( $\hat{\jmath})$ : length:width ratio: 2.40-2.89 (fig. 11B); segment $\mathrm{V}$, ventral surface sparsely granular, comprising scattered granules in posterior third (fig. 11B); segment $\mathrm{V}$ with 10-14 DL setae and 9-13 VL setae; pedipalp chela slender, length:width ratio: 4.41-4.40 (के), 4.53-4.74 () (figs. 11E, 12B); pectinal tooth count: 21$23($ ( ) ), 18-21 ( + ); hemispermatophore lamina curved in distal half (fig. 13) . . . . H. geckoi

- Metasomal segment V short ( $\hat{\delta}$ ): length:width ratio: 1.97-2.14 (fig. 8F); segment $\mathrm{V}$, ventral surface densely granular (fig. 8F); segment $\mathrm{V}$ with 5-8 DL setae and 6-10 VL setae; pedipalp chela relatively broad, length:width ratio: 3.66-4.02 (o) ), 4.0-4.18 (ㅇ) (fig. 8E); pectinal tooth count: 17-20 (ô), 16 ( $(+)$; hemispermatophore lamina straight in distal half (fig. 9E-H) . . . . . H. H. chinchaysuyu

12. Tergites I-IV each with paired dorsosubmedian and dorsolateral spots of pigmentation, forming four longitudinal stripes along mesosoma; legs I-IV each with several prolateral spots of pigmentation; pedipalp chela (8) relatively broad, length:width ratio: 3.09-3.36 . . . . . . . . H. bustamantei

- Tergites I-IV unpigmented, mesosoma without longitudinal stripes; legs without prolateral spots of pigmentation; pedipalp chela $(\hat{\delta})$ relatively slender, length:width ratio: $2.7-$ $2.8 \ldots \ldots \ldots \ldots \ldots \ldots \ldots$. mauryi

Hadruroides aguilari

Francke and Soleglad, 1980

Figure 1

Hadruroides aguilari Francke and Soleglad, 1980: 2-8, figs. 1, 3-20; Kovař́k, 1998: 135; Sissom and Fet, 2000: 411; Fet et al., 2004: 24; Ochoa and Chaparro, 2008: 5 .

Type Material: PERU: Lima Department: Lima Province: Holotype $\hat{\sigma}, 2$ q paratypes $(\mathrm{AMNH})$, Cajamarquilla $\left(11^{\circ} 57^{\prime} \mathrm{S}\right.$ $76^{\circ} 54^{\prime} \mathrm{W}$, ca. 800 m), 3.i.1976, O.F. Francke.

Diagnosis: Hadruroides aguilari appears to be most closely related to $H$. lunatus and $H$. juanchaparroi, based on the similar carination of sternite VII and metasomal segments I-IV. Haduroides aguilari may be separated from these species by the elongated metasomal segments, e.g., segment II is longer than wide and segment $\mathrm{V}(\hat{\delta})$ approximately three times longer than wide in $H$. aguilari, compared with $H$. lunatus and $H$. juanchaparroi, in which segment II is as wide as long, and the length:width ratio of segment $\mathrm{V}(\delta)$ varies from 2.04 to 2.59. Additionally, in $H$. lunatus and $H$. juanchaparroi, the pedipalp chela fixed finger of the adult male is curved, creating a distinct proximal gap with the movable finger when the fingers are closed, whereas the fixed and movable fingers of the adult male are straight, such that no proximal gap is evident when the fingers are closed, in H. aguilari.

Distribution: This endemic Peruvian species is known only from the type series and, despite extensive searches, no additional material has been collected. The type locality is now an urban zone, close to the Peruvian capital of Lima (fig. 1), and no natural habitat remains there. However, it is possible that the species still occurs in adjacent areas of natural habitat.

Ecology: According to Francke and Soleglad (1980), H. aguilari has been collected at night from the tops of terrestrial bromeliads (Tillandsia sp., Bromeliaceae), and is sympatric with $H$. lunatus, found under stones and bromeliad mats. 


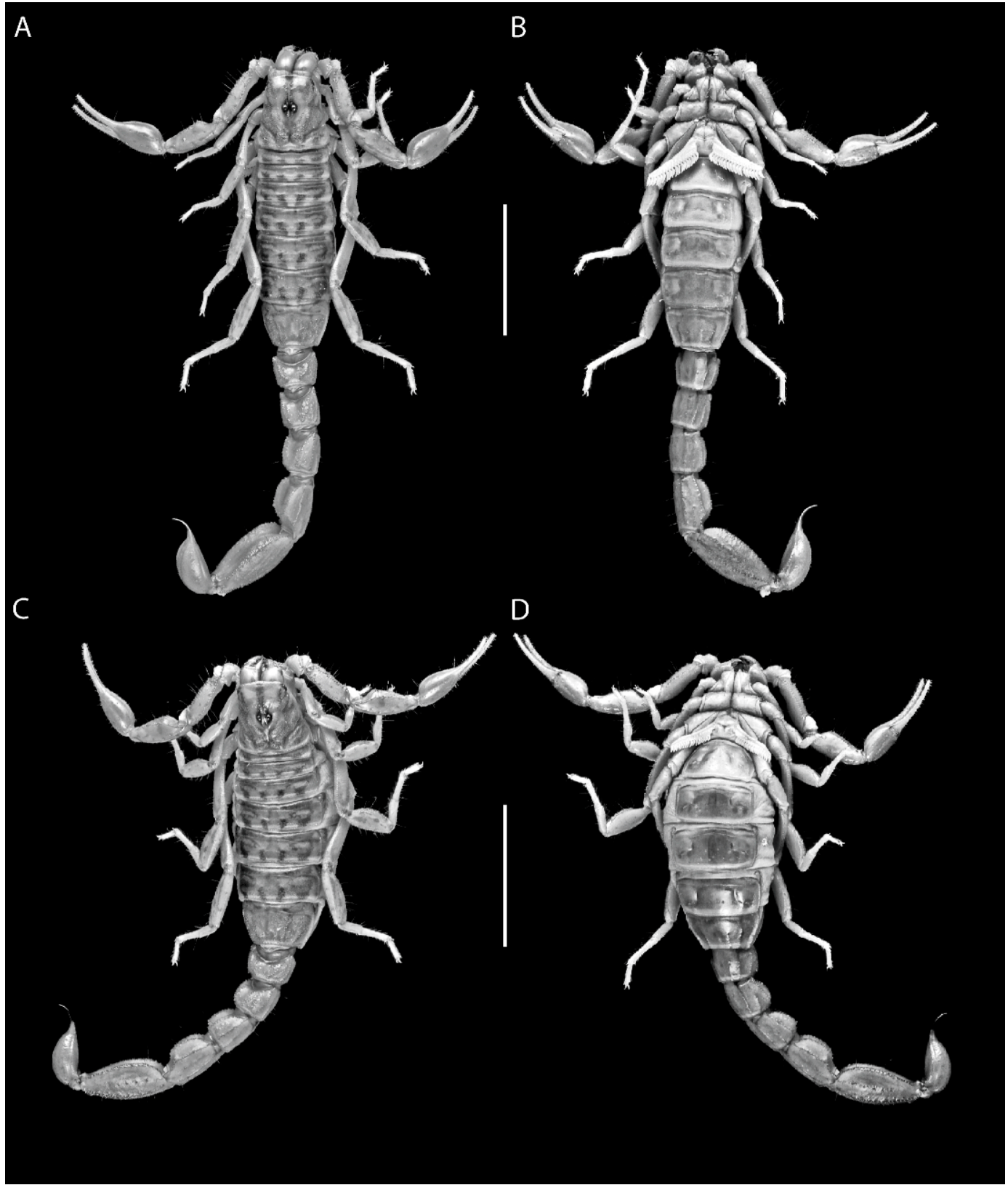

Fig. 6. Hadruroides chinchaysuyu, n. sp., habitus. A, B. Holotype $\delta$ (MHNC). C, D. Paratype $q$ (MHNC). A, C. Dorsal aspect. B, D. Ventral aspect. Scale bars $=1 \mathrm{~cm}$.

\section{Hadruroides bustamantei} Ochoa and Chaparro, 2008

Figures 1, 3D

Hadruroides bustamantei Ochoa and Chaparro, 2008: 610, figs. $1-18$, table 1 .
Hadruroides mauryi: Francke and Soleglad, 1980: 8 (part); Sissom and Fet, 2000: 413 (part).

Type Material: PERU: Ayacucho Department: Huanta Province: Holotype ô, 1 ô, 2 क, 1 juv. paratypes (MHNC), $1 \hat{\delta}, 1$ क paratypes (CDA 158), paratype $\hat{o}$ (MUSM), near 

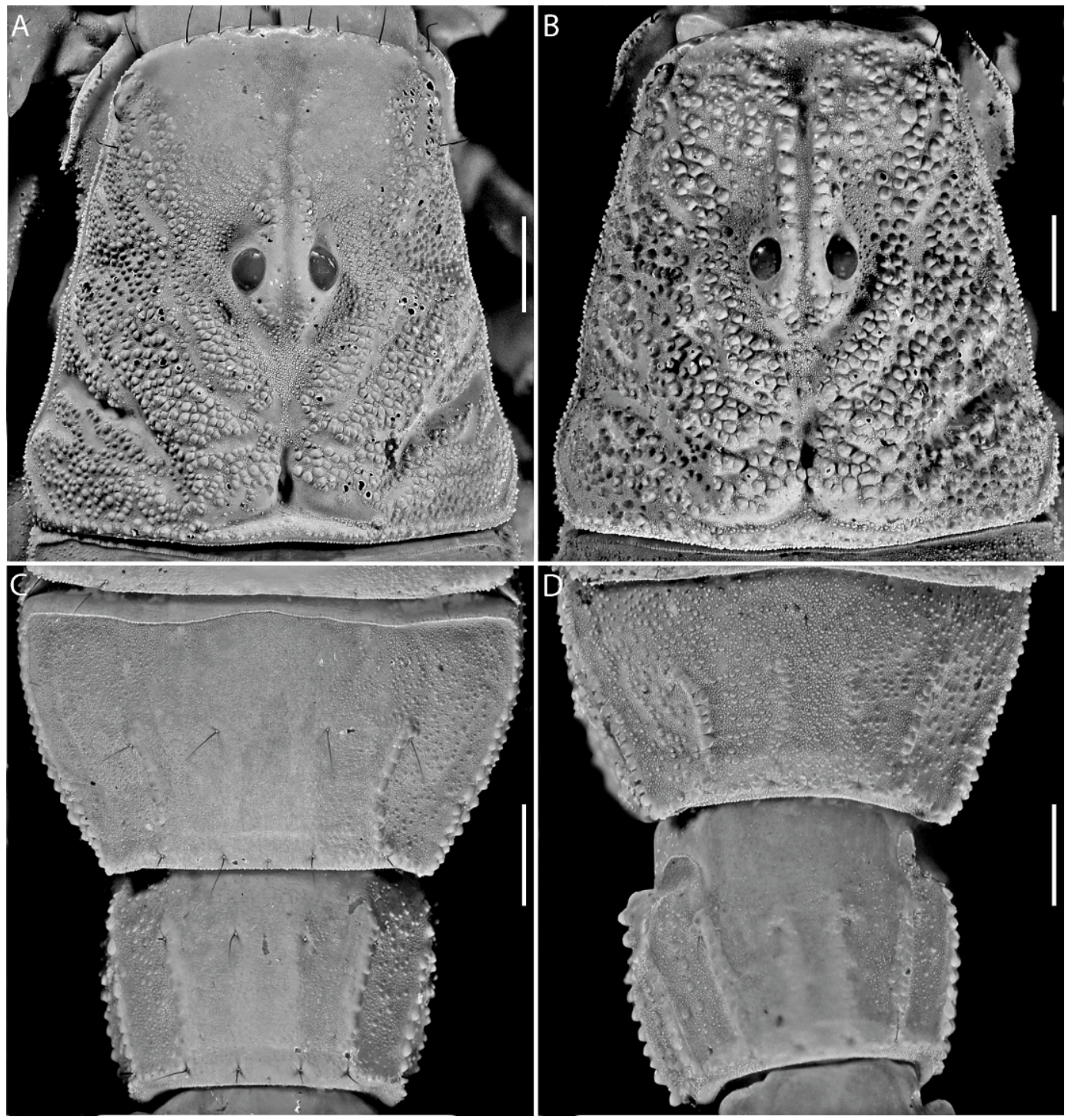

Fig. 7. Hadruroides Pocock, 1893, diagnostic characters. A, C. Hadruroides chinchaysuyu, n. sp., paratype $\hat{\sigma}$ (MHNC). B, D. Hadruroides maculatus (Thorell, 1876), of (MHNC). A, B. Carapace. C, D. Sternite VII and metasomal segment I, ventral aspect. Scale bars $=1 \mathrm{~mm}$.

Huanta, $12^{\circ} 57^{\prime} 18^{\prime \prime} \mathrm{S} \quad 74^{\circ} 14^{\prime} 35^{\prime \prime} \mathrm{W}, 2630 \mathrm{~m}$, 20.xii.1998, J. Achicahuala and J.A. Ochoa. Huancavelica Department: Churcampa Province: 3 q, 2 juv. $\delta, 2$ juv. + paratypes (also paratypes of $H$. mauryi) (AMNH), along Río Mantaro, $15 \mathrm{~km} \mathrm{~N}$ Anco (ca. $12^{\circ} 33^{\prime} \mathrm{S} 74^{\circ} 42^{\prime} \mathrm{W}$, 2700 m), 25.vii.1971, O.F. Francke.

New Records: PERU: Ayacucho Department: Huamanga Province: Vinchos, $13^{\circ} 19^{\prime}$
13"S 74²0'53"W, 3379 m, 20.xii.2007, J Vitorino and J.A. Ochoa, $1 \hat{\delta}, 1$,+ 1 juv. (AMNH); Wari ruins, $13^{\circ} 03^{\prime} 25^{\prime \prime} \mathrm{S} 74^{\circ} 11^{\prime} 53^{\prime \prime} \mathrm{W}$, 2736 m, ii.2005, E. Escobar, 1 subad. of, 1 subad. \& (AMNH); 21.xii.2007, J. Vitorino and J.A. Ochoa, $1 \hat{\delta}, 1$ क (AMNH).

DiAgnosis: Hadruroides bustamantei appears to be most closely related to $H$. mauryi, with which it was previously confused. The 


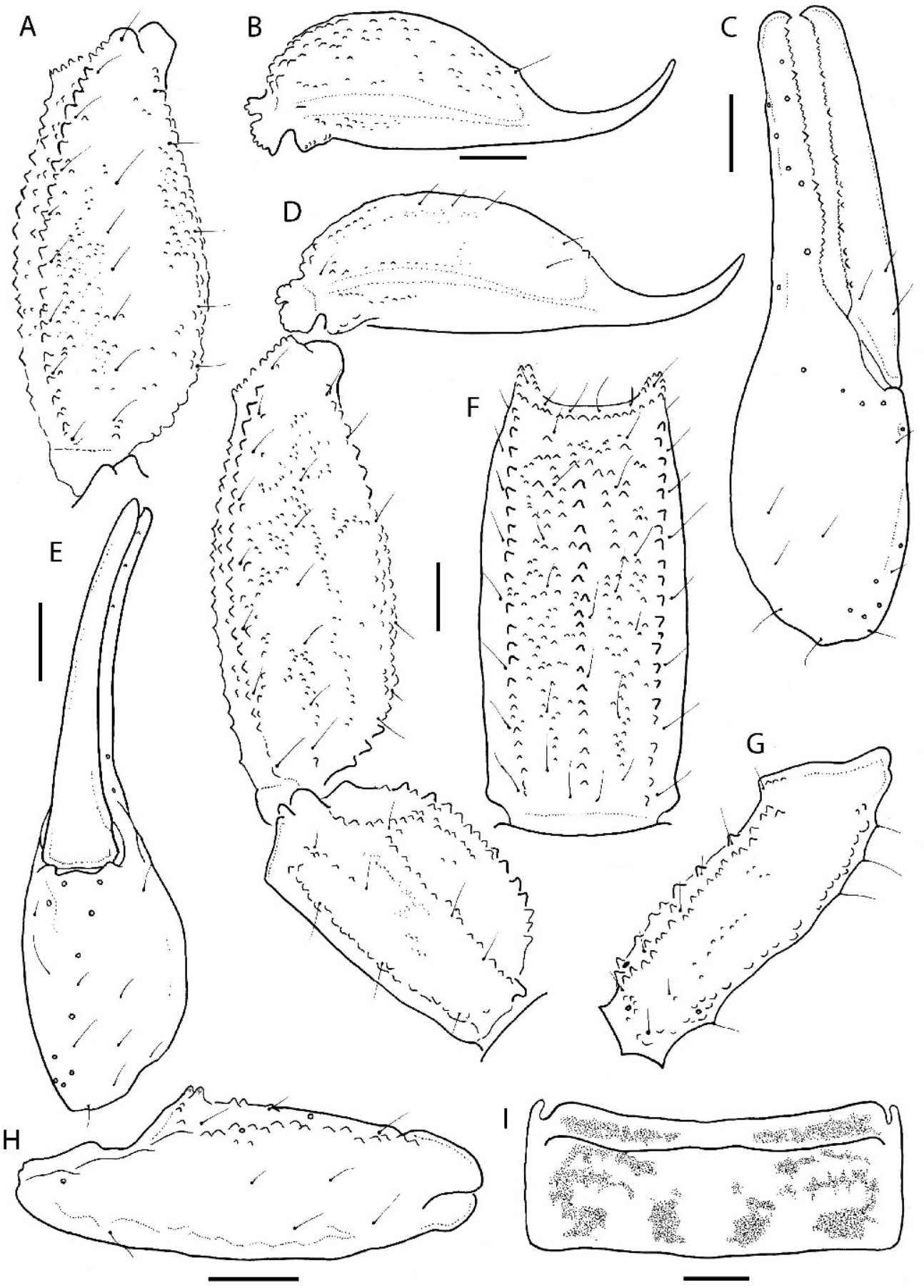

Fig. 8. Hadruroides chinchaysuyu, n. sp., diagnostic characters. A, B. Paratype $q$ (MHNC). A. Metasomal segment V, lateral aspect. B. Telson, lateral aspect. C-I. Paratype $\hat{\delta}$ (MHNC). C. Dextral pedipalp chela, external aspect. D. Metasomal segments IV, V and telson, lateral aspect. E. Dextral pedipalp chela, ventral aspect. F. Metasomal segment IV, ventral aspect. G. Dextral pedipalp femur, dorsal aspect. H. Dextral pedipalp patella, dorsal aspect. I. Tergite V, dorsal aspect showing pigmentation pattern. Scale bars $=1 \mathrm{~mm}$. 


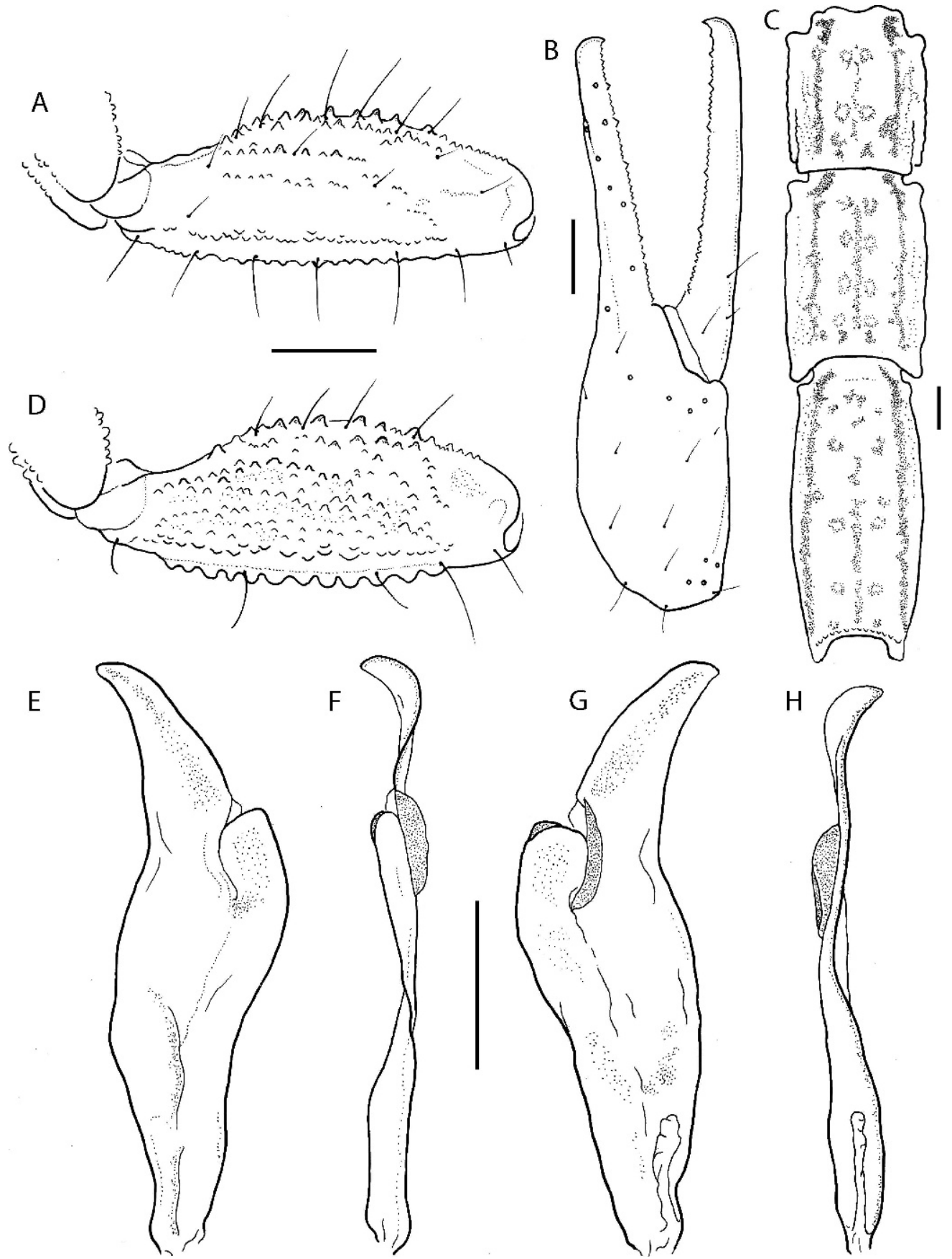

Fig. 9. Hadruroides Pocock, 1893, diagnostic characters. A-C. Hadruroides chinchaysuyu, n. sp. A. Paratype $\delta$ (MHNC), leg III, dextral patella, dorsal aspect. B. Paratype + (MHNC), dextral pedipalp chela, external aspect. C. Paratype $\hat{\delta}$ (MHNC), metasomal segments III-V, ventral aspect showing pigmentation pattern. D. Hadruroides maculatus (Thorell, 1876), ô (MHNC), leg III, dextral patella, dorsal aspect. E-H. H. chinchaysuyu, holotype $\hat{\delta}$ (MHNC), sinistral hemispermatophore. E. Ental aspect. F. Dorsal aspect. G. Ectal aspect. H. Ventral aspect. Scale bars $=1 \mathrm{~mm}$. 

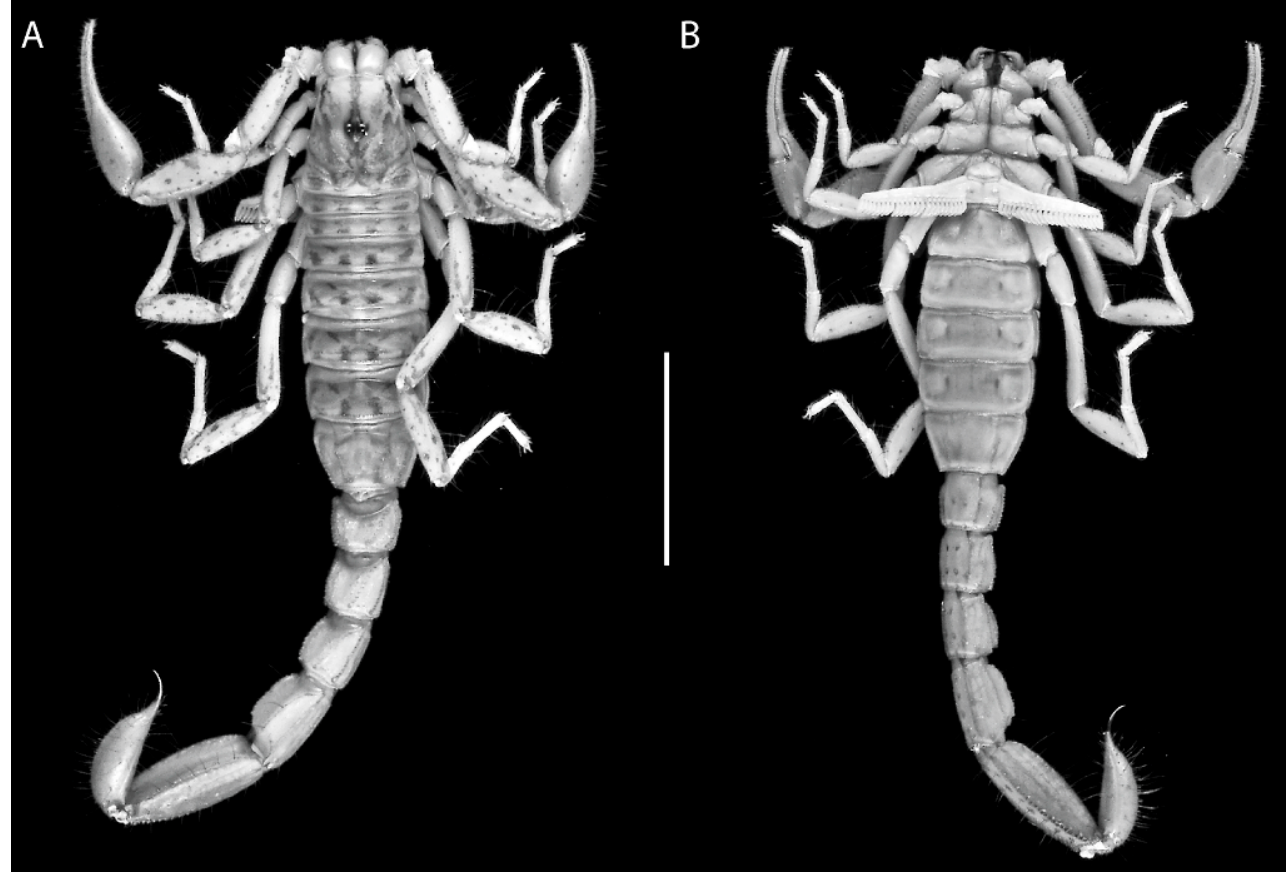

C

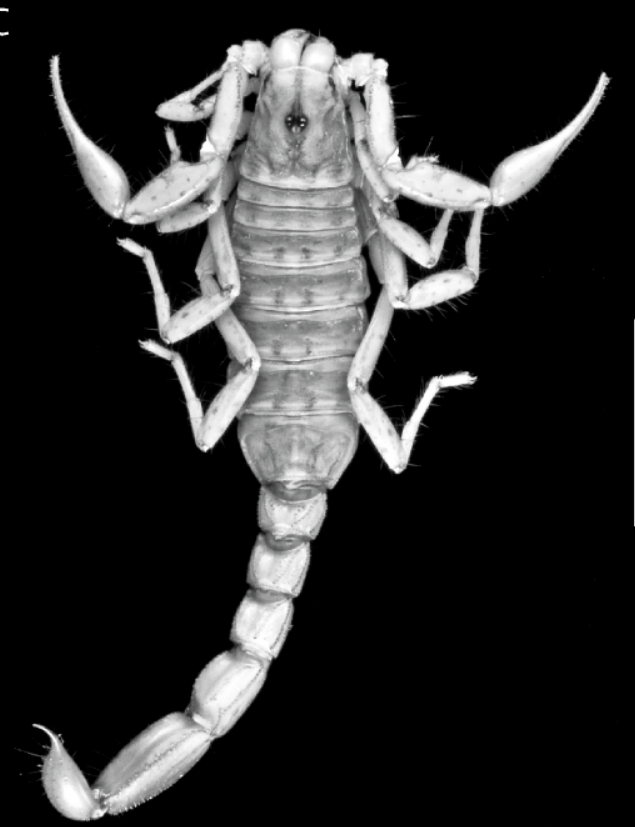

D

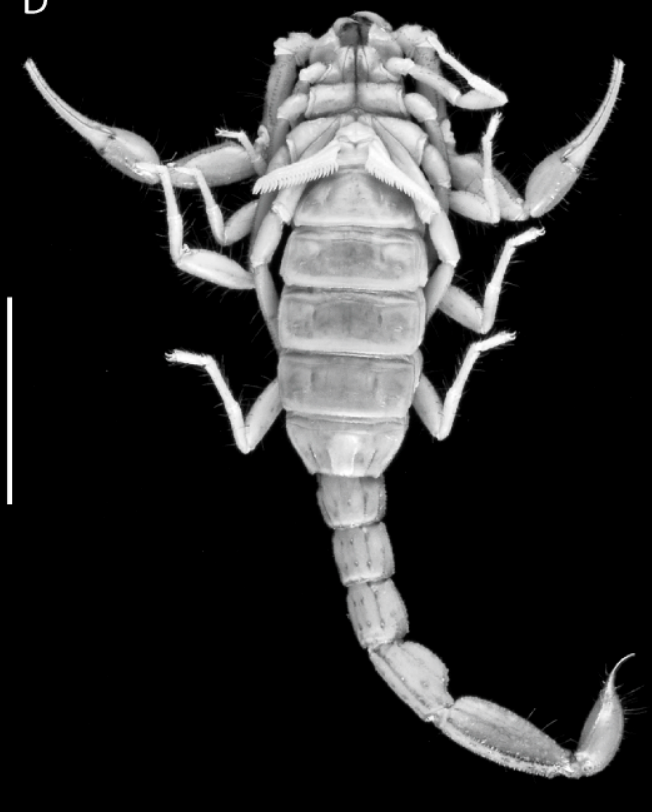

Fig. 10. Hadruroides geckoi, n. sp., habitus. A, B. Paratype ô (AMNH). C, D. Paratype + (AMNH). A, C. Dorsal aspect. B, D. Ventral aspect. Scale bars $=1 \mathrm{~cm}$. 


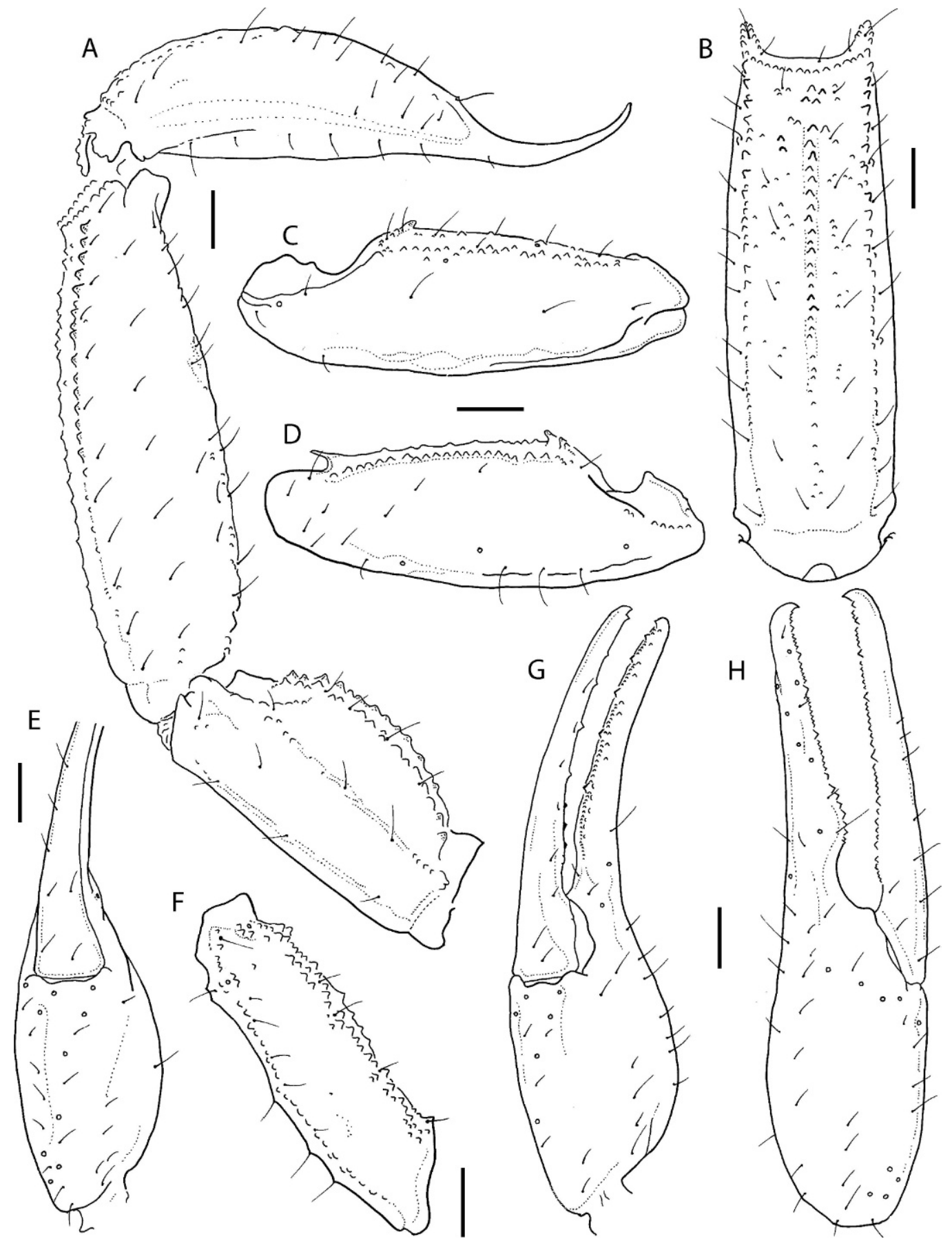

Fig. 11. Hadruroides geckoi, n. sp., holotype $\hat{\delta}$ (MHNC). A. Metasomal segments IV, V and telson, lateral aspect. B. Metasomal segment V, ventral aspect. C. Dextral pedipalp patella, dorsal aspect. D. Dextral pedipalp patella, ventral aspect. E. Dextral pedipalp chela, ventral aspect. F. Dextral pedipalp femur, dorsal aspect. G. Dextral pedipalp chela, ventrointernal aspect. H. Dextral pedipalp chela, external aspect. Scale bars $=1 \mathrm{~mm}$. 

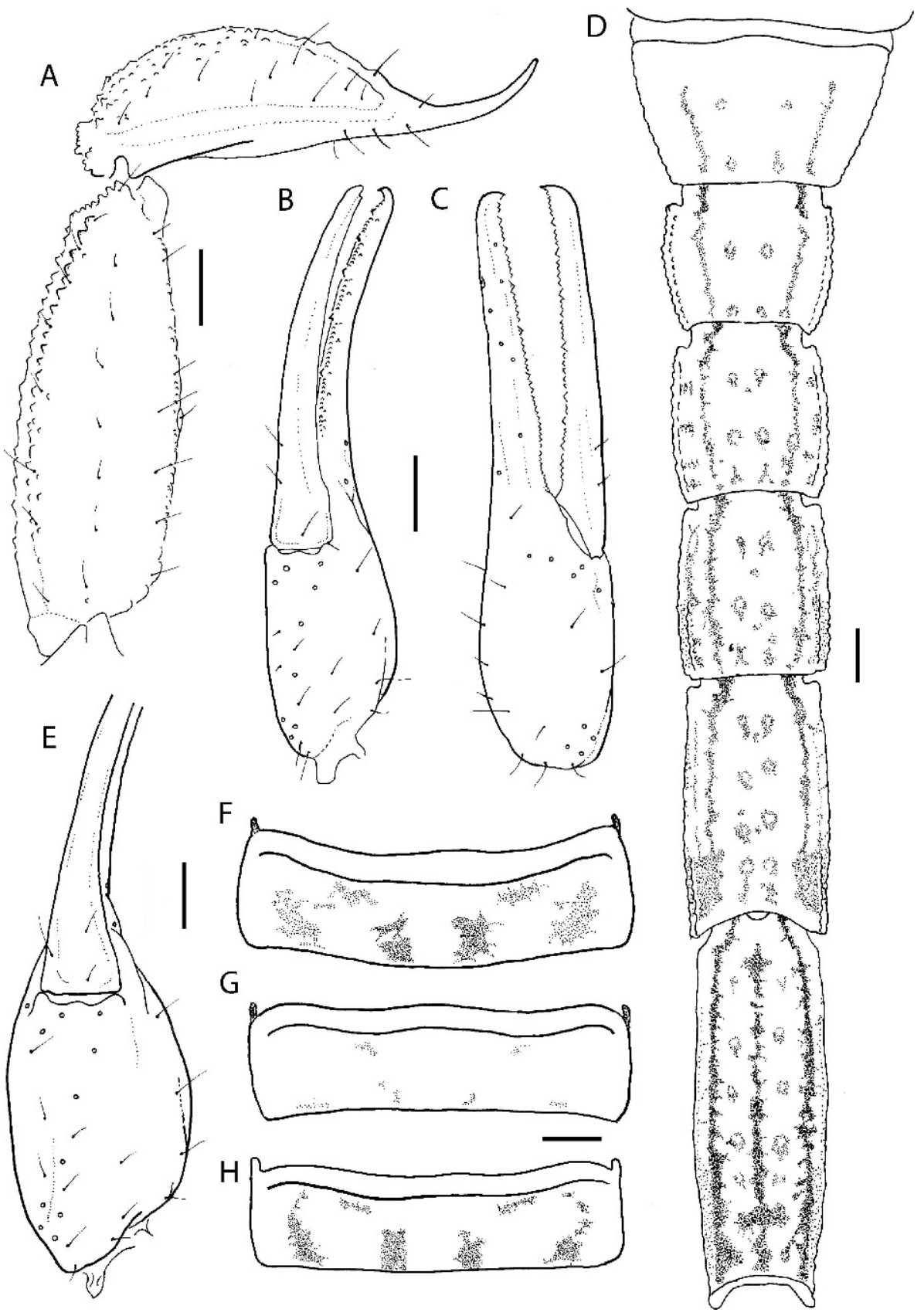

Fig. 12. Hadruroides Pocock, 1893, diagnostic characters. A-C. Hadruroides geckoi, n. sp., paratype $q$ (MHNC). A. Metasomal segment V and telson, lateral aspect. B. Dextral pedipalp chela, ventrointernal aspect. C. Dextral pedipalp chela, external aspect. D. H. geckoi, paratype $\hat{\sigma}$ (MHNC), sternite VII and metasomal segments I-V, ventral aspect showing pigmentation pattern. E. Hadruroides carinatus Pocock, 1900, of (MHNC), dextral pedipalp chela, ventral aspect. F. H. geckoi, paratype ô (MHNC), tergite IV, dorsal aspect showing pigmentation pattern. G. Hadruroides vichayitos, n. sp., paratype $\hat{\delta}$ (MHNC), tergite IV, dorsal aspect showing pigmentation pattern. H. H. carinatus, of (MHNC), tergite IV, dorsal aspect showing pigmentation pattern. Scale bars $=1 \mathrm{~mm}$. 
A

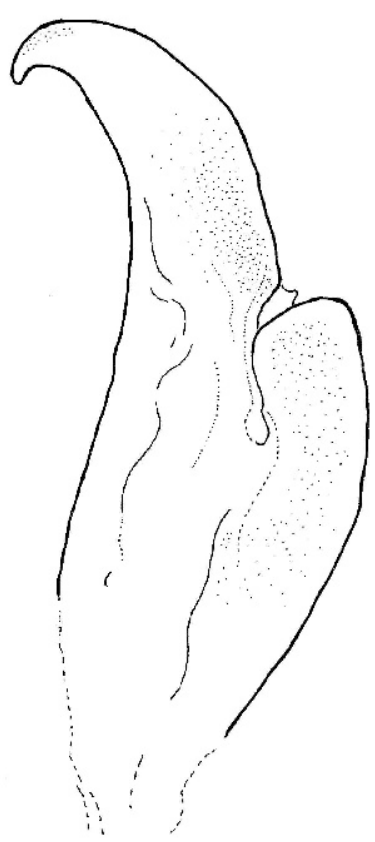

B

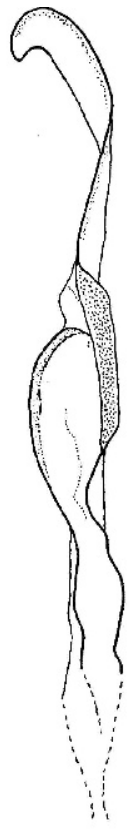

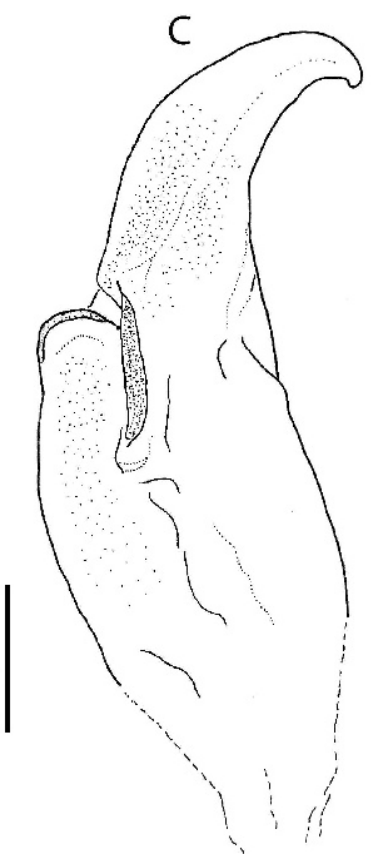

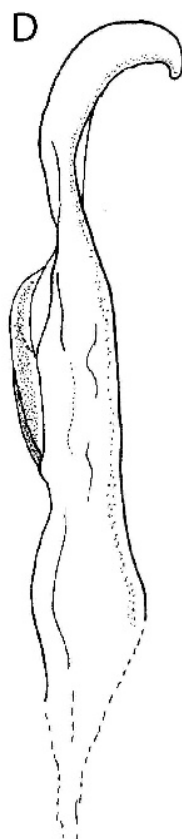

Fig. 13. Hadruroides geckoi, n. sp., paratype \$̊ (MHNC), sinistral hemispermatophore. A. Ental aspect. B. Dorsal aspect. C. Ectal aspect. D. Ventral aspect. Scale bar $=0.5 \mathrm{~mm}$.

two species are similar in hemispermatophore dimensions; pectinal tooth count; carination of sternite VII and metasomal segments; and the curvature of the pedipalp chela fixed finger of the adult male, which creates a welldeveloped proximal gap with the movable finger when the fingers are closed, that is also present but less developed in females. They may be distinguished from one another based on the dimensions of the male pedipalp chela and the pigmentation pattern of the tergites and legs. The length:width ratio of the chela ( $\delta$ ) varies from 3.09 to 3.36 in $H$. bustamantei and from 2.7 to 2.8 in $H$. mauryi. Tergites I-IV display pairs of dorsosubmedian and dorsolateral spots, forming four distinct stripes along the mesosoma, in $H$. bustamantei, whereas only faint spots are evident along the posterior margin of each tergite in $H$. mauryi. Additionally, several spots are evident on the prolateral side of legs I-IV in $H$. bustamantei, whereas the legs of $H$. mauryi are unpigmented.

Distribution: Hadruroides bustamantei is endemic to inter-Andean valleys in the
Ayacucho and Huancavelica departments of central Peru (fig. 1). We provide new records at elevations between 2600 and $3379 \mathrm{~m}$. The known locality records correspond to the Valles Interandinos Cálidos biogeographical zone (Ceballos Bendezú, 1976; Ochoa, 2005). Recently reported records of $H$. maculatus from Huancayo $(3200 \mathrm{~m})$ in the Junín Department of the Peruvian central Andes (Soleglad and Sissom, 2001; Soleglad and Fet, 2003a, 2003b; Fet et al., 2004; Fet and Soleglad, 2008) are probably referable to $H$. bustamantei.

ECOLOGY: Hadruroides bustamantei inhabits rocky areas with sparse xerophytic vegetation, comprising shrubs and cacti.

Hadruroides carinatus Pocock, 1900

Figures 2, 4A, 12E, H

Hadruroides carinatus Pocock, 1900: 475; Maury, 1975: 15, 16, figs. 23-33; Francke, 1977: 75; Lourenço, 1994: 157, 1995: 76, fig. 10; Kovař́k, 1998: 135; Sissom and Fet, 2000: 411; Fet et al., 2004: 24; Ochoa and Chaparro, 2008: 5. 


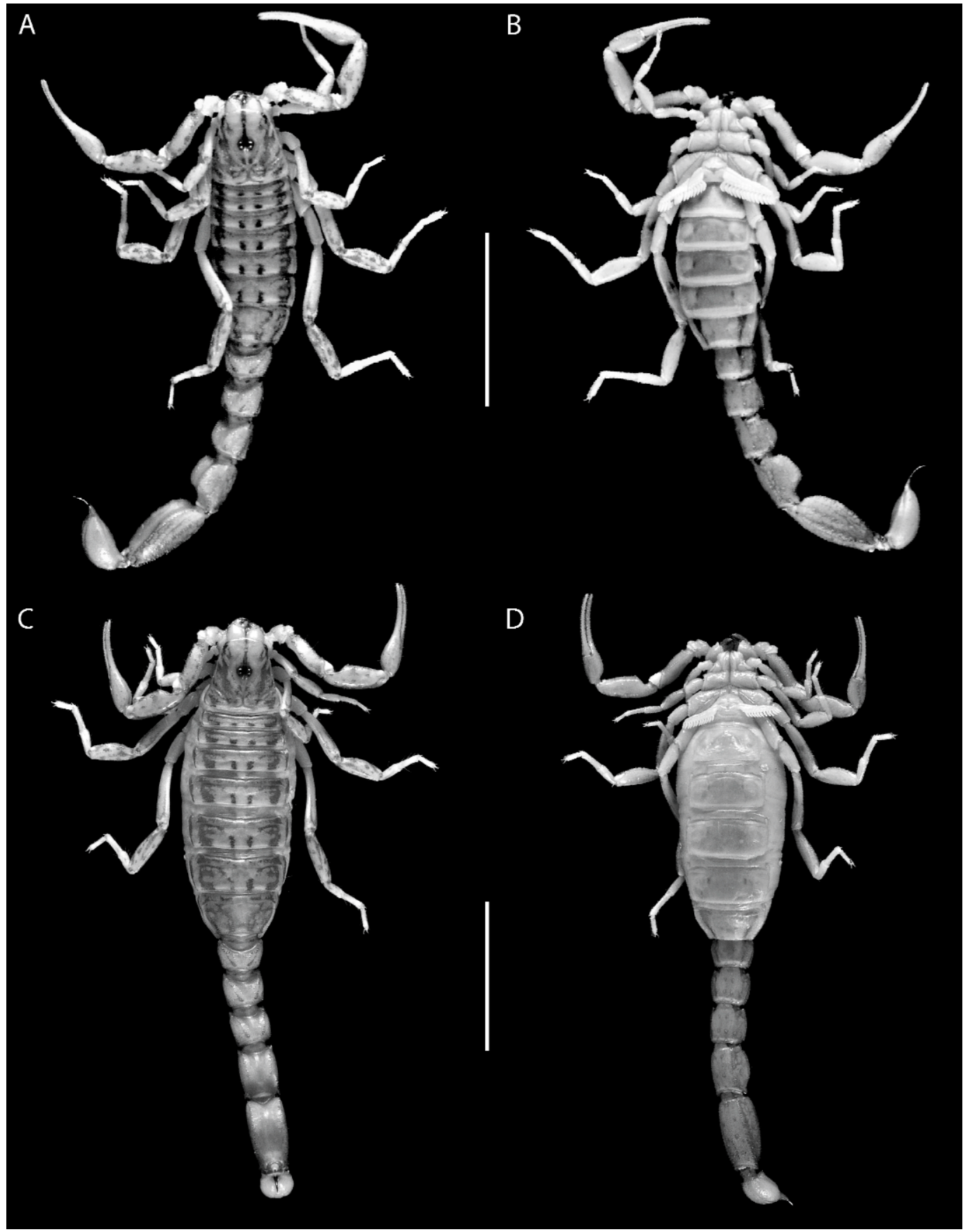

Fig. 14. Hadruroides graceae, n. sp., habitus. A, B. Paratype ô (AMNH). C, D. Paratype + (AMNH). A, C. Dorsal aspect. B, D. Ventral aspect. Scale bars $=1 \mathrm{~cm}$. 


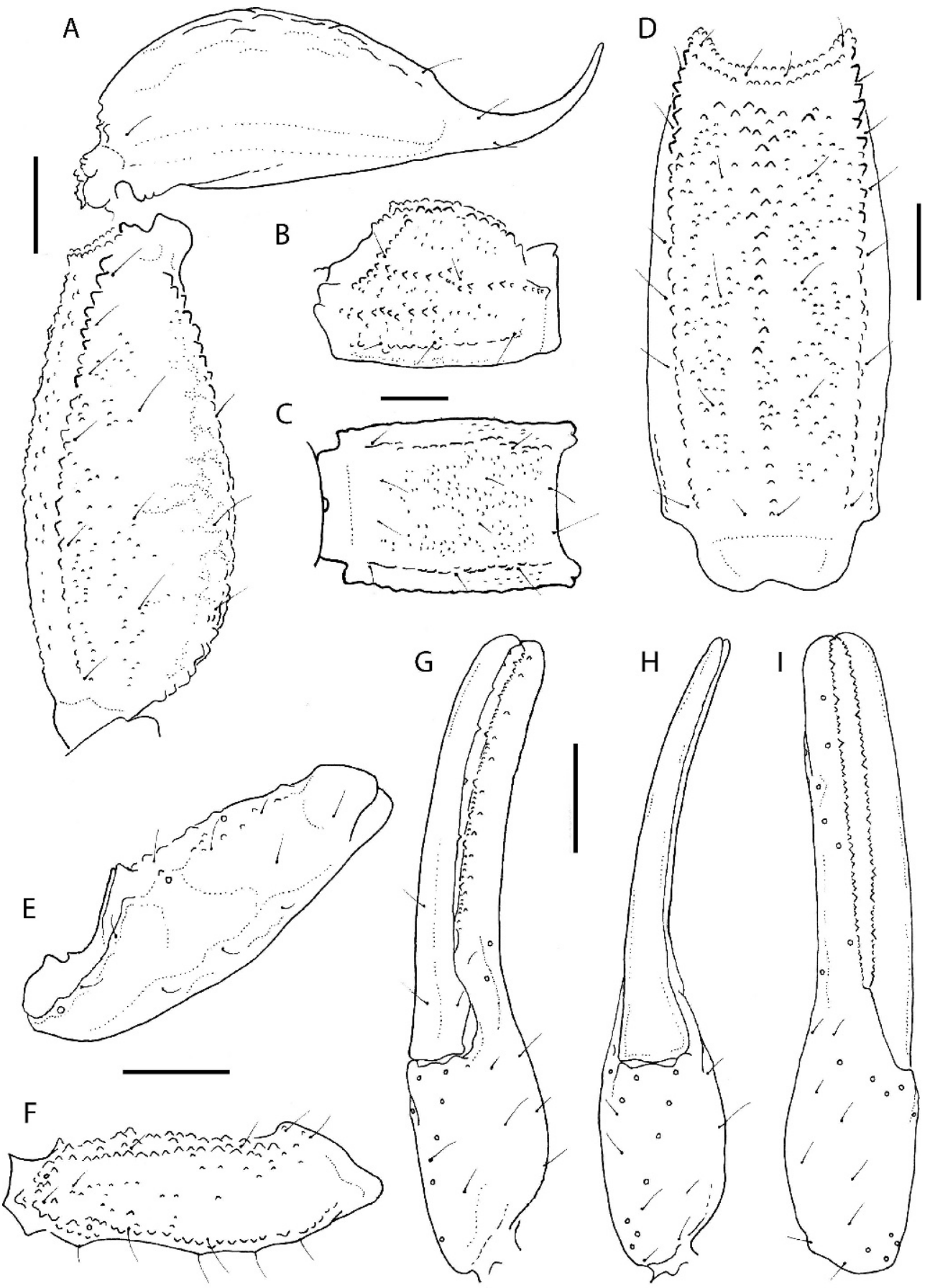

Fig. 15. Hadruroides graceae, n. sp., holotype of (MHNC). A. Metasomal segment V and telson, lateral aspect. B. Metasomal segment IV, lateral aspect. C. Metasomal segment IV, ventral aspect. D. Metasomal segment V, ventral aspect. E. Dextral pedipalp patella, dorsal aspect. F. Dextral pedipalp femur, dorsal aspect. G. Dextral pedipalp chela, ventrointernal aspect. H. Dextral pedipalp chela, ventral aspect. I. Dextral pedipalp chela, external aspect. Scale bars $=1 \mathrm{~mm}$. 


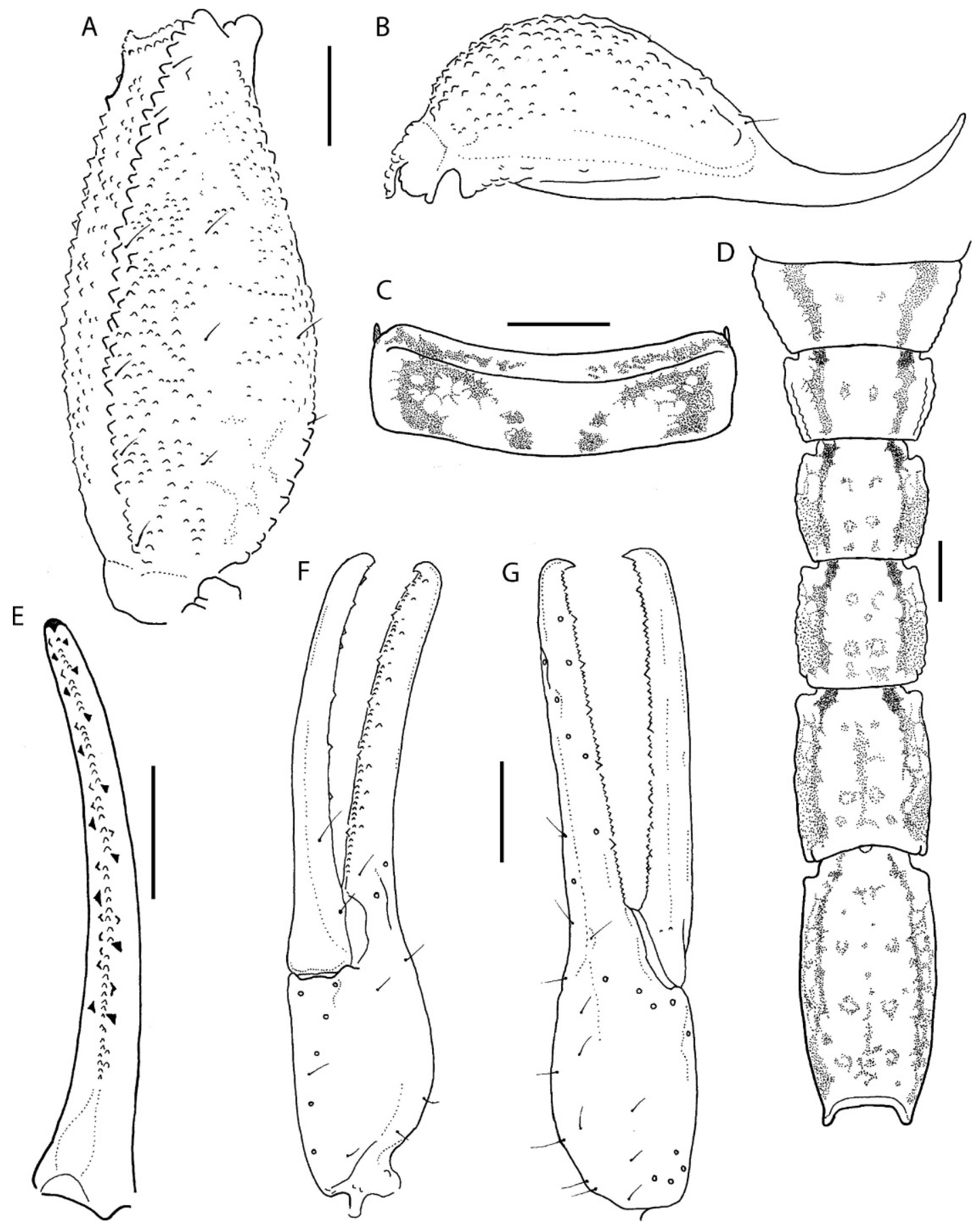

Fig. 16. Hadruroides graceae, n. sp., diagnostic characters. A, B. Paratype $q$ (MHNC). A. Metasomal segment V, lateral aspect. B. Telson, lateral aspect. C-E. Paratype ô (MHNC). C. Tergite IV, dorsal aspect showing pigmentation pattern. D. Sternite VII and metasomal segments I-V, ventral aspect showing pigmentation pattern. E. Dextral pedipalp chela, movable finger, dorsal aspect showing dentition. F, G. Paratype $q$ (MHNC). F. Dextral pedipalp chela, ventrointernal aspect. G. Dextral pedipalp chela, external aspect. Scale bars $=1 \mathrm{~mm}$. 
A

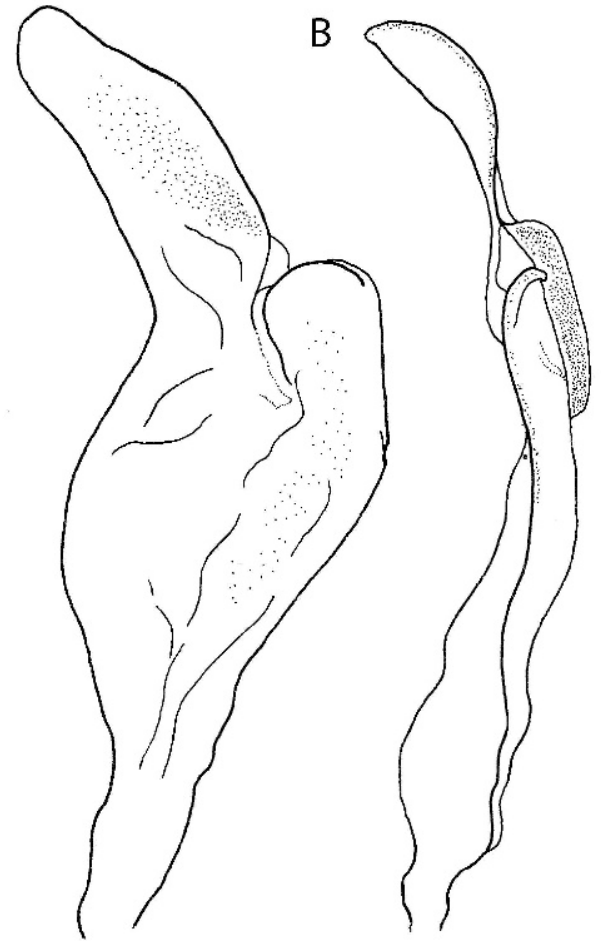

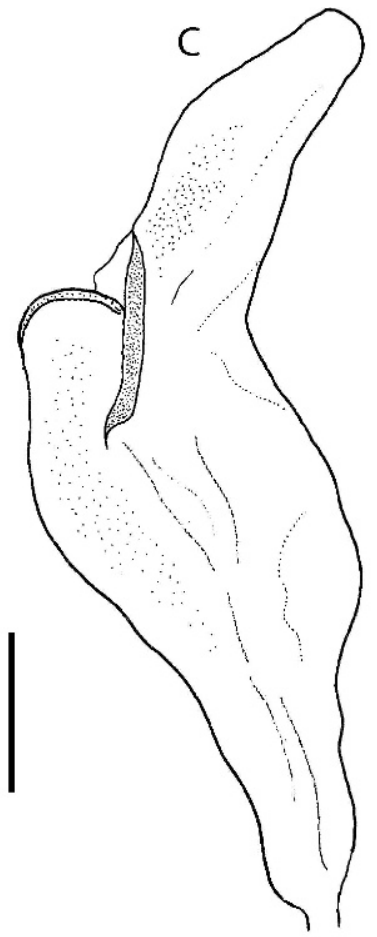

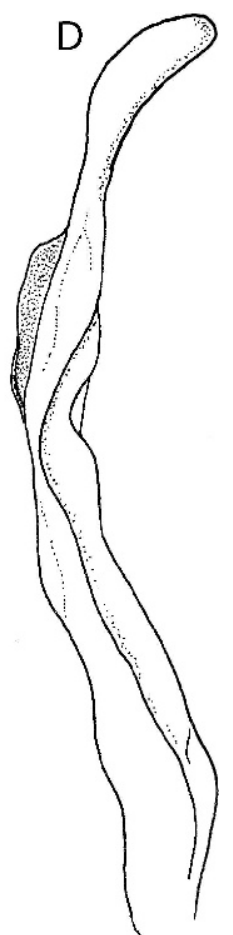

Fig. 17. Hadruroides graceae, n. sp., paratype $\delta$ (MHNC), sinistral hemispermatophore. A. Ental aspect. B. Dorsal aspect. C. Ectal aspect. D. Ventral aspect. Scale bar $=0.5 \mathrm{~mm}$.

Type Material: PERU: Cajamarca Department: Cajamarca Province: Holotype ô, 4 paratypes, including allotype + (BMNH), Los Baños del Inca, near Cajamarca $\left(07^{\circ} 10^{\prime} 32^{\prime \prime} \mathrm{S}\right.$ $\left.78^{\circ} 26^{\prime} 50^{\prime \prime} \mathrm{W}, 2880 \mathrm{~m}\right)$, P.O. Simons.

New ReCords: PERU: Cajamarca Department: Cajamarca Province: Baños del Inca, Cerro Palina, $07^{\circ} 10^{\prime} 32^{\prime \prime} \mathrm{S} 78^{\circ} 26^{\prime} 50^{\prime \prime} \mathrm{W}, 2880 \mathrm{~m}$, 17.xi.2004, J.C. Chaparro and J.A. Ochoa, 1 s, 1 juv. (AMNH), 2 §ิ, 1 क, 2 juv. (MHNC). San Marcos Province: Villanueva, near Crisnejas bridge, $07^{\circ} 27^{\prime} 32.8^{\prime \prime} \mathrm{S} 78^{\circ} 06^{\prime} 59.3^{\prime \prime} \mathrm{W}, 2037 \mathrm{~m}$, 6.i.2008, R. Gutiérrez, D. Apaza and J.A.

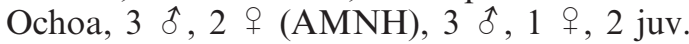
(MHNC).

Diagnosis: Hadruroides carinatus appears to be most closely related to $H$. geckoi, from which it may be distinguished based on the carination of sternite VII and metasomal segment V. Sternite VII exhibits four welldeveloped carinae in $H$. carinatus, but only the VL carinae are distinct (the VSM carinae are obsolete) in $H$. geckoi. The DL carinae of segment $\mathrm{V}$ are acarinate in $H$. carinatus, but comprise some granules in H. geckoi. Other differences between the two species are as follows: the pedipalp chela and metasomal segment $\mathrm{V}$ are longer in $H$. geckoi than in $H$. carinatus; metasomal segment $\mathrm{V}$ exhibits fewer dorsolateral and ventrolateral setae in $H$. carinatus than $H$. geckoi; the telson is entirely smooth in female $H$. carinatus, compared with $H$. geckoi, in which the ventral surface is granular; the lamina of the hemispermatophore is acuminate apically in $H$. geckoi, but rounded in $H$. carinatus.

Distribution: Hadruroides carinatus was previously known only from the type locality, situated at $2650 \mathrm{~m}$, near the city of Cajamarca. Based on new material collected during recent fieldwork, we confirm the presence of this species at Baños del Inca and report additional records between 2037 and $2880 \mathrm{~m}$. The known locality records occur in the inter- 


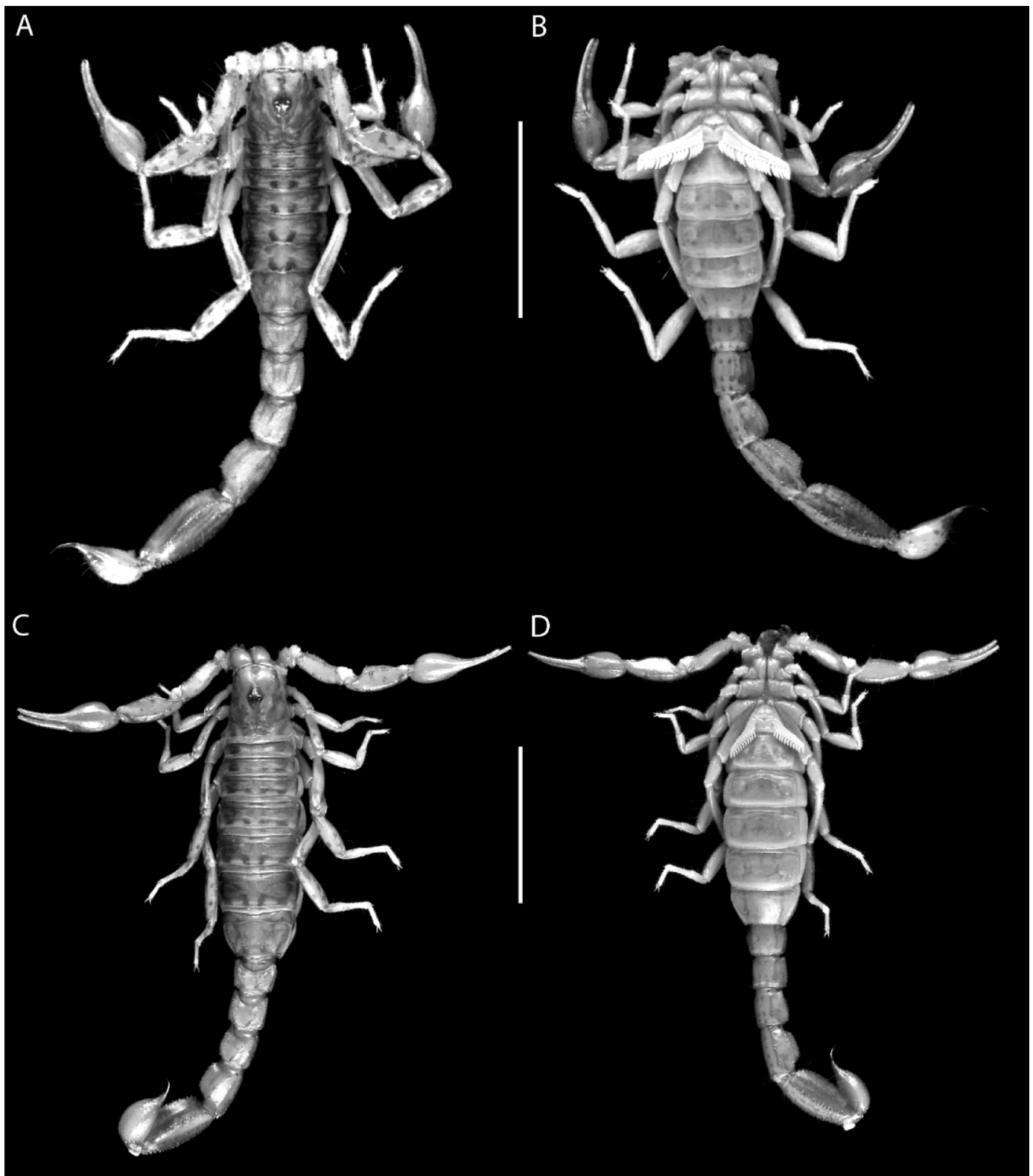

Fig. 18. Hadruroides juanchaparroi, n. sp., habitus. A, B. Holotype oै (MHNC). C, D. Paratype $q$ (MHNC). A, C. Dorsal aspect. B, D. Ventral aspect. Scale bars $=1 \mathrm{~cm}$.

Andean valleys of southern Cajamarca Department (fig. 2). Lourenço and Dastych's (2001) record of $H$. carinatus from Chala (Arequipa Department in southern Peru) is probably a misidentification. Chala is situated at 350-500 m near the coast and H. carinatus inhabits mountainous regions in northern Peru.

Ecology: This species is restricted to rocky areas with thornbush vegetation. Some specimens were collected under stones during daytime, others with UV light detection at night. 


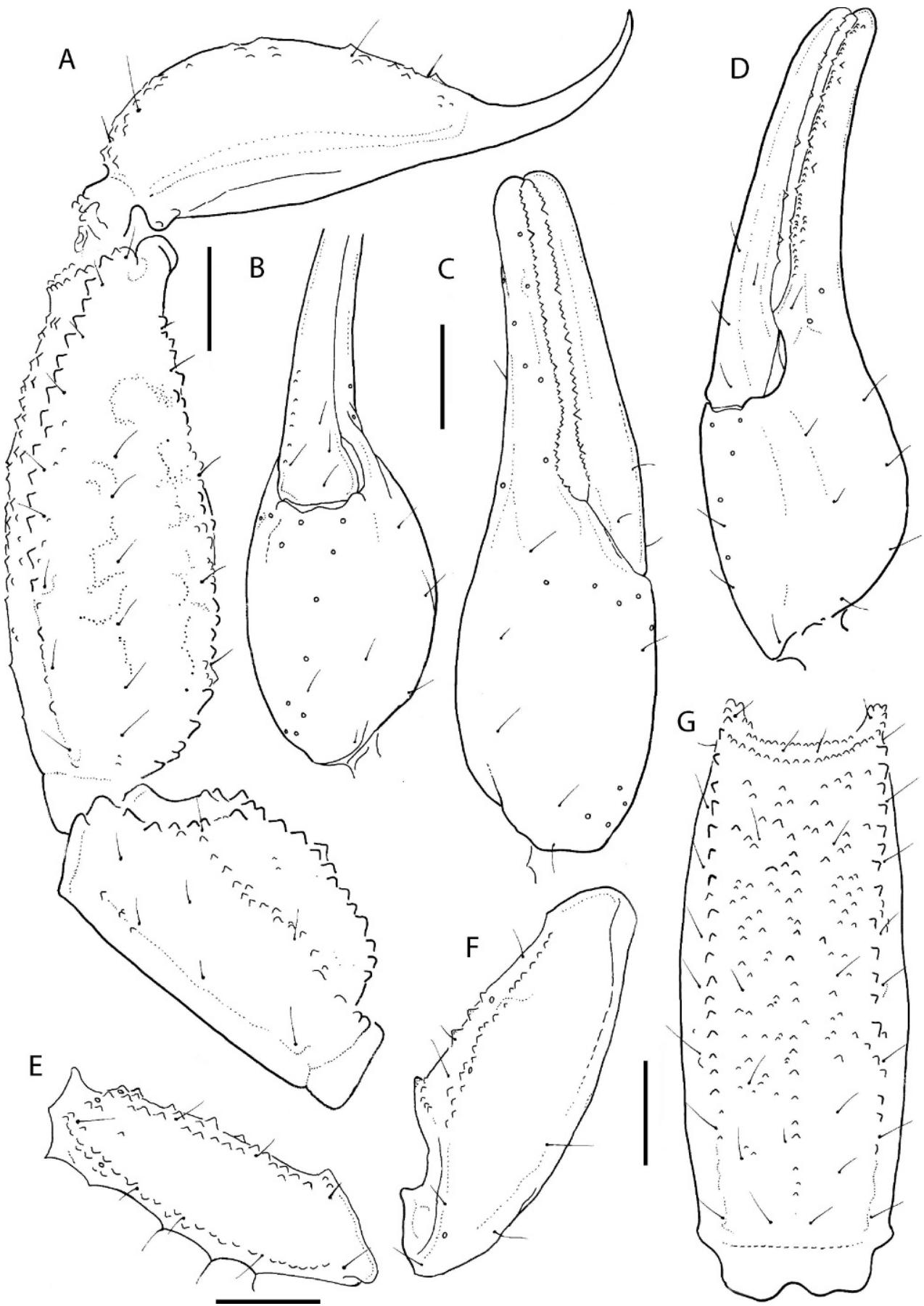

Fig. 19. Hadruroides juanchaparroi, n. sp., holotype $\hat{o}$ (MHNC). A. Metasomal segments IV, V and telson, lateral aspect. B. Dextral pedipalp chela, ventral aspect. C. Dextral pedipalp chela, external aspect. D. Dextral pedipalp chela, ventrointernal aspect. E. Dextral pedipalp femur, dorsal aspect. F. Dextral pedipalp patella, dorsal aspect. G. Metasomal segment V, ventral aspect. Scale bars $=1 \mathrm{~mm}$. 


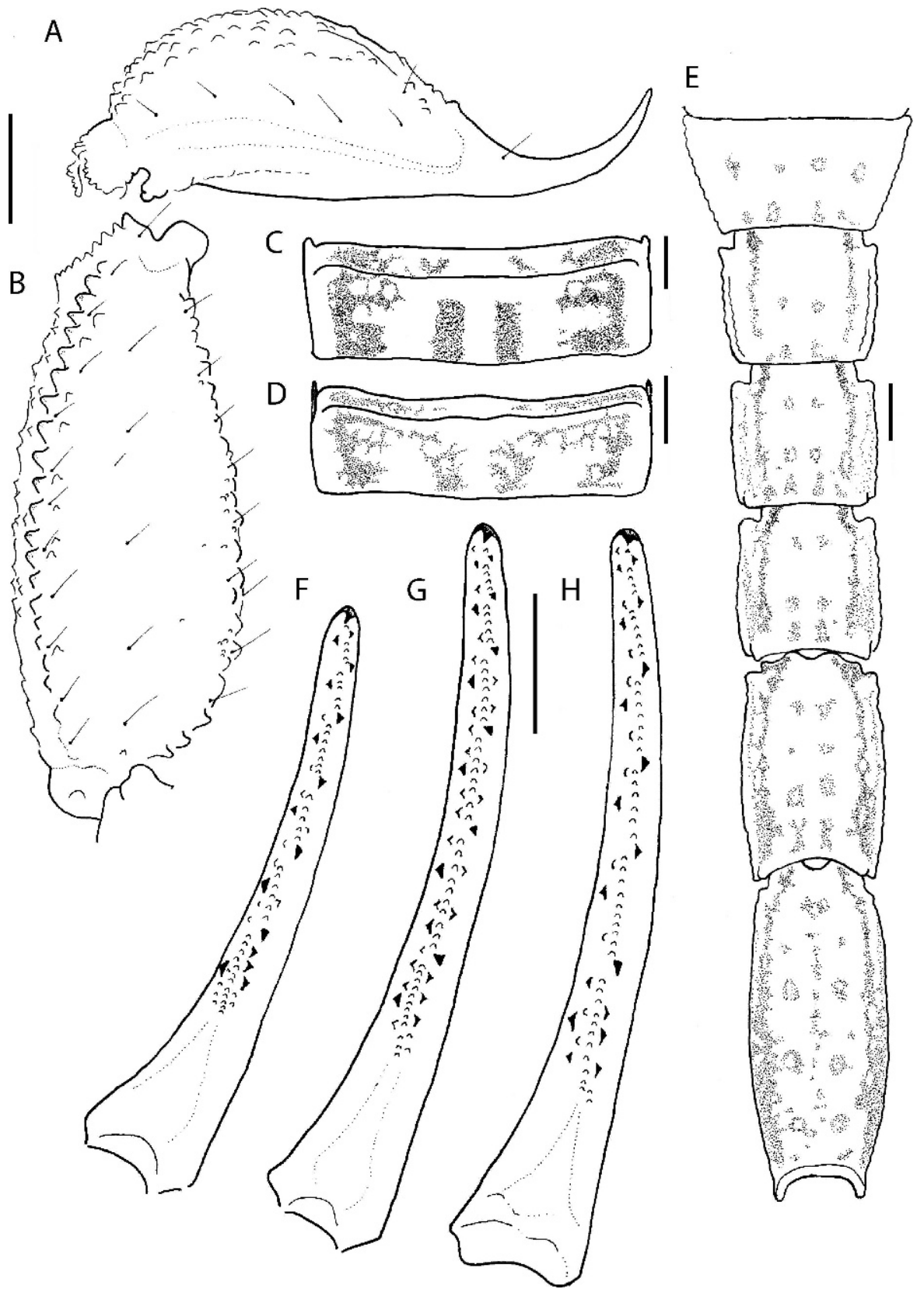

Fig. 20. Hadruroides Pocock, 1893, diagnostic characters. A, B. Hadruroides juanchaparroi, n. sp., paratype + (MHNC). A. Telson, lateral aspect. B. Metasomal segment V, lateral aspect. C. Hadruroides lunatus (L. Koch, 1867), + (AMNH), tergite V, dorsal aspect showing pigmentation pattern. D-F. $H$. juanchaparroi, paratype ô (MHNC). D. Tergite IV, dorsal aspect showing pigmentation pattern. E. Sternite VII and metasomal segments I-V, ventral aspect showing pigmentation pattern. F. Dextral pedipalp chela, movable finger, dorsal aspect showing dentition. G. Hadruroides geckoi, n. sp., paratype $\hat{\delta}$ (MHNC), dextral pedipalp chela, movable finger, dorsal aspect showing dentition. H. Hadruroides vichayitos, n. sp., paratype of (MHNC), dextral pedipalp chela, movable finger, dorsal aspect showing dentition. Scale bars $=1 \mathrm{~mm}$. 
Hadruroides charcasus (Karsch, 1879)

Figures 2, 4E

Hadrurus charcasus Karsch, 1879: 135.

Hadrurus paaschi Karsch, 1881: 290 (synonymized by Maury, 1975: 11); Williams, 1970: 31.

Caraboctonus charcasus: Pocock, 1893a: 92.

Hadruroides charcasus: Pocock, 1893b: 329, 1900: 475; Williams, 1970: 31; Maury, 1975: 11-13, figs. 1-10; Francke, 1977: 75; Francke and Soleglad, 1980: 11; Moritz and Fischer, 1980: 312; Francke and Soleglad, 1981: 245, figs. 30-33; Lourenço, 1994: 157, 1998: 141, fig. 8; Kovař́k, 1998: 135; Sissom and Fet, 2000: 411; Lourenço and Dastych, 2001: 56; Acosta and Ochoa, 2002: 19; Soleglad and Fet, 2003a: 5, 2003b: 8; Fet et al., 2004: 18, 24, figs. $15,16,35$, 48, 2006: 269, fig. 8; Ochoa and Chaparro, 2008: 5; Francke and Prendini, 2008: 210, 218, fig. 4, table 4; Fet and Soleglad, 2008: 257, figs. 5, 22-26, table 3; Kamenz and Prendini, 2008: 25, 43, pl. 64, table 2; Volschenk et al., 2008: 661, 675 , fig. 5A, tables $1,2$.

Hadruroides lunatus: Kraepelin, 1894: 207 (part); Kraepelin, 1899: 188 (part); Kraepelin, 1901: 274 (part); Mello-Leitão, 1945: 120 (part).

Type Material: Holotype $q$ [Hadrurus charcasus] (ZMB 3062), BOLIVIA [erroneous], Wascewicz. Holotype ô [Hadrurus paaschi] (ZMB 4072), ECUADOR.

New Records: PERU: Lambayeque Department: Lambayeque Province: Southern Olmos $\left(05^{\circ} 59^{\prime} 30^{\prime \prime} \mathrm{S} 79^{\circ} 44^{\prime} 36^{\prime \prime} \mathrm{W}, 175 \mathrm{~m}\right), 1$ juv. $(\mathrm{AMNH})$; Motupe $\left(06^{\circ} 09^{\prime} 12^{\prime \prime} \mathrm{S} 79^{\circ} 42^{\prime} 53^{\prime \prime} \mathrm{W}\right.$, 133 m), 20.viii.1969, G. Arboleda, 2 ㅇ (AMNH), 3.iv.1970, G. Arboleda, 1 ô, 1 ㅇ, 3 juv. (AMNH); between Porculla and intersection to Olmos, $05^{\circ} 56^{\prime} 09.6^{\prime \prime} \mathrm{S} 79^{\circ} 35^{\prime} 55.1^{\prime \prime} \mathrm{W}$, 498 m, 17.i.2008, R. Gutiérrez, D. Apaza and J.A. Ochoa, $1+$ (MHNC); EPM Anchovira, between Motupe and Jayanca, near intersection to Salas, $06^{\circ} 16^{\prime} 02.7^{\prime \prime} \mathrm{S} 7^{\circ} 44^{\prime} 10.7^{\prime \prime} \mathrm{W}$, 101 m, 17.i.2008, R. Gutiérrez, D. Apaza and J.A. Ochoa, 3 s, 1 q, 1 juv. (AMNH), 2 o, 2 +, 3 juv. (MHNC); Northern Lambayeque $\left(06^{\circ} 41^{\prime} \mathrm{S} \quad 79^{\circ} 54^{\prime} \mathrm{W}, 17 \mathrm{~m}\right)$, 13.xi.1970, 3 o , 10 क, 9 juv. (AMNH). Piura Department: Sechura Province: Sechura $\left(05^{\circ} 33^{\prime} 52^{\prime \prime} \mathrm{S} 80^{\circ} 48^{\prime} 41^{\prime \prime} \mathrm{W}, 15 \mathrm{~m}\right)$, 14.xi.1970, 1 $\uparrow, 1$ juv. (AMNH).

DiAgnosis: Hadruroides charcasus may be distinguished from all other species of the genus by means of the carination of the pedipalp chela. The internomedian, dorsointernal, and dorsal marginal carinae are well developed, comprising strong granules in adult $H$. charcasus, compared with other species of Hadruroides, in which the pedipalp chela is acarinate.

Distribution: Hadruroides charcasus is widely distributed throughout northern Peru. It has been recorded from the Lambayeque, Piura, and Tumbes departments, as well as the western slopes of the Andes in Cajamarca Department (Maury, 1975; Francke, 1977). Specimens examined during the present study were collected at elevations between 15 and $498 \mathrm{~m}$ (fig. 2). It is doubtful whether this species occurs in the inter-Andean valleys on the eastern side of the Cordillera. Maury's (1975) record from Baños del Inca (2660 m, Cajamarca Department) is probably erroneous. We conducted several field expeditions to the Cajamarca region and $H$. carinatus was the only Hadruroides species collected at Baños del Inca. Other records from Cajamarca, Trujillo, Tumbes, and Lobos de Afuera (Maury, 1975; Francke, 1977) should be reassessed.

ECOLOGY: The vegetation in the region inhabited by $H$. charcasus is characterized by cacti, shrubs, and scattered trees, e.g., Bursera graveolens (Kunth) Triana and Planch. (Burseraceae), Capparis sp. (Brassicaceae), Ceiba insignis (Kunth) Gibbs and Semir (Malvaceae), Loxopterigium huasango Spruce ex Engl. (Anacardiaceae), Prosopis pallida (Humboldt and Bonpland ex Willdenow) Kunth (Fabaceae). Hadruroides charcasus is sympatric with $H$. leopardus.

\section{Hadruroides chinchaysuyu, n. sp.}

Figures 2, 4B, 6, 7A, C, 8, 9A-C, E-H; table 2

Hadruroides maculatus maculatus: Maury, 1975: 19 (part). Hadruroides maculatus: Francke, 1977: 75 (part).

Type Material: PERU: Tumbes Depart-

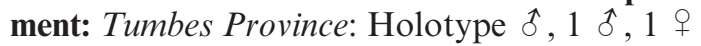
paratypes (MHNC), $2 \hat{\delta}$ paratypes (AMNH), San Juan de la Virgen, Brujas Bajas, near Cerro Blanco village $\left(03^{\circ} 39^{\prime} \mathrm{S} 80^{\circ} 24^{\prime} \mathrm{W}, 35 \mathrm{~m}\right)$, 23.xi.2004, P. Castillo, J.C. Chaparro and J.A. Ochoa; $1 \hat{\delta}, 1+$ paratypes (AMNH), $1 \hat{\delta}, 1$ juv. क paratypes (MHNC), Campus Universitario, Universidad Nacional de Tumbes, $03^{\circ} 35^{\prime} 32^{\prime \prime} \mathrm{S} 80^{\circ} 30^{\prime} 14^{\prime \prime} \mathrm{W}, 8 \mathrm{~m}, 23 . x i .2004$, J.C. Chaparro and J.A. Ochoa. 
Etymology: The Inca Empire was divided into four administrative regions (suyus): Chinchay (NW), Anti (NE), Qonti (SW), and Qolla (SE). The northwestern region, Chinchay Suyu, included large parts of modern Ecuador, central and northern Peru, and southern Colombia (Pasto). The specific name is a noun in apposition, taken from the Quechua Chinchay Suyu, and refers to the geographic distribution of this species in northern Peru.

DiAgnosis: This species appears to be most closely related to $H$. maculatus, with which it was previously confused. The two species are similar in the pigmentation pattern of the carapace, tergites, and pedipalps; pectinal tooth count; dimensions of the pedipalp chela; and curvature of the chela fixed finger of the adult male, which creates a proximal gap with the movable finger when the fingers are closed. The hemispermatophore is also similar in the two species (fig. 9E, $\mathrm{G})$ : the apex is acuminate, as observed also in $H$. geckoi, in which the lamina is more strongly curved distally (fig. 13). Hadruroides chinchaysuyu and $H$. maculatus may be separated by means of the granulation of the carapace and the development of the ventral carinae of the metasomal segments and sternite VII. Hadruroides maculatus is in general more granular than $H$. chinchaysuyu. The carapace of the male $H$. maculatus is entirely coarsely granular, compared with $H$. chinchaysuyu, in which the anterior third is finely granular (fig. 7A, B). Four well-developed carinae are present on sternite VII in $H$. maculatus (fig. 7D), compared with $H$. chinchaysuyu, in which only the VL carinae are distinct, and the VSM obsolete (fig. 7C). The VSM carinae of metasomal segments I-III are also more strongly developed in $H$. maculatus than $H$. chinchaysuyu. The legs are densely granular in $H$. maculatus and sparsely granular in $H$. chinchaysuyu (fig. 9A, D). The pigmentation pattern provides other differences, e.g., $H$. chinchaysuyu displays a VM stripe on metasomal segments III-V fig. 9C) which is present only on segment $\mathrm{V}$ in $H$. maculatus.

DESCRIPTION: Based on the holotype and paratypes. Measurements of the holotype $\hat{\sigma}$ and a paratype + are recorded in table 2 .
Color: Base color yellowish with light brown spots on carapace and tergites; pedipalps, legs, and metasomal segments I-IV with light brown spots; metasomal segment $\mathrm{V}$ slightly darker; telson slightly orange. Carapace markedly pigmented, especially on lateral and posterior surfaces; anteromedian longitudinal sulcus with narrow stripe; ocular tubercle blackish. Tergites I-VI each with four spots, two small spots submedially in posterior half, two sublateral spots larger, irregular, with some depigmented areas extending from anterior to posterior margin; pretergites with two elongated spots of pigmentation sublaterally (fig. 8I); VII less pigmented, only some reticulation evident above carinae. Sternites III-VI depigmented; VII with very faint spots surrounding VL carinae and insertion of submedian setae. Metasomal segments I-IV, dorsal surfaces depigmented, weakly pigmented on DL carinae in some specimens; lateral surfaces: between LIM and VL carinae, slightly reticulate in posterior half of segments III and IV or depigmented on segments I-IV; ventral surfaces with two narrow stripes along VL carinae, more evident on segments III and IV, pigmentation becoming more intense anteriorly (fig. 9C); VM stripe complete or discontinuous on segments III and IV; some spots surround insertion of setae on ventral surfaces: in most specimens, segment I with $2+2$ spots, II and III with $3+3$, IV with $4+4$, additional small spots evident in some specimens (fig. 9C); spots faint on segments I and II. Metasomal segment V, dorsal and lateral surfaces with markedly reticulate pigmentation in posterior third; ventral surface with three stripes along VL and VM carinae, pigmentation faint in some specimens, but always more pronounced than on segments III and IV; additionally with 12-16 extra spots, surrounding insertion of some setae; VM stripe complete or discontinuous. Telson with some spots on ventral surface. Chelicerae dorsolateral surfaces pigmented; movable fingers with small spot medially. Pigmentation of pedipalps generally less developed than on carapace and tergites. Femur pigmented along DI and DE carinae; internal and external surfaces spotted; other surfaces depigmented. Patella dorsal surface with some spots surrounding insertion of setae; external surface 


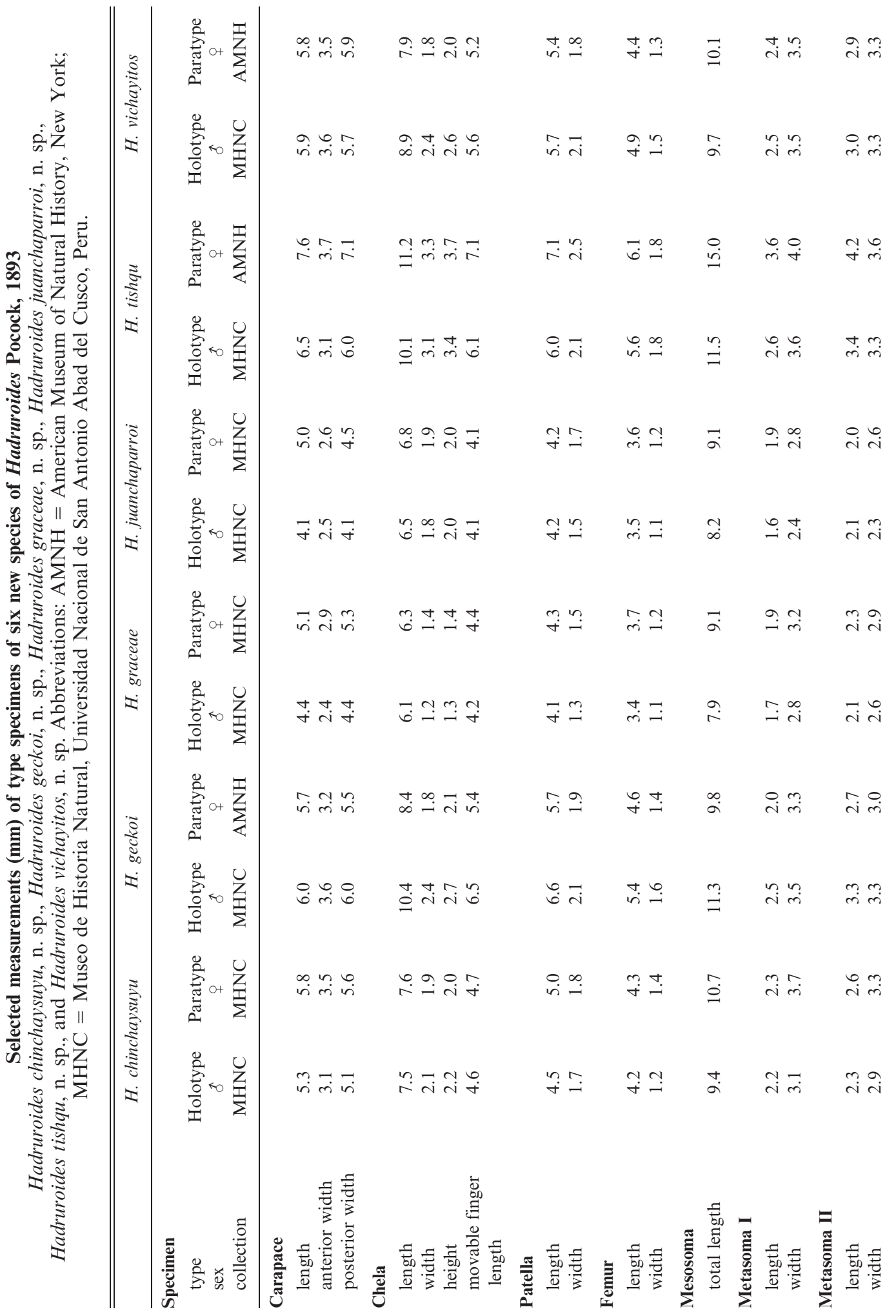




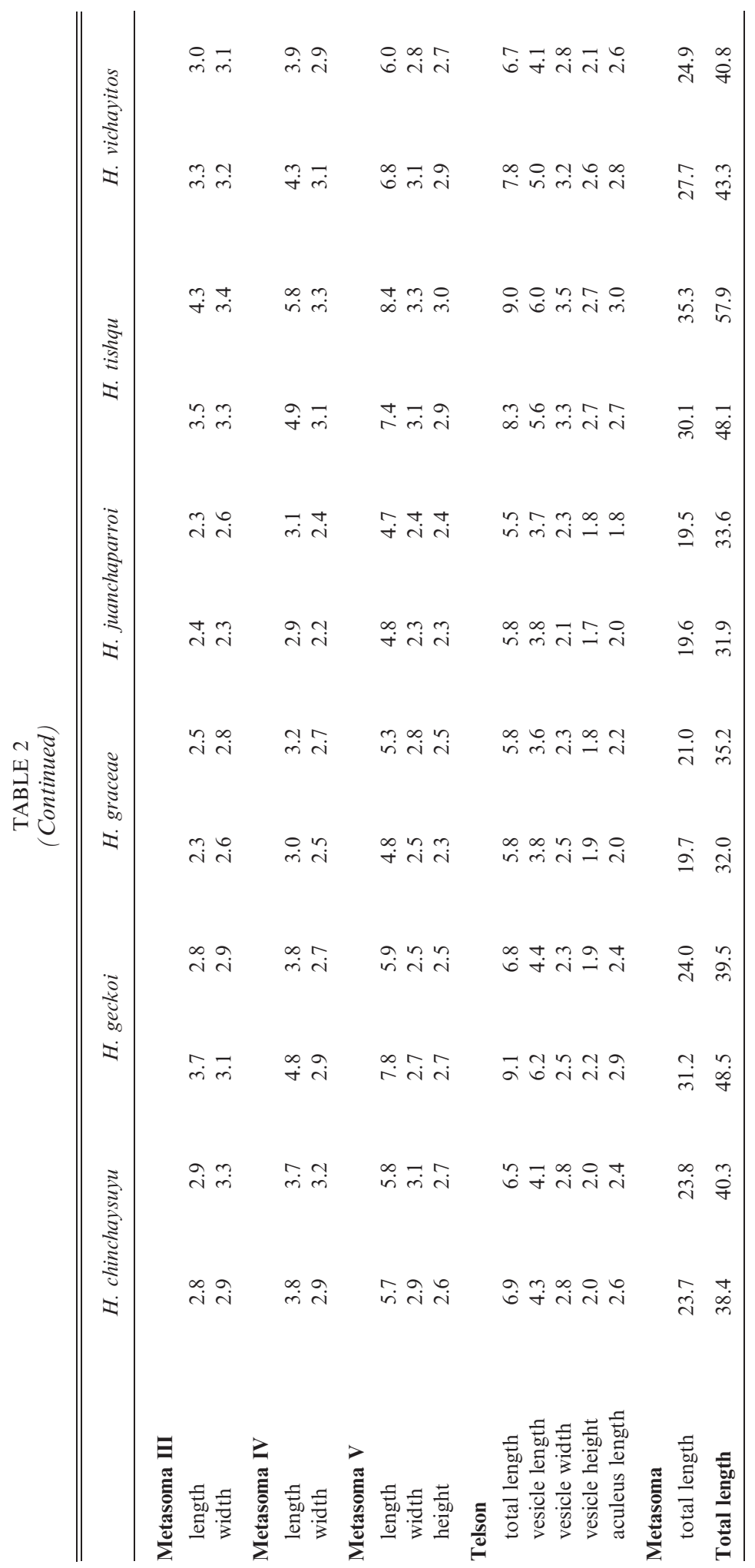


with longitudinal stripe. Chela with three or four longitudinal stripes of pigmentation in place of carinae; additionally with irregular spots surrounding insertion of some setae. Legs with some spots on prolateral surfaces.

Chelicerae: Typical of genus; surfaces smooth; dorsal surface with two macrosetae situated near base of fingers.

Carapace: Anterior margin with weak median projection and 8-9 macrosetae; surfaces mostly coarsely granular, except for anterior third, which is finely granular ( $\vec{b}$ ) (fig. 7A) or smooth $(+)$; anteromedian longitudinal sulcus obsolete, with few granules along borders; posteromedian longitudinal and posterolateral sulci well developed; median ocular sulcus obsolete.

Pedipalps: Femur with VI, DI and DE carinae complete, granular, VE vestigial, VM comprising small granules in proximal half (fig. 8G); dorsal and internal surfaces with few granules medially; ventral surface smooth. Patella with DI and VI carinae complete (fig. 8H); DPP and VPP comprising prominent spiniform granule and additional subspiniform granules; other surfaces smooth. Chela acarinate (figs. 8C, E, 9B); fingers relatively elongated; fixed finger straight ( $(+)$ or curved, creating distinct proximal gap with movable finger when fingers are closed ( $\hat{\sigma})$; movable finger, median denticle row comprising six subrows, two or four internal and external accessory denticles flanking subrows I and II (proximal), one or two internal and external accessory denticles flanking subrows III and IV, and one or two internal accessory denticles flanking subrows $\mathrm{V}$ and VI.

Trichobothrial pattern: Typical of genus; femur with three trichobothria, patella with 20 , chela with 26; chelal trichobothrium $e b$ situated slightly distal to proximal gap between fixed and movable fingers (fig. 8C).

Legs: Prolateral surfaces granular; retrolateral surfaces smooth. Leg III, femur tetracarinate, DE, DI, VI, and EM carinae present; patella, DM carinae present in proximal half of segment, DI in distal half, IM, DE, VI and EM complete (fig. 9A). Telotarsus with 7-12 ventromedian spinule clusters (setaceous tufts).

Tergites: Pretergites granular. Post-tergites I-VI, anterior and median surfaces finely granular, posterior and lateral surfaces more coarsely granular; VII coarsely granular, with four well-developed longitudinal carinae.

Sternum: Subpentagonal; surface with six macrosetae; posterolateral surfaces granular along borders; median sulcus well developed.

Pectines: Pectinal tooth count: 17-20 (ठ)), $16($ ( ) $)$.

Sternites: Sternites III-VI, surfaces finely granular ( $\hat{\sigma})$ or smooth ( + ); spiracles small, situated in posterior half of segment; VII, VL carinae well developed, VSM carinae obsolete, comprising small, sparse granules or absent (fig. 7C).

Metasoma: Segments I-IV, dorsal surfaces with scattered granules; DL and ML carinae complete; LIM carinae complete on I and II, present in posterior half of III and posterior third of IV, comprising sparse granules on these segments; surfaces between DL, ML, and LIM carinae with scattered granules on segments I and II, smooth (most specimens) or finely and sparsely granular on III and IV; VL carinae complete on I-IV; VSM carinae obsolete, comprising few granules on I (fig. 7C) and II, obsolete or absent on III, absent on IV. Segment V densely granular (fig. 8A, D, F); DL carinae complete, comprising numerous granules along edge and adjacent dorsal and lateral surfaces; lateral surface granular, especially near VL edge, more so in $\hat{\delta}$; VL and VM carinae well developed, granules increasing in size posteriorly; ventral surface densely granular throughout (fig. 8F). Segment I with two pairs of ventral setae; II and III with three pairs; IV with five pairs and additional setae along posteromedian margin; $\mathrm{V}$ with $13-18$ ventral setae and 5-6 additional setae along posterior margin.

Telson: Vesicle, surfaces sparsely setose; with scattered granulation ventrally $(q)$ or few granules in anterior third ( $\hat{\jmath}$ ) (fig. 8B, D).

Hemispermatophore: Distal lamina slightly inclined to ventral border, apex acuminate; crest less than half lamina length (fig. 9E-H).

Variation: Total length: 8 , 37.9-41.1 (mean $=39.1, n=6)$; 우 $36.7-40.3(n=2)$. Pedipalp chela, length:width ratio: o , 3.66-4.02 (mean $=3.83, n=6)$; ㅇ , 4.0-4.18 $($ mean $=4.09, n=$ 2); length:height ratio: $\hat{\delta}, 3.33-3.52$ (mean $=$ $3.45, n=6)$; 9 , 3.78-3.80 $($ mean $=3.79, n=$ 2). Pedipalp femur, length:width ratio: $\hat{\delta}$, 3.23-3.46 (mean $=3.37, n=6)$; + , 3.07-3.21 
$($ mean $=3.14, n=2)$. Pectinal tooth count: $\hat{\delta}$ $(n=12), 17(n=1), 18(5), 19(4), 20(2)$; ㅇ $(n$ $=6), 16$ (6). Metasomal segment V, length:width ratio: $\delta, 1.97-2.14$ (mean = $2.05, n=6)$; ㅇ, $1.87-1.92($ mean $=1.89, n=$ 2); length:height ratio: $\delta, 2.19-2.24$ (mean $=$ 2.22, $n=6)$; + , $1.92-2.15($ mean $=2.04, n=$ $2)$; number of setae: dorsolateral $(n=16): 5(n$ $=5), 6(8), 7(2), 8(1)$; lateral $(n=18): 4(1), 5$ (8), 6 (6), 7 (3); ventrolateral $(n=18): 6(2), 7$ (1), 8 (13), $9(1), 10(1)$; ventral $(n=9)$ : $13(2)$, 14 (1), 15 (1), 16 (2), 17 (2), 18 (1). Telson, length:height ratio: $\hat{\sigma}, 3.13-3.45$ (mean $=$ $3.29, n=6)$; 우 $3.25-3.28$ (mean 3.27, $n=2$ ). Telotarsus, number of ventromedian spinule clusters (setaceous tufts): III $(n=17), 7(n=$ 1), 8 (7), 9 (5), 10 (4); IV ( $n=18), 9$ (1), 10 (9), $11(7), 12(1)$.

Distribution: This species is known only from two localities at elevations between 8 and $35 \mathrm{~m}$ in the Tumbes Department of northern Peru (fig. 2). The known locality records occur in the equatorial dry forest ecoregion (Brack, 1986).

ECOLOGY: Some specimens were collected under stones and fallen tree trunks, whereas others were collected at night with UV light detection in dry forest and open areas.

Notes: According to Thorell's (1876) description, H. maculatus may be distinguished from $H$. lunatus by the presence of four carinae (VL and VSM carinae) on sternite VII and VSM carinae on metasomal segmens I-III. Although only two species of Hadruroides were known at the time of Thorell's (1876) description, we currently recognize 16 valid species in the genus, and these characters occur in several of them. Maury (1975) studied specimens from Ecuador and northern Peru that possess VSM and VL carinae on sternite VII, as well as other characters mentioned by Thorell (1876), and considered these specimens to be conspecific with $H$. maculatus. Maury (1975) did not examine the holotype of $H$. maculatus, however, because it was lost. Callao (Lima), the type locality of $H$. maculatus, is evidently erroneous, because $H$. aguilari and H. lunatus, the only two Hadruroides recorded from Lima and surrounding areas, do not possess carinae on sternite VII and the ventral surfaces of metasomal segments I-III. Maury (1975) based his redescription of $H$. maculatus on a male from Machalillo (Ecuador) and a female from Guayaquil (Ecuador), and listed additional material of $H$. maculatus from the Piura and Tumbes departments of northern Peru. We agree in part with Maury's (1975) assessment, but do not consider the specimens from the Piura and Tumbes departments to be conspecific with those from Ecuador. In our opinion, H. maculatus is endemic to Ecuador. The specimens from Tumbes, and perhaps also those from Piura, are referable to $H$. chinchaysuyu.

Hadruroides geckoi, n. sp.

Figures 1, 3B, 4C, 10, 11, 12A-D, F, 13, 20G; table 2

Type Material: PERU: Cajamarca Department: Celendin Province: Holotype $\hat{\sigma}$, $2 \hat{\delta}, 2$ ㅇ, 1 juv. paratypes (MHNC), 3 रे, 2 ㅇ, 2 juv. paratypes (AMNH), $1 \hat{\delta}, 1+$ paratypes (MUSA), Balsas, Marañón river valley, $06^{\circ} 50^{\prime} 49.4^{\prime \prime} \mathrm{S} 78^{\circ} 02^{\prime} 09.4^{\prime \prime} \mathrm{W}, 1141 \mathrm{~m}, 8 . \mathrm{i} .2008$, R. Gutiérrez, D. Apaza, and J.A. Ochoa, dry forest.

Etymology: The specific name is a patronym honoring the Peruvian biologist, Roberto Gecko Gutiérrez (Universidad Nacional San Agustín, Arequipa), in recognition of his assistance with fieldwork in Peru, including the trip during which this new species was collected.

Diagnosis: Hadruroides geckoi appears to be most closely related to $H$. carinatus. The two species may be distinguished from one another based on the dimensions of the pedipalp chela and metasomal segment V: the length:width ratio of the chela is 4.41-4.60 (o) and 4.53-4.74 (ㅇ) in H. geckoi (fig. 11E) compared with 3.48-3.73 (o) and 3.92-3.96 (q) in $H$. carinatus (fig. 12E). Metasomal segment $\mathrm{V}$ is longer in male $H$. geckoi, the length:width ratio being 2.40-2.89, compared with $2.17-2.36$ in $H$. carinatus. The telson is entirely smooth in female $H$. carinatus, compared with $H$. geckoi, in which the telson ventral surface is granular. Additionally, the lobe on the fixed finger of the chela and the proximal gap between the fixed and movable fingers are more developed in $H$. carinatus than $H$. geckoi. The two species may be 
further separated by means of the pigmentation pattern: the VL stripes merge with the lateral pigmentation on metasomal segments II-V in H. carinatus, and on segments IV and $\mathrm{V}$ in $H$. geckoi (fig. 12D). Other differences between the two species are as follows: sternite VII with four well-developed carinae in $H$. carinatus, but with only VL carinae distinct and VSM carinae obsolete in $H$. geckoi; metasomal segment $\mathrm{V}$ without DL carinae in $H$. carinatus, but comprising some granules in H. geckoi; metasomal segment $\mathrm{V}$ with 5-9 dorsolateral setae and 7-10 ventrolateral setae in $H$. carinatus, but with 10-14 dorsolateral setae and 9-13 ventrolateral setae in H. geckoi; chela trichobothrium $e b$ situated proximal to base of fixed finger in male $H$. carinatus, but situated near fixed finger lobe of male $H$. geckoi (fig. 11H). Finally, the shape of the lamina of the hemispermatophore, which is curved in the distal half and acuminate apically, provides a distinctive character for separating $H$. geckoi from other species of the genus.

DESCRIPTION: Based on the holotype and paratypes. Measurements of the holotype $\hat{\sigma}$ and a paratype $q$ are recorded in table 2 .

Color: Base color yellowish with light brown spots on carapace, tergites, legs, and pedipalps; pigmentation of metasomal segment $\mathrm{V}$ and telson more pronounced. Carapace markedly pigmented, especially laterally and posteriorly; anteromedian longitudinal sulcus with narrow stripe; ocular tubercle and lateral ocelli blackish. Tergites I-VI each with four irregular spots, two spots submedially in posterior half, two sublateral spots slightly paler; additionally with two small spots near anterior margin (fig. 12F); VII with carinae faintly pigmented. Sternites III-VI depigmented; VII with two narrow lines of pigmentation along VL carinae and four faint spots surrounding insertion of VSM setae in some specimens. Metasomal segments I-IV, dorsal surfaces faintly pigmented around granulation; lateral surfaces with some spots on segments II and III, more pigmented on IV; ventral surfaces with two narrow stripes along VL carinae, independent of lateral pigmentation of segments I-III, and joining posteriorly to lateral pigmentation of segment IV (fig. 12D); additionally with some spots sur- rounding insertion of setae: segment I with $2+2$ spots, II and III with $3+3$, IV with $5+5$, further small spots evident in some specimens (fig. 12D). Metasomal segment $\mathrm{V}$ with pigmentation more pronounced than on other segments; reticulation along DL carinae; lateral surface with pronounced reticulation, more so in posterior third; ventral surface with three stripes along VL and VM carinae, 7-8 pairs of spots surrounding insertion of setae, and three or more additional spots (fig. 12D). Chelicerae, dorsolateral surfaces pigmented; distal margins with reticulate spots; movable fingers each with small spot. Pedipalp femur with some spots along dorsal carinae and near articulation; additional spots surrounding insertion of setae; external surface with stripe in place of EM carina; other surfaces depigmented. Patella dorsal surface with several spots surrounding insertion of setae; external surfaces with stripe in place of EM carina. Chela external surface with few irregular spots surrounding insertion of setae, as well as three stripes joining proximally on ventral and external surfaces. Legs pigmented on prolateral surfaces.

Chelicerae: Typical of genus; surfaces smooth; dorsal surface with two macrosetae situated near base of fingers.

Carapace: Anterior margin with weak median projection and eight or nine macrosetae; surfaces granular, more coarsely so in $\hat{\sigma}$, except for anterior third, which is finely granular ( $\delta$ ) or smooth ( + ); anteromedian longitudinal sulcus obsolete with few small granules along borders; posteromedian longitudinal and posterolateral sulci well developed; median ocular sulcus obsolete.

Pedipalps: Femur with VI, DI, and DE carinae complete, granular; VE and VM vestigial (fig. 11F); dorsal surface smooth or sparsely granular; internal surface with scattered coarse granules; ventral surface smooth. Patella with DI and VI carinae granular (fig. 11C, D), DPP and VPP comprising prominent spiniform granules; all other surfaces smooth. Chela acarinate (figs. 11E, G, $\mathrm{H}, 12 \mathrm{~B}, \mathrm{C})$; fingers relatively elongated; fixed finger straight $(+)$ or curved and lobed, creating distinct proximal gap with movable finger when fingers are closed $(\hat{\delta})$; movable finger, median denticle row comprising six 
subrows, two or three internal and external accessory denticles flanking subrows I-IV (proximal) and two internal accessory denticles flanking subrows $\mathrm{V}$ and VI (fig. 20G).

Trichobothrial pattern: Typical of genus; femur with three trichobothria, patella with 20 , chela with 26; chelal trichobothrium $e b$ situated distal to proximal gap between fixed and movable fingers (fig. $11 \mathrm{H}$ ).

Legs: Prolateral surfaces granular; retrolateral surfaces smooth. Leg III, femur tetracarinate, DE, DI, VI, and EM carinae present; patella, DM carinae present in proximal half of segment, DI in distal third, IM comprising two or three granules medially; DE, VI, and EM carinae complete, granular; VI and EM more developed than DE. Telotarsus with 813 ventromedian spinule clusters (setaceous tufts).

Tergites: Pretergites finely granular ( $\hat{\sigma})$ or smooth ( + ). Post-tergites I-VI, surfaces finely granular; VII coarsely granular, with four well-developed longitudinal carinae.

Sternum: Subpentagonal; surface with six macrosetae; posterolateral surfaces granular along borders; median sulcus well developed.

Pectines: Pectinal tooth count: 21-23 (ô), 18-21 (ㅇ).

Sternites: Sternites III-VI, surfaces matte (đ) or smooth (ㅇ); spiracles small, narrow, elliptical, situated in posterior half of segment; VII, VL carinae well developed, VSM carinae absent or obsolete, comprising small isolated granules.

Metasoma: Segments I-IV, dorsal surfaces with scattered granules, more sparsely granular on IV than preceding segments; DL carinae complete and well developed, posterior granule slightly larger than others; ML carinae complete, well developed on segments I-III, comprising smaller granules on IV (fig. 11A); LIM carinae complete on I, present in posterior two-thirds of segment II and posterior half of III, absent ( $\vec{f}$ ) or comprising three or four granules posteriorly $(+)$ on IV; surfaces between DL, ML, LIM, and VL carinae with scattered granules on segment I, smooth ( + ) or finely granular ( $\delta$ ) on II-IV; VL carinae complete on segments I-IV, granular on I, obsolete, smooth on II-IV (fig. 11A); VSM carinae complete on segments
I and II, comprising few granules on I, less developed on II, obsolete on III, absent on IV. Segment V relatively elongated, setose (figs. 11A, B, 12A); DL carinae complete, comprising few granules; VL and VM carinae well developed, granules increasing in size posteriorly; VSM carinae absent; lateral and dorsal surfaces smooth; ventral surface with scattered granules in posterior third (fig. 11B). Segment I with two pairs of ventral setae; II and III with three pairs, one specimen with additional setae along posterior margin of III; IV with five pairs and additional setae along posteromedian margin; $\mathrm{V}$ with $15-18$ ventral setae, and five or six additional setae along posterior margin.

Telson: Vesicle, surfaces densely setose; ventral surface sparsely ( $\hat{\sigma})$ or densely ( $(+)$ granular in anterior half (figs. 11A, 12A).

Hemispermatophore: Distal lamina inclined to ventral border and strongly curved distally, apex acuminate; crest less than half lamina length (fig. 13).

Variation: Total length: $\delta$, 40.2-48.5 (mean $=42.8, n=6)$; + , 38.9-40.4 (mean $=39.7, n$ $=4)$. Pedipalp chela, length:width ratio: $\hat{\sigma}$, 4.33-4.60 (mean $=4.48, n=6)$; + , 4.53-4.74 (mean $=4.61, n=5)$; length:height ratio: $\delta$, 3.85-4.10 (mean $=4.01, n=6) ; 9,4.00-4.26$ (mean $=4.14, n=5$ ). Pedipalp femur, length:width ratio: $\hat{\sigma}, 3.38-3.45$ (mean $=$ $3.44, n=6)$; ㅇ, 3.21-3.28 (mean $=3.24, n=$ 5). Pectinal tooth count: $\delta \quad(n=12), 21(n=$ 2), 22 (4), 23 (6); 우 ( $n=14), 18$ (3), 19 (5), 20 (2), 21 (4). Metasomal segment V, length:width ratio: $\hat{\sigma}, 2.40-2.89$ (mean $=$ $2.61, n=6)$; ㅇ, $2.10-2.36($ mean $=2.21, n=$ 5); length:height ratio: $\hat{\delta}, 2.55-2.89$ (mean $=$ 2.71, $n=6)$; + , $2.14-2.47$ (mean $=2.31, n=$ 5); number of setae: dorsolateral $(n=18)$ : 10 $(n=2), 11(2), 12$ (9), 13 (2), 14 (3); lateral (n $=18): 7(10), 8(6), 9(2)$; ventrolateral $(n=$ 18): 9 (1), 10 (8), 11 (6), 12 (2), 13 (1); ventral $(n=9)$ : 15 (1), 16 (2), 17 (4), 18 (2). Telson, length:height ratio: $\delta, 3.79-4.13$ (mean $=$ 3.91, $n=6$ ); 9 , 3.37-3.70 (mean 3.55, $n=5$ ). Telotarsus, number of ventromedian spinule clusters (setaceous tufts): III $(n=18), 8(n=$ 2), 9 (10), 10 (4), 11 (2); IV ( $n=18), 10$ (2), 11 (8), 12 (6), 13 (2).

Distribution: Hadruroides geckoi inhabits the dry inter-Andean forest of the Marañón 
river valley in the Cajamarca Department of northern Peru (fig. 1). The Marañón valley is an important biogeographical region characterized by abundant cacti (including some columnar species), shrubs and scattered trees, with limited riverine vegetation (fig. 3B).

ECOLOGY: All specimens were collected at an elevation of $1140 \mathrm{~m}$ by UV light detection, in semiopen areas with shrubs and cacti.

Hadruroides graceae, $\mathrm{n}$. sp.

Figures 1, 4D, 14-17; table 2

Type Material: PERU: Ancash Department: Huarmey Province: Holotype of, 5 के, 5 +, 1 juv. paratypes (MHNC), $6 \delta, 6$ \& 2 subad. $\hat{\sigma}$ paratypes $(\mathrm{AMNH}), 1 \hat{\delta}, 1$ + paratypes (MUSA), $1 \hat{\delta}, 1$ q paratypes (MUSM), Huarmey, $10 \mathrm{~km} \mathrm{E}$ on road to Huambo, $10^{\circ} 00^{\prime} 52.2^{\prime \prime} \mathrm{S} \quad 78^{\circ} 01^{\prime} 00.2^{\prime \prime} \mathrm{W}, \quad 89$ 157 m, 3.i.2008, R. Gutiérrez, D. Apaza, and J.A. Ochoa.

Etymology: The specific name is a patronym honoring Grace Servat, a Peruvian ornithologist from Huarmey, who made valuable contributions to the knowledge of the biodiversity and conservation of the fauna in the Peruvian Andes.

Diagnosis: Hadruroides graceae appears to be most closely related to $H$. leopardus, based not only on their small size and similar pigmentation pattern on the metasoma, but on the slender pedipalp chela, compared with other species of the genus, in which the fixed and movable fingers of the adult male are straight (i.e., no proximal gap is evident when the fingers are closed); and the similar carination of sternite VII and the metasomal segments (except for the VSM carinae of segment I). The two species may be distinguished by means of the macrosetal count of metasomal segment V. Hadruroides leopardus possesses 12-18 ventral setae and 3-5 lateral setae, whereas $H$. graceae possesses 7-8 ventral setae and 6-8 lateral setae. The hemispermatophore is similar in the two species but the lamina is less inclined in $H$. leopardus. Both species may be further separated by means of the dimensions of the pedipalp chela: in $H$. graceae, the length:width ratio of the chela is 5.00-5.41 ( $\delta$ ) and 4.46$5.12(+)$, whereas in $H$. leopardus the ratio is
3.93-4.54 ( $\delta$ ) and 4.23-4.64 (q). The ventral surface of metasomal segment IV, which is densely granular in $H$. graceae (fig. 15C) and smooth in $H$. leopardus, provides another diagnostic difference between these species. The lateral surface of metasomal segment $\mathrm{V}$ is also more granular in $H$. graceae (figs. 15A, 16A) than in $H$. leopardus. In some respects, $H$. graceae is similar to $H$. udvardyi. For example, the chela fixed and movable fingers of both species are straight, without a proximal gap. However, the two species do not occur in close geographical proximity: $H$. $u d v a r d y i$ inhabits inter-Andean valleys above $2000 \mathrm{~m}$ in southern Ecuador, whereas $H$. graceae inhabits the coastal desert of central Peru. Hadruroides graceae may be separated from $H$. udvardyi based on the granulation of the metasoma and telson: the ventral surface of the vesicle is smooth in both sexes of $H$. $u d v a r d y i$, but very granular in female $H$. graceae; the ventral and lateral surfaces of metasomal segment $\mathrm{V}$ are more densely granular in $H$. graceae than in $H$. udvardyi; and the ventral surface of metasomal segment IV is smooth in $H$. udvardyi, but granular in H. graceae.

DesCRIPTION: Based on the holotype and paratypes. Measurements of the holotype $\hat{\sigma}$ and a paratype $q$ are recorded in table 2 .

Color: Base color yellowish with brown spots on carapace, tergites, metasomal segments, pedipalps, and legs. Carapace markedly pigmented, especially laterally and posteriorly; two oblique stripes extending from median to anterolateral surfaces, creating two depigmented surfaces anteriorly, divided by narrow stripe along anteromedian longitudinal sulcus; ocular tubercle darker. Tergites each with four irregular spots, two shorter submedian spots restricted to posterior third of segment, two longer sublateral spots extending from anterior to posterior margins, including pretergites (fig. 16C), spots usually disconnected and comprising longitudinal bands across mesosoma; VII with similar pattern but spots connected by reticulate pigmentation, creating depigmented surface medially. Sternites III-VI without spots; VII with two lateral bands along VL carina and, occasionally, two faint VSM spots surrounding insertion of setae (fig. 16D). Metasomal 
segments I-IV, dorsal surfaces with narrow stripes along DL carinae, complete on I and II, restricted to posterior third of III, and usually absent on IV; lateral surfaces with faint pigmentation; ventral surfaces (fig. 16D) with stripes along VL carina connected to lateral pigmentation in posterior half of segments II-IV, additionally with some spots surrounding insertion of setae: segment I usually with $1+1$ or $2+2$ spots, II and III with $3+3$, IV with $4+4$ and some median spots forming a narrow VM stripe. Metasomal segment $\mathrm{V}$, dorsal surface with reticulate pigmentation in anterior half and dense pigmentation in posterior third, near DL margin; lateral surface with reticulation, especially in posterior third; ventral surface with two narrow stripes along VL carinae and few spots along VM carina, additionally with $8-10$ spots surrounding insertion of setae, depending on number of setae, not all of which surrounded by pigmentation (fig. 16D). Chelicerae with reticulate pigmentation on dorsolateral surface, at base of fixed finger and medially on movable finger. Pedipalp femur pigmented on anterior and posterior margins and near articulations; patella and chela each with irregular spots surrounding insertion of setae, and single stripe on ventral surface of chela and external surface of patella.

Chelicerae: Typical of genus; surfaces smooth; dorsal surface with two macrosetae situated near base of fingers.

Carapace: Anterior margin with weak median projection and six macrosetae; surfaces granular, especially laterally and posteriorly where pigmented, except for anterior third, which is smooth; anteromedian longitudinal sulcus obsolete; posteromedian longitudinal and posterolateral sulci well developed; median ocular sulcus obsolete, bordered with small granules; ocular tubercle well developed.

Pedipalps: Femur with VI, DI, and DE carinae complete, granular; VM and VE vestigial (fig. $15 \mathrm{~F}$ ); dorsal surface smooth or with few scattered granules; internal surface with scattered granules; external and ventral surfaces smooth. Patella with DI carina comprising scattered granules; VI well developed (fig. 15E); DPP with moderately devel- oped spiniform granule and smaller subspiniform granules in anterior half; VPP with small spiniform granule; all other surfaces smooth. Chela narrow, surfaces acarinate and smooth (figs. $15 \mathrm{G}-\mathrm{I}, 16 \mathrm{~F}, \mathrm{G}$ ); fingers relatively elongated and straight (i.e., no proximal gap evident when fingers closed); movable finger, median denticle row comprising six subrows, each flanked by one or two internal and external accessory denticles (fig. 16E).

Trichobothrial pattern: Typical of genus; femur with three trichobothria, patella with 20, chela with 26; chelal trichobothrium $E t_{5}$ situated slightly distal to $E t_{4}$ (figs. 15I, 16G).

Legs: Prolateral surfaces granular; retrolateral surfaces smooth. Leg III, femur tetracarinate, DE, DI, VI, and EM carinae present, VI and EM well developed; patella, DE carinae present in proximal two-thirds of segment, DM in proximal half, DI in distal third, IM comprising few granules medially, VI well developed and complete, EM complete, VM vestigial (some $\delta$ ). Basitarsus with several setae. Telotarsus with 7-14 ventromedian spinule clusters (setaceous tufts).

Tergites: Pretergites finely granular ( $\delta$ ) or smooth ( + ). Post-tergites I-VI finely granular, becoming more coarsely so posteriorly; VII coarsely granular, with four well-developed longitudinal carinae, less developed in + .

Sternum: Subpentagonal; surface granular (ठ) or smooth (q) medially, with six macrosetae; posterolateral surfaces smooth; median sulcus well developed.

Pectines: Pectinal tooth count: 14-16 (§)), $11-13($ ( $)$.

Sternites: Sternites III-VI, surfaces matte (ठ) or smooth ( + ); spiracles small, narrow, elliptical, situated in posterior half of segment; VII, granulation more developed near external margins, VL carinae well developed, VSM carinae absent or obsolete.

Metasoma: Segments I-IV, dorsal surfaces granular near DL carinae, granulation pronounced on segment I, less so on II and III, absent on IV; surfaces between DL, ML, and LIM carinae granular, becoming less so from segments I to IV (fig. 15B); surfaces between LIM and VL carinae sparsely granular; ventral surfaces, segment I entirely coarsely granular ( $₫$ ) or granular between VSM and VL carinae only $(+)$, II and III finely and 
sparsely granular ( $\delta$ ) or smooth ( + ), IV densely granular across entire length of segment (fig. 15C); DL carinae complete, granular on segments I-IV; ML carinae complete, weakly developed on segment IV (fig. 15B); LIM carinae complete on segment I, complete but less developed than on I (some $\hat{\delta}$ ) or restricted to posterior two-thirds of II, restricted to posterior third of III, absent $(+)$ or comprising few granules in posterior half $(\hat{\delta})$ of IV; VL carinae complete on segments I-IV, more developed on I, obsolete and comprising few granules on II and III; VSM carinae absent on segments I-IV (q) or II-IV, comprising few small granules on I ( $\hat{\sigma})$. Segment V short and broad, DL, VL, and VM carinae complete, granular (figs. 15A, D, 16A); dorsal surface with small granules near DL carina; lateral surfaces densely granular, especially near VL carina (more so in + ); ventral surface densely granular; VM carina well developed, extending entire length of segment (fig. 15D); VSM carinae evident in anterior third of segment, obscured by granulation in posterior two-thirds. Segment I with two pairs of ventral setae; II and III each with three pairs; IV with four pairs, the second pair microsetae; V with 7-8 ventral setae and four additional setae along posterior margin.

Telson: Vesicle, ventral surface smooth ( $\hat{\sigma})$ or granular ( + ), sparsely setose; aculeus comparatively short (figs. 15A, 16B).

Hemispermatophore: Distal lamina inclined to ventral border, apex rounded; crest more than half lamina length (fig. 17).

Variation: Total length: ô, 29.1-34.5 (mean $=31.4, n=10)$; $9,34.6-37.9($ mean $=35.9, n$ $=8$ ). Pedipalp chela, length:width ratio: $\hat{\delta}$, 5.00-5.41 $($ mean $=5.24, n=10)$; + , 4.46-5.12 (mean $=4.79, n=8$ ); length:height ratio: $\delta$, 4.62-4.96 (mean $=4.74, n=10) ;$ ㅇ, 4.37-4.70 (mean $=4.55, n=8)$. Pedipalp femur, length:width ratio: $\delta, 3.19-3.47$ (mean = $3.32, n=10)$; + , $2.88-3.23$ (mean $=3.07, n$ $=9)$. Pectinal tooth count: $\delta \quad(n=34), 14(n=$ 5), 15 (17), $16(12)$; 우 $(n=28), 11(1), 12$ (19), 13 (8). Metasomal segment V, length:width ratio: $\delta$, $1.90-2.00$ (mean $=1.95, n=10)$; 우 1.79-1.91 (mean $=1.85, n=9)$; length:height ratio: of , 2.04-2.26 (mean $=2.18, n=10)$; + , $2.02-2.15$ (mean $=2.07, n=9)$; number of setae: dorsolateral $(n=38): 3(n=7), 4(29), 5$
(2); lateral $(n=38): 3$ (26), 4 (11), 5 (1); ventrolateral $(n=38): 4$ (1), 5 (13), 6 (20), 7 (4); ventral ( $n=17)$ : 7 (2), 8 (15). Telson, length:height ratio: $\hat{\sigma}, 2.89-3.14$ (mean $=$ $3.06, n=10)$; ㅇ, 3.09-2.24 (mean $=3.19, n=$ 9). Telotarsus, number of ventromedian spinule clusters (setaceous tufts): III $(n=30), 8(n$ =7), 9 (19), 10 (4); IV ( $n=34), 10$ (5), 11 (12), 12 (13), 13 (3), 14 (1).

Distribution: Hadruroides graceae inhabits coastal desert at elevations between 89 and $157 \mathrm{~m}$ in the Ancash Department of central Peru (fig. 1). The type locality of this species occurs in the Pacific desert ecoregion (Brack, 1986).

ECOLOGY: All specimens were collected at night with UV light detection. The Monte Ribereño vegetation (Ferreyra, 1983) of the habitat in which this species occurs is characterized by scattered cacti, shrubs, and small trees.

Hadruroides juanchaparroi, n. sp.

Figures 2, 3C, 5A, 18, 19, 20A, B, D-F, 21; table 2

Type Material: PERU: La Libertad Department: Trujillo Province: Holotype $\hat{\delta}$, paratype $\delta$ (MHNC), $2 \hat{\text { paratypes }}$ (AMNH), Cerro Campana, 07 $58^{\prime} 08^{\prime \prime} \mathrm{S}$ $79^{\circ} 05^{\prime} 59^{\prime \prime} \mathrm{W}, \quad 450 \mathrm{~m}, \quad 15 . x i .2004$, J.C. Chaparro, J. Nuñez and J.A. Ochoa. Ancash Department: Santa Province: $2 \hat{\delta}$ paratypes (AMNH), 1 $\delta, 1$ q paratypes (MHNC), Chimbote, Caleta Santa, 08 59'25.8'S 78 39'12.9”W, 13.5 m, 4.i.2008, R. Gutiérrez, D. Apaza and J.A. Ochoa.

Etymology: The specific name is a patronym honoring Peruvian herpetologist, Juan Carlos Chaparro (Universidad Nacional San Antonio Abad, Cusco), in recognition of his help and participation in several fieldtrips in Peru.

Diagnosis: Hadruroides juanchaparroi appears most closely similar to $H$. lunatus in the following respects: the VSM carinae are absent and the VL carinae obsolete on metasomal segments I-IV; sternite VII is acarinate; the EM carinae of the leg patella are absent; the fixed finger of the pedipalp chela of the adult male is curved, creating a distinct proximal gap with the movable finger when the fingers are closed; the granulation of 
A

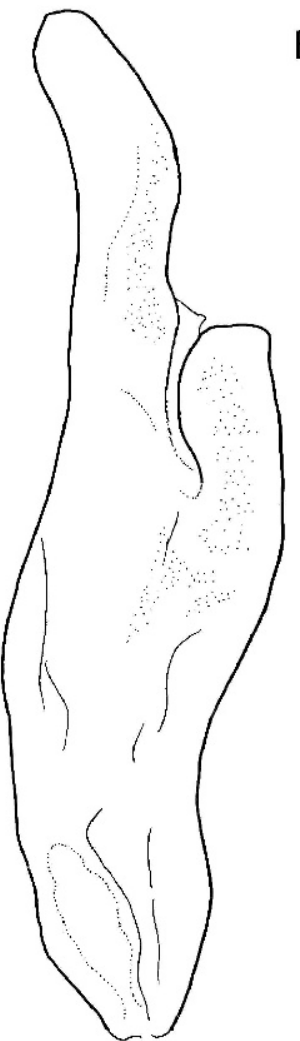

B

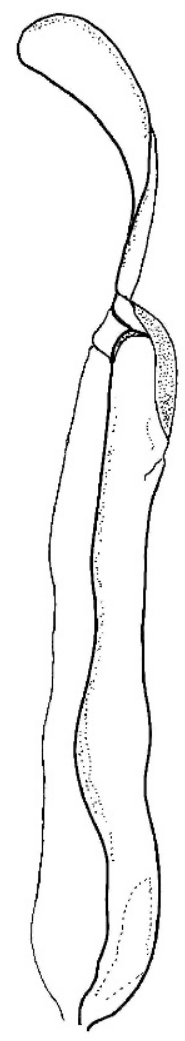

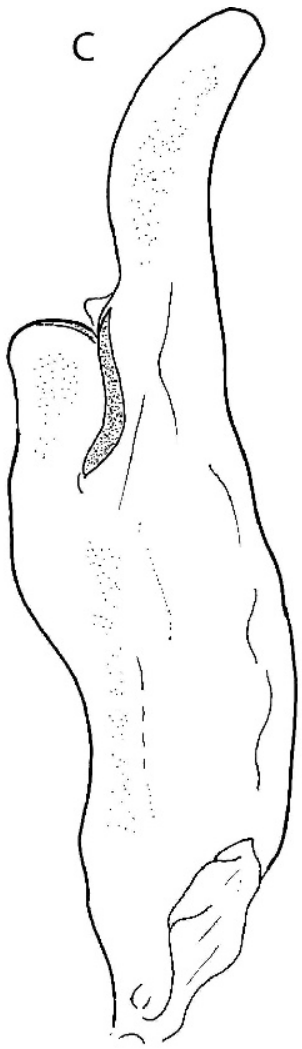

$\mathrm{D}$

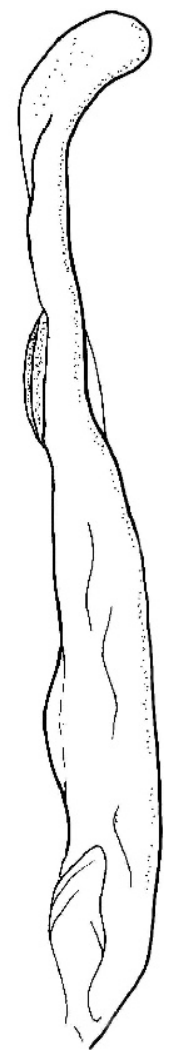

Fig. 21. Hadruroides juanchaparroi, n. sp., paratype $\delta$ (MHNC), sinistral hemispermatophore. A. Ental aspect. B. Dorsal aspect. C. Ectal aspect. D. Ventral aspect. Scale bar $=0.5 \mathrm{~mm}$.

metasomal segment $\mathrm{V}$ and telson are similar; and the relative dimensions of the pedipalp chela, metasomal segment $\mathrm{V}$, and telson are similar. The two species may be distinguished as follows: $H$. juanchaparroi is smaller in size, reaching ca. $32 \mathrm{~mm}$ in total length (o), compared with $H$. lunatus, which reaches $45 \mathrm{~mm}$; the proximal gap between the pedipalp chela fingers of the male is less pronounced in $H$. juanchaparroi than in H. lunatus. There are also some differences in pigmentation between the two species: the dorsosubmedian spots on the tergites are rectangular in $H$. lunatus (fig. 20C) and irregular in $H$. juanchaparroi (fig. 20D); H. lunatus lacks pigmentation on sternite VII and metasomal segment I whereas several spots surround the insertion of setae on these segments in $H$. juanchaparroi (fig. 20E); the pigmentation pattern on the ventral surfaces of metasomal segments II-IV is similar in the two species, but the stripes and spots are less evident and may be vestigial in some adult specimens of $H$. lunatus. The most important difference between the two species is the shape of hemispermatophore, which is slender with a small crest in $H$. juanchaparroi (fig. 21A, C), but broader basally with a relatively longer crest in $H$. lunatus.

DESCRIPTION: Based on the holotype and paratypes. Measurements of the holotype $\hat{\sigma}$ and a paratype $q$ are recorded in table 2 .

Color: Base color yellowish, except for pedipalp chela, metasomal segment $\mathrm{V}$, and telson, which are brownish yellow. Carapace markedly pigmented, especially laterally, where two oblique stripes extend from median to anterolateral margins; ocular tubercle darker; anteromedian longitudinal sulcus markedly pigmented; four irregular spots situated near posterior margin; anterior margin with band of pigmentation connecting lateral ocelli. Tergites I-VI each with four 
irregular spots, two submedian and two sublateral, occasionally joining weakly at anterior margin; pretergites with two lateral spots (fig. 20D); VII faintly pigmented laterally, depigmented medially. Sternites III-VI depigmented; VII with eight small spots surrounding insertion of setae (fig. 20E). Metasomal segments I-IV, dorsal surfaces faintly pigmented along DL carinae and granulation, occasionally with two submedian spots medially (as in holotype); lateral surfaces pigmented in posterior half; ML and LIM carinae pigmented; ventral surfaces with two stripes along VL carinae, joining posteriorly to lateral pigmentation on segments II-IV, often also with spots surrounding insertion of setae: usually with $2+2$ spots on segment I, $3+3$ on segments II and III, and $4+4$ or $5+5$ spots on segment IV (fig. 20E). Metasomal segment V, dorsal and lateral surfaces markedly pigmented in posterior half; ventral surface with two stripes along VL carinae, connected to lateral pigmentation in posterior half, additionally with $12-15$ spots; VM carina discontinuously pigmented medially (fig. 20E). Cheliceral manus and fingers usually markedly pigmented, less so in specimens from Caleta Santa. Pedipalp femur pigmented along DI and DE carinae, and near articulations, densely so in some specimens; internal surfaces spotted; external surface with stripe along EM carinae. Patella markedly spotted on dorsal, internal, and external surfaces. Legs pigmented on prolateral surfaces.

Chelicerae: Typical of genus; surfaces smooth; dorsal surface with two macrosetae situated near base of fingers.

Carapace: Anterior margin with weak median projection and 8-9 macrosetae; surfaces coarsely granular, especially where pigmented, except for anterior third which is smooth; anteromedian longitudinal sulcus obsolete, bordered by few granules posteriorly; posteromedian longitudinal and posterolateral sulci well developed; median ocular sulcus obsolete; ocular tubercle well developed.

Pedipalps: Femur with VI, DI, and DE carinae complete, granular; VM present in proximal half of segment; VE vestigial (fig. 19E); dorsal surface with few scattered granules; internal surface with prominent granules medially; ventral surfaces smooth.
Patella with DI and VI carinae complete, granular; DPP and VPP with prominent spiniform granules proximally (fig. 19F). Chela robust, with relatively elongated fingers; surfaces smooth and acarinate (fig. 19B-D); fixed finger of adult $\hat{\sigma}$ strongly curved and lobed, creating distinct proximal gap with movable finger when fingers are closed, which is weakly developed in $q$. Movable finger, median denticle row comprising six subrows; one or two internal and external accessory denticles flanking subrows II and III; distal three subrows without external accessory denticles (fig. 20F).

Trichobothrial pattern: Typical of genus; femur with three trichobothria, patella with 20 , chela with 26; chelal trichobothrium $e b$ situated in line with proximal gap between fixed and movable fingers ( $\delta$ ); trichobothrium $E t_{5}$ situated level with $E t_{4}$ (fig. 19C).

Legs: Prolateral surfaces granular; retrolateral surfaces smooth. Leg III, femur tetracarinate, DI and DE carinae obsolete, VI and EM well developed; patella, DE carinae comprising few granules in proximal third of segment, DM comprising few granules proximally, DI present in distal half, IM comprising four or five granules medially, VI comprising few granules distally, EM absent. Telotarsus with 8-13 ventromedian spinule clusters (setaceous tufts).

Tergites: Pretergites finely granular ( $\hat{\delta})$ or smooth ( + ). Post-tergites I-VI, surfaces finely granular, slightly more so laterally; VII coarsely granular, with four well-developed longitudinal carinae.

Sternum: Subpentagonal; surface granular medially, with 6 macrosetae; posterolateral surfaces granular; median sulcus well developed.

Pectines: Pectinal tooth count: 16-18 (ई)), 11-11 (ㅇ).

Sternites: Sternites III-VI, surfaces smooth () or becoming slightly matte laterally ( $\hat{\delta})$; spiracles narrow, situated in posterior half of segment; VII, surface smooth, acarinate, only a few small granules evident in position of $\mathrm{VL}$ carinae.

Metasoma: Segments I-IV, dorsal surfaces coarsely granular, less so on IV; DL and ML carinae complete; LIM carinae complete on segment I, restricted to posterior half of II, and posterior third of III, absent on IV; 
surfaces between DL and ML carinae granular on segments I-III; VL carinae obsolete, smooth on segments I-III, comprising few granules on IV (fig. 19A); VSM carinae absent on all segments. Segment V short (figs. 19A, G, 20B); DL carinae complete; VL carinae complete but well developed in posterior three-quarters of segment; VM carinae complete but obscured by granulation of ventral surface; dorsal and lateral surfaces smooth. Segment I with two pairs of ventral setae; II and III each with three pairs; IV with five pairs; V with 11-15 ventral setae and 4-7 additional setae along posterior margin.

Telson: Vesicle, surfaces sparsely setose, ventral surface sparsely granular anteriorly ( $\hat{\sigma}$ ) or densely granular (q) (figs. 19A, 20A).

Hemispermatophore: Distal lamina slender, slightly curved, with apex rounded; crest equal to or less than half lamina length; basal portion slender (fig. 21).

Variation: Total length: ô, 31.9-35.8 (mean $=33.8, n=7$ ); + , 33.6. Pedipalp chela, length:width ratio: $\delta, 3.29-3.70$ (mean = 3.48, $n=7)$; + , 3.49; length:height ratio: $\delta$, 3.00-3.34 (mean = 3.18, $n=7$ ); +, 3.32 . Pedipalp femur, length:width ratio: $\delta, 3.00$ $3.33($ mean $=3.17, n=7)$; + , 3.00. Pectinal tooth count: $\delta(n=14), 16(n=3), 17(10), 18$ (1);,+ 11 (2). Metasomal segment V, length:width ratio: $\hat{\delta}, 2.04-2.33$ (mean $=$ 2.14, $n=7)$; + , 1.97; length:height ratio: $\hat{\sigma}$, 2.09-2.29 (mean $=2.19, n=7$ ); +, 2.02 ; number of setae: dorsolateral $(n=16): 5(n=$ 1), $6(5), 8(9), 9(1)$; lateral $(n=16)$ : $5(5), 6(8)$, 7 (3); ventrolateral $(n=16)$ : $8(9), 9(6), 10(1)$; ventral $(n=7)$ : $11(3), 12(1), 13(1), 14(1), 15$ (1). Telson, length:height ratio: of, 3.15-3.40 (mean $=3.26, n=6$ ); + , 3.06. Telotarsus, number of ventromedian spinule clusters (setaceous tufts): III $(n=16), 8(n=1), 9(3), 10$ (9), 11 (3); IV ( $n=15), 11$ (7), 12 (3), 13 (5).

Distribution: This species is presently known from only two localities in northern Peru, Cerro Campana $(450 \mathrm{~m})$ and Caleta Salta (13 m), close to the coast. Both localities occur in the Pacific desert ecoregion (Brack, 1986; fig. 2).

ECOLOGY: Hadruroides juanchaparroi was collected at night with UV light detection. At the type locality (Cerro Campana), a typical Lomas biotope (Péfaur, 1981) with shrub vegetation and columnar cacti (fig. 3C), specimens were observed climbing on terrestrial bromeliads (Bromeliaceae), a behavior previously described for $H$. aguilari (Francke and Soleglad, 1980). At Caleta Santa, the species was collected in an area with shrub vegetation.

\section{Hadruroides leopardus Pocock, 1900}

(Figs. 1, 3A, 5B)

Hadruroides leopardus Pocock, 1900: 476; Maury, 1975: 16, 17, figs. 34 40; Francke, 1977: 75; Francke and Soleglad, 1980: 12; Lourenço, 1994: 157, 1995: 74-76; Kovař́ik, 1998: 135; Sissom and Fet, 2000: 412; Fet et al., 2004: 24; Ochoa and Chaparro, 2008: 5.

Hadruroides leopardus vittatus Pocock, 1900: 477 (synomymized by Maury, 1975: 16, 17).

Type Material: PERU: Lambayeque Department: Chiclayo Province: Holotype of, 3 paratypes, including allotype $+(\mathrm{BMNH})$, Eten $\left(06^{\circ} 55^{\prime} 33^{\prime \prime} \mathrm{S} 79^{\circ} 51^{\prime} 57^{\prime \prime} \mathrm{W}, 10 \mathrm{~m}\right), 1900$, P.O. Simons. Cajamarca Department: Cajamarca Province: 3 syntypes [Hadruroides leopardus vittatus] (BMNH), Los Baños del Inca, near Cajamarca $\left(07^{\circ} 10^{\prime} 32^{\prime \prime} \mathrm{S} \quad 78^{\circ} 26^{\prime}\right.$ $\left.50^{\prime \prime} \mathrm{W}, 2880 \mathrm{~m}\right)$, P.O. Simons.

New Records: PERU: Lambayeque Department: Chiclayo Province: Eten, $30 \mathrm{~km} \mathrm{~S}$, $06^{\circ} 59^{\prime} 24^{\prime \prime} \mathrm{S} 79^{\circ} 39^{\prime} 04^{\prime \prime} \mathrm{W}, 50 \mathrm{~m}, 19.1 .2008$, R. Gutiérrez and D. Apaza, 1 $\delta, 2$ +1 juv. $(\mathrm{AMNH}), 2 \hat{\delta}, 1$ +, 1 juv. (MHNC). Ferreñafe Province: Puchaca Alto, Incawasi, $06^{\circ} 22^{\prime} \mathrm{S}$ $79^{\circ} 28^{\prime} \mathrm{W}, 320 \mathrm{~m}, 20 . x i .2004$, J.C. Chaparro and J.A. Ochoa, $2 \hat{\delta}, 2$ ㅇ (AMNH), $1 \hat{\delta}, 2$ ㅇ (MHNC). Lambayeque Province: between Porculla and intersection to Olmos, $05^{\circ} 56^{\prime} 09.6^{\prime \prime} \mathrm{S}$ 79³5'55.1”'W, 498 m, 17.i.2008, R. Gutiérrez, D. Apaza, and J.A. Ochoa, $2 \hat{\delta}, 5$ + (AMNH), $1 \hat{\delta}$, 4 ㅇ (MHNC); EPM Anchovira, between Motupe and Jayanca, near intersection to Salas, $06^{\circ} 16^{\prime} 02.7^{\prime \prime} \mathrm{S} \quad 79^{\circ} 44^{\prime} 10.7^{\prime \prime} \mathrm{W}, 101 \mathrm{~m}$, 17.i.2008, R. Gutiérrez, D. Apaza and J.A. Ochoa, $3 \hat{\delta}, 4$ 을 (AMN), $3 \hat{\delta}, 3$ ㅇ, 1 subad. $\hat{\sigma}$ (MHNC).

Diagnosis: Hadruroides leopardus appears to be most closely related to $H$. graceae and $H$. udvardyi. Hadruroides leopardus may be distinguished from $H$. graceae by means of the macrosetal count of metasomal segment $\mathrm{V}$. Hadruroides leopardus possesses 12-18 ventral setae and 3-5 lateral setae, whereas $H$. graceae possesses 7-8 ventral setae and 6-8 lateral 
setae. The hemispermatophore is similar in the two species, but the lamina is less inclined in $H$. leopardus. Both species may be further separated by means of the dimensions of the pedipalp chela: in $H$. graceae, the length:width ratio of the chela is 5.00-5.41 (o) and 4.465.12 ( + ), whereas in $H$. leopardus the ratio is 3.93-4.54 ( 8 ) and 4.23-4.64 ( + ). The ventral surface of metasomal segment IV, which is densely granular in $H$. graceae (fig. 15C) and smooth in $H$. leopardus, provides another diagnostic difference between these species. The lateral surface of metasomal segment $\mathrm{V}$ is also more granular in $H$. graceae (figs. 15A, 16A) than in $H$. leopardus. Hadruroides leopardus may be separated from $H$. udvardyi by means of the granulation of the telson and the carination of sternite VII, metasoma, and pedipalps. Hadruroides udvardyi is in general more granular than $H$. leopardus. The VSM carinae comprise small granules on sternite VII and metasomal segment I in H. udvardyi, but are obsolete (sternite VII) or absent (segment I) in $H$. leopardus. The DL carinae of segment $\mathrm{V}$ are complete and granular in $H$. leopardus, but granular in the anterior half of the segment only in $H$. udvardyi. The vesicle is smooth in both sexes of $H$. udvardyi, but granular in female $H$. leopardus. The pedipalp patella DI carina is smooth or comprises small, scattered granules in $H$. leopardus, but complete and granular in $H$. udvardyi. Additionally, the pigmentation pattern of the carapace, tergites, and metasoma is more pronounced, especially on metasomal segment $\mathrm{V}$ and telson, in H. udvardyi.

Distribution: Hadruroides leopardus was described from Puerto Eten in the coastal desert of Lambayeque Department, northern Peru (fig. 1). We confirm the presence of this species at Eten and additional localities around Chiclayo up to an elevation of $498 \mathrm{~m}$ (fig. 3A). The known locality records of this species occur in the equatorial dry forest ecoregion (Brack, 1986), located between the Pacific Ocean and the western slopes of the Andes at elevations below 1300-1500 m, in southern Ecuador and the Cajamarca, Lambayeque, Piura, and Tumbes departments of northern Peru. Records of $H$. leopardus from Loja in Ecuador (Maury, 1975) are probably referable to $H$. udvardyi (Lourenço,
1995). Records of $H$. leopardus vittatus from Baños del Inca in Cajamarca (Pocock, 1900) are probably the result of mislabelling by P.O. Simons, who also mistakenly labelled "Baños" as a locality for $H$. charcasus, a species that occurs only on the western slopes of the Andes. The specimens of $H$. leopardus vittatus and $H$. charcasus were probably collected along the road from Eten to Baños. Based on data from our fieldwork in Cajamarca, $H$. carinatus is the only Hadruroides species occurring at Baños del Inca.

ECOLOGY: The vegetation in the area inhabited by $H$. leopardus is characterized by shrubs, cacti, and scattered trees, e.g., Bursera graveolens (Kunth) Triana and Planch. (Burseraceae), Capparis sp. (Brassicaceae), Ceiba insignis (Kunth) Gibbs and Semir (Malvaceae), Loxopterigium huasango Spruce ex Engl. (Anacardiaceae), Prosopis pallida (Humboldt and Bonpland ex Willdenow) Kunth (Fabaceae). Hadruroides leopardus is sympatric with $H$. charcasus.

\section{Hadruroides lunatus (L. Koch, 1867)}

Figures 2, 3G, 5C, 20C

Telegonus lunatus L. Koch, 1867: 235-237.

Hadrurus parvulus Karsch, 1879: 135 (synonymized by Kraepelin, 1894: 207; confirmed by Armas, 1984: 1); Moritz and Fischer, 1980: 322.

Hadrurus robustus Boeris, 1889: 125, 126 (synonymized by Kraepelin, 1894: 207).

Hadruroides lunatus: Kraepelin, 1894: 207 (part), 1899: 188 (part); Pocock, 1900: 474; Kraepelin, 1901: 274 (part?); Chamberlin, 1920: 35 (part); Banks, 1924: 95; Mello-Leitão, 1942: 130, 1945: 120 (part); Weidner, 1959: 103; Bücherl, 1964: 61; Cekalovic, 1966: 3; Aguilar, 1968: 166, 167, 169, 171, figs. 1, 2, 5, 6A, 6D; Bücherl, 1969: 768; Aguilar and Meneses, 1970: 2, 4; Bücherl, 1971: 328; Vachon, 1974, fig. 16(5); Maury, 1975: 13-15, figs. 11-22, 46, 47; Aguilar, 1977: 91, fig. 4; Aguilar and Türkowsky, 1977: 83; Francke, 1977: 75; Francke and Soleglad, 1980: 7, 1981: 238, 244, figs. 27-29; Armas, 1984: 1; Flórez, 1990: 124; Lourenço, 1994: 157, 1995: 74, 1997a: 601; Kovař́ík, 1998: 135; Sissom and Fet, 2000: 412; Lourenço and Dastych, 2001: 56 (part); Escobar et al., 2002: 4, 2003: 89; Iannacone, 2003: 86; Teruel, 2003: 237; Fet et al., 2004: 24; Ochoa, 2005: 53; Ochoa and Chaparro, 2008: 5.

Hadruroides parvulus: Williams, 1970: 31.

Hadruroides robustus: Williams, 1970: 31.

Type Material: Holotype ot [Telegonus lunatus] (ZMH), "South America." Seven 
syntypes [Hadrurus parvulus] (ZMB 3059), four syntypes (ZMB 3013) [lost], "India occid." Syntypes [Hadrurus robustus] (MCSNG?), PERU: Lima.

New ReCords: PERU: Lima Department: Cañete Province: Quebrada Chillca, $7 \mathrm{~km} \mathrm{E}$ Santa María $\left(12^{\circ} 28^{\prime} \mathrm{S} 76^{\circ} 42^{\prime} \mathrm{W}, 100 \mathrm{~m}\right)$, 28.v.1969, O.F. Francke, 1 o , 7 q, 15 juv. (AMNH). Huaral Province: Lomas Iguanil (11 $\left.{ }^{\circ} 28^{\prime} \mathrm{S} \quad 77^{\circ} 09^{\prime} \mathrm{W}, 330 \mathrm{~m}\right)$, viii.1975, P. Aguilar, $2 \hat{\delta}, 4$ +, 1 juv. (AMNH); Lomas Lachay, $11^{\circ} 21^{\prime} 34^{\prime \prime} \mathrm{S} 77^{\circ} 22^{\prime} 06^{\prime \prime} \mathrm{W}, 380 \mathrm{~m}$, 11.xii.2008, L. Nizama, E. Carrillo and J.A. Ochoa, 6 s, 4 ㅇ (AMNH), 7 s, 4 ㅇ

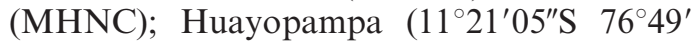
21"W, 1950 m), 29.vii.1985, E. Perez, $1+$ (MUSM). Huarochiri Province: Songos, $62 \mathrm{~km}$ from Chosica on road to La Oroya $\left(11^{\circ} 54^{\prime} \mathrm{S}\right.$ $\left.76^{\circ} 30^{\prime} \mathrm{W}, 1600 \mathrm{~m}\right), 14 . x i .2004$, J.C. Chaparro and J.A. Ochoa, 2 s, 2 o (MHNC). Lima Province: Isla Pachacamac $\left(12^{\circ} 18^{\prime} 07^{\prime \prime} \mathrm{S}\right.$ 76 54'08'W), 20.iv.1973, M. Ortiz and P. Aguilar, 1 \& (AMNH); Chosica, El Bosque (11 $\left.{ }^{\circ} 56^{\prime} 34^{\prime \prime} \mathrm{S} 76^{\circ} 42^{\prime} 11^{\prime \prime} \mathrm{W}, 830 \mathrm{~m}\right)$, 28.ix.1972, A. Esquerre, 1 of, 1 ㅇ (AMNH); Cieneguilla, $6 \mathrm{~km} \mathrm{~W}\left(12^{\circ} 05^{\prime} \mathrm{S} 76^{\circ} 50^{\prime} \mathrm{W}\right)$, ca. $400 \mathrm{~m}$, 30.xii.1975, O.F. Francke, 4 sै, 13 ㅇ, 17 juv. (AMNH); Cieneguilla $\left(12^{\circ} 05^{\prime} 07^{\prime \prime} \mathrm{S} \quad 76^{\circ} 46^{\prime}\right.$ $\left.16^{\prime \prime} \mathrm{W}, 380 \mathrm{~m}\right)$, vi.1986, A. Tejada, 2 o , 3 우 (MUSM); CIP, La Molina $\left(12^{\circ} 04^{\prime} 52^{\prime \prime} \mathrm{S}\right.$ $\left.76^{\circ} 56^{\prime} 13^{\prime \prime} \mathrm{W}, 254 \mathrm{~m}\right)$, 8.vi.1983, F.D. Bennett, 1 (AMNH); Lima, $31 \mathrm{~km}$ on road to Canta, ca. 400 m, O.F. Francke, 1 ㅇ (AMNH); Lima, $89 \mathrm{~km}$ on road to Canta, $1800 \mathrm{~m}$, 8.i.1976, O.F. Francke, 2 s, 10 क , 32 juv. (AMNH); Jesus María $\left(12^{\circ} 04^{\prime} 26^{\prime \prime} \mathrm{S} 77^{\circ} 02^{\prime} 08^{\prime \prime} \mathrm{W}, 119 \mathrm{~m}\right)$, 15.ii.1986, L. Sarmiento, 1 ô (MUSM), 18.xii. 1989, M. Medina, 1 ๙े (MUSM); Lomas Atocongo (ca. $12^{\circ} 08^{\prime} \mathrm{S} 76^{\circ} 55^{\prime} \mathrm{W}, 730 \mathrm{~m}$ ), 9.ix.1983, L. Romero, 1 §, 2 juv. (MUSM); Lomas San Bartolo (ca. $12^{\circ} 22^{\prime} \mathrm{S} 76^{\circ} 42^{\prime} \mathrm{W}$, 530 m), 23.xi.1954, 1 juv. (MUSM); Pantanos de Villa $\left(12^{\circ} 13^{\prime} 04^{\prime \prime} \mathrm{S} \quad 76^{\circ} 59^{\prime} 15^{\prime \prime} \mathrm{W}, 2 \mathrm{~m}\right)$, 21.viii.1994, D. Silva and J. Duárez, 1 శิ (MUSM), 25.viii.1994, S. Cordova, D. Florindez, M. Samané and J. Duárez, 1 sิ (MUSM). Oyón Province: Churín $\left(10^{\circ} 48^{\prime} 39^{\prime \prime} \mathrm{S}\right.$ $\left.76^{\circ} 51^{\prime} 58^{\prime \prime} \mathrm{W}, 2290 \mathrm{~m}\right), \quad 1 . i x .1969$, O.F. Francke, 2 \%, 7 juv. (AMNH).

Diagnosis: Hadruroides lunatus appears to be most closely related to $H$. aguilari, $H$. juanchaparroi, and H. tishqu, based on the similar carination of sternite VII and metasomal segments I-IV. Hadruroides lunatus may be distinguished from these species by means of the pigmentation pattern of the tergites and metasomal segments, the ventral carinae of metasomal segment $\mathrm{V}$, the granulation of the ventral surface of the telson, the dimensions of the pedipalp chela, and the shape of the hemispermatophore. Haduroides lunatus may be separated from $H$. aguilari as follows: the pedipalp chela fixed finger of the adult male is curved, creating a distinct proximal gap with the movable finger when the fingers are closed, in $H$. lunatus, whereas the fixed and movable fingers of the adult male are straight, such that no proximal gap is evident when the fingers are closed, in $H$. aguilari; metasomal segment II is as wide as long, and $\mathrm{V}(\hat{\delta})$ is approximately twice as long as wide in H. lunatus, whereas segment II is longer than wide and $\mathrm{V}(\hat{\delta})$ is approximately three times longer than wide in $H$. aguilari. Hadruroides lunatus may be distinguished from $H$. juanchaparroi by means of its larger size: H. lunatus reaches ca. $45 \mathrm{~mm}$ in total length, compared with $H$. juanchaparroi, which reaches ca. $32 \mathrm{~mm}$ in total length. Hadruroides lunatus may also be differentiated from $H$. juanchaparroi and $H$. tishqu based on pigmentation pattern: the dorsosubmedian spots on the tergites are rectangular in $H$. lunatus (fig. 20C), irregular in $H$. juanchaparroi (fig. 20D) and faint to absent in $H$. tishqu (fig. 24B); H. lunatus lacks pigmentation on sternite VII and metasomal segment I whereas several spots surround the insertion of setae on these segments in $H$. juanchaparroi (fig. 20E); the pigmentation pattern on the ventral surfaces of metasomal segments II-IV is well developed in $H$. lunatus, but absent in H. tishqu. Furthermore, the ventral surface of the telson is granular in the female H. lunatus, but smooth in both sexes of $H$. tishqu (fig. 23A, C). The pedipalp chela is more slender in $H$. lunatus than in $H$. tishqu: the length:width ratio ( $\delta$ ) is $3.44-3.54$ in $H$. lunatus and 2.98-3.34 in H. tishqu. The shape of hemispermatophore provides additional diagnostic features: the lamina and basal portion are broader basally with a relatively longer crest in $H$. lunatus than in $H$. juanchaparroi (fig. 21A, C). 
Distribution: The type locality of $H$. parvulus is obviously erroneous (Armas, 1984). Hadruroides lunatus has been reported to occur in Chile, Colombia, Ecuador, Peru, and Venezuela (Mello-Leitão, 1945; Esquivel de Verde, 1968; Cekalovic, 1983; Maury, 1975; Sissom and Fet, 2000; Ochoa, 2005). The records for Colombia and Venezuela (MelloLeitão, 1945; Flórez, 1990; Esquivel de Verde, 1968) are also erroneous and no subsequent authors included this species in the scorpion fauna of these countries (Flórez, 1990; Lourenço, 1997b; González-Sponga, 1984, 1996; Rojas-Runjaic and De Sousa, 2007). Records from northern Chile and Ecuador (Cekalovic, 1983; Sissom and Fet, 2000) are probably misidentifications of other Hadruroides species. In the present contribution, we can confirm the presence of this species only in the Lima Department of central Peru and Isla Pachacamac (fig. 2). Other records from northern Peru must be confirmed in the future. Records from Tacna and Arequipa in southern Peru (Ochoa, 2005) correspond to new species, the descriptions of which are in preparation by the authors (fig. 2).

Ecology: Hadruroides lunatus inhabits rocky areas and Lomas formations in the coastal Pacific Desert (Aguilar, 1968; Aguilar and Meneses, 1970; fig. 3G).

\section{Hadruroides mauryi}

Francke and Soleglad, 1980

\section{Figure 2}

Hadruroides mauryi Francke and Soleglad, 1980: 8-12, figs. 2, 21-38 (part); Kovař́k, 1998: 135; Sissom and Fet, 2000: 413 (part); Fet et al., 2004: 24; Ochoa, 2005: 53, 58, fig. 3, table 2; Ochoa and Chaparro, 2008: 5, 6, 10.

Type Material: PERU: Cusco Department: Paruro Province: Holotype $\delta, 1$ juv. $\delta$ paratype (AMNH), Paruro $\left(13^{\circ} 45^{\prime} \mathrm{S} 71^{\circ} 51^{\prime} \mathrm{W}\right.$, 3000 m), 28.x.1966, A. Guerra.

New Records: PERU: Cusco Department: Calca Province: Hacienda Urco $\left(13^{\circ} 19^{\prime} 34^{\prime \prime} \mathrm{S}\right.$ $\left.71^{\circ} 58^{\prime} 59^{\prime \prime} \mathrm{W}, 2937 \mathrm{~m}\right), \quad 15.1 x .1939, \quad$ K.P. Schmidt, 1 ex. (FMNH); near Calca $\left(13^{\circ} 18^{\prime} 74^{\prime \prime} \mathrm{S} 71^{\circ} 56^{\prime} 48^{\prime \prime} \mathrm{W}, 3054 \mathrm{~m}\right)$, 25.ii.1995, R. Paredes, 3 \& (MHNC). Urubamba Province: Aguanmarka (13 $\left.17^{\prime} 16^{\prime \prime} \mathrm{S} 72^{\circ} 07^{\prime} 30^{\prime \prime} \mathrm{W}, 3060 \mathrm{~m}\right)$, 13.ii.1993, J. Achicahuala and J.A. Ochoa, 1 s,
2 juv. (MHNC); between Ollantaytambo and Pallata $\left(13^{\circ} 14^{\prime} \mathrm{S} \quad 72^{\circ} 13^{\prime} \mathrm{W}, \quad 3000-3100 \mathrm{~m}\right)$, 19.xi.1994, O. Ochoa M. and J.A. Ochoa, 3 ㅇ, 1 juv. (MHNC), 14.i.2002, J.A. Ochoa, 1 으, 1 juv. (MHNC); Ollantaytambo $\left(13^{\circ} 15^{\prime} 38^{\prime \prime} \mathrm{S}\right.$ $\left.72^{\circ} 15^{\prime} 56^{\prime \prime} \mathrm{W}, 2830 \mathrm{~m}\right), 29$. iv.1915, O.F. Cook, 1 q (USNM), 15.xii.1979, O. Ochoa M., 4 q (MHNC), 19.i.1995, A. Cusipaucar, 1 q (MHNC); Yucay $\left(13^{\circ} 18^{\prime} 43^{\prime \prime} \mathrm{S} \quad 72^{\circ} 04^{\prime} 88^{\prime \prime} \mathrm{W}\right.$, 2970 m), 20.vi.1994, C. Aragón, 1 + (MHNC).

Diagnosis: Hadruroides mauryi appears to be most closely related to $H$. bustamantei, with which it was previously confused. The two species are similar in hemispermatophore dimensions; pectinal tooth count; carination of sternite VII and metasomal segments; and curvature of the pedipalp chela fixed finger of the adult male, which creates a well developed proximal gap with the movable finger when the fingers are closed, that is also present but less developed in females. The two species may be distinguished based on the dimensions of the male pedipalp chela and the pigmentation pattern of the tergites and legs. The length:width ratio of the chela ( $\delta$ ) varies from $3.09-3.36$ in H. bustamantei and from 2.7-2.8 in $H$. mauryi. Tergites I-IV display pairs of dorsosubmedian and dorsolateral spots, forming four distinct stripes along the mesosoma in $H$. bustamantei, whereas only faint spots are evident along the posterior margin of each tergite in $H$. mauryi. Additionally, several spots are evident on the prolateral side of legs I-IV in $H$. bustamantei, whereas the legs of $H$. mauryi are depigmented.

Distribution: Although the type series of $H$. mauryi comprises specimens from the Ayacucho, Cusco, and Huancavelica departments, the paratypes from Ayacucho and Huancavelica are not conspecific with the holotype from Paruro (Cusco Department), but are instead referable to $H$. bustamantei (Ochoa and Chaparro, 2008). Based on data gathered during the course of this study, we confirm that $H$. mauryi is endemic to the Cusco Department (fig. 2), where it occurs in inter-Andean valleys from $2830-3100 \mathrm{~m}$.

ECOLOGY: Hadruroides mauryi is endemic to the Queswa biogeographical region (Ceballos Bendezú, 1976; Ochoa, 2005), the vegetation of which is characterized by abundant cacti, shrubs, and small trees including 
Alnus acuminata Kunth (Betulaceae), Cedrela lilloi C. DC. (Meliaceae), Escallonia resinosa (Ruiz and Pav.) Pers. (Escalloniaceae), Schinus sp. (Anacardiaceae) (Marin Moreno, 1961). Hadruroides mauryi has been collected under stones and is syntopic with the bothriurid, Brachistosternus andinus Chamberlin, 1916, and the buthid, Tityus footei Chamberlin, 1916.

\section{Hadruroides tishqu, n. sp.}

Figures 1, 3E, 5E, 22-25; table 2

Type Material: PERU: Ancash Department: Santa Province: Holotype $\hat{\delta}, 1 \hat{\delta}, 2$ subad. \&, 2 subad.,+ 1 juv. paratypes (MHNC), 1 के, 1 subad. $\hat{\sigma}, 1$ subad. +2 juv. paratypes (AMNH), Isla Santa, 09 09' $20^{\prime \prime} \mathrm{S} 78^{\circ} 39^{\prime} 50^{\prime \prime} \mathrm{W}, 10-25 \mathrm{~m}, 4.1 .2008$, R. Gutiérrez, D. Apaza and J.A. Ochoa; 1 s, 3 + paratypes (AMNH), same locality, xixii.2004, A. Catennazzi; 1 s, 1 subad. + paratypes (MHNC), Caleta Santa (Northern Chimbote), $08^{\circ} 59^{\prime} 25.8^{\prime \prime} \mathrm{S} 78^{\circ} 39^{\prime} 12.9^{\prime \prime} \mathrm{W}, 13.5$ m, 4.i.2008, R. Gutiérrez, D. Apaza, and J.A. Ochoa.

ETYMology: The specific name is a noun in apposition, taken from the Quechua word tishqu, meaning "island," and refers to the occurrence of this species on Isla Santa.

Diagnosis: Hadruroides tishqu may be distinguished from other species of the genus by means of the reduced VM and VL carinae on metasomal segment $\mathrm{V}$, which comprise small granules and are present only in the posterior two-thirds of the segment (fig. 23B). These carinae are complete and generally comprise strong granules in other species of the genus (figs. $8 \mathrm{~F}, 15 \mathrm{D}, 19 \mathrm{G}, 27 \mathrm{D}$ ). The shape of the lamina of the hemispermatophore provides additional diagnostic characters. For example, the distal portion is strongly curved along the ventral border in $H$. tishqu (fig. 25A, $\mathrm{C}$ ), as in $H$. carinatus and $H$. geckoi; however, the apex is acuminate in $H$. geckoi (fig. 13A) and rounded in $H$. carinatus and $H$. tishqu (fig. 25A). Hadruroides tishqu is similar to $H$. juanchaparroi and H. lunatus in the following respects: sternite VII and metasomal segments I-IV without VSM carinae; pedipalp chela robust, fixed finger of male strongly curved, creating a distinct proximal gap with movable finger when the fingers are closed. The pedipalp chela is slightly more robust in $H$. tishqu than in the other two species: the length:width ratio ( $\delta$ ) is $2.98-3.34$ in $H$. tishqu, 3.29-3.70 in H. juanchaparroi and 3.44-3.54 in H. lunatus. The three species may also be distinguished based on the pigmentation pattern: pigmentation is absent on the metasomal segments, and limited to faint spots on the carapace and tergites of $H$. tishqu (fig. 24D), but well developed on the tergites and metasomal segments of $H$. juanchaparroi and $H$. lunatus (fig. 20C-E). Furthermore, the ventral surface of the telson is smooth in both sexes of $H$. tishqu (fig. 23A, C), but granular in the female $H$. juanchaparroi, $H$. lunatus and most other species of the genus (fig. 20A).

DESCRIPTION: Based on the holotype and paratypes. Measurements of the holotype $\hat{\sigma}$ and a paratype $q$ are recorded in table 2.

Color: Base color yellowish in most specimens and especially juveniles, but some adults slightly orange on carapace, tergites, and pedipalps. Pigmentation absent in several specimens, except for very faint spots in some adults and juveniles. Carapace with some pigmentation laterally; ocular tubercle slightly darker. Tergites I-VI each with four irregular spots, two submedian spots in posterior half, and two larger sublateral spots; pretergites depigmented (fig. 24B); VII with faint lines of pigmentation along carinae. Sternites depigmented. Metasomal segments depigmented, except in some juveniles where faint pigmentation is evident along VL carinae and surrounding insertion of ventral setae on metasomal segment V. Chelicerae faintly pigmented at base of fingers. Pedipalp femur depigmented; patella pigmented along DE margin, external surface occasionally spotted; chela depigmented. Legs sparsely spotted on prolateral surfaces.

Chelicerae: Typical of the genus; surfaces smooth; dorsal surface with two macrosetae situated near base of fingers.

Carapace: Anterior margin with weak median projection and eight macrosetae; surfaces coarsely granular, especially laterally and posterolaterally, anterior third finely granular (§) or with smooth areas ( + ); anteromedian 


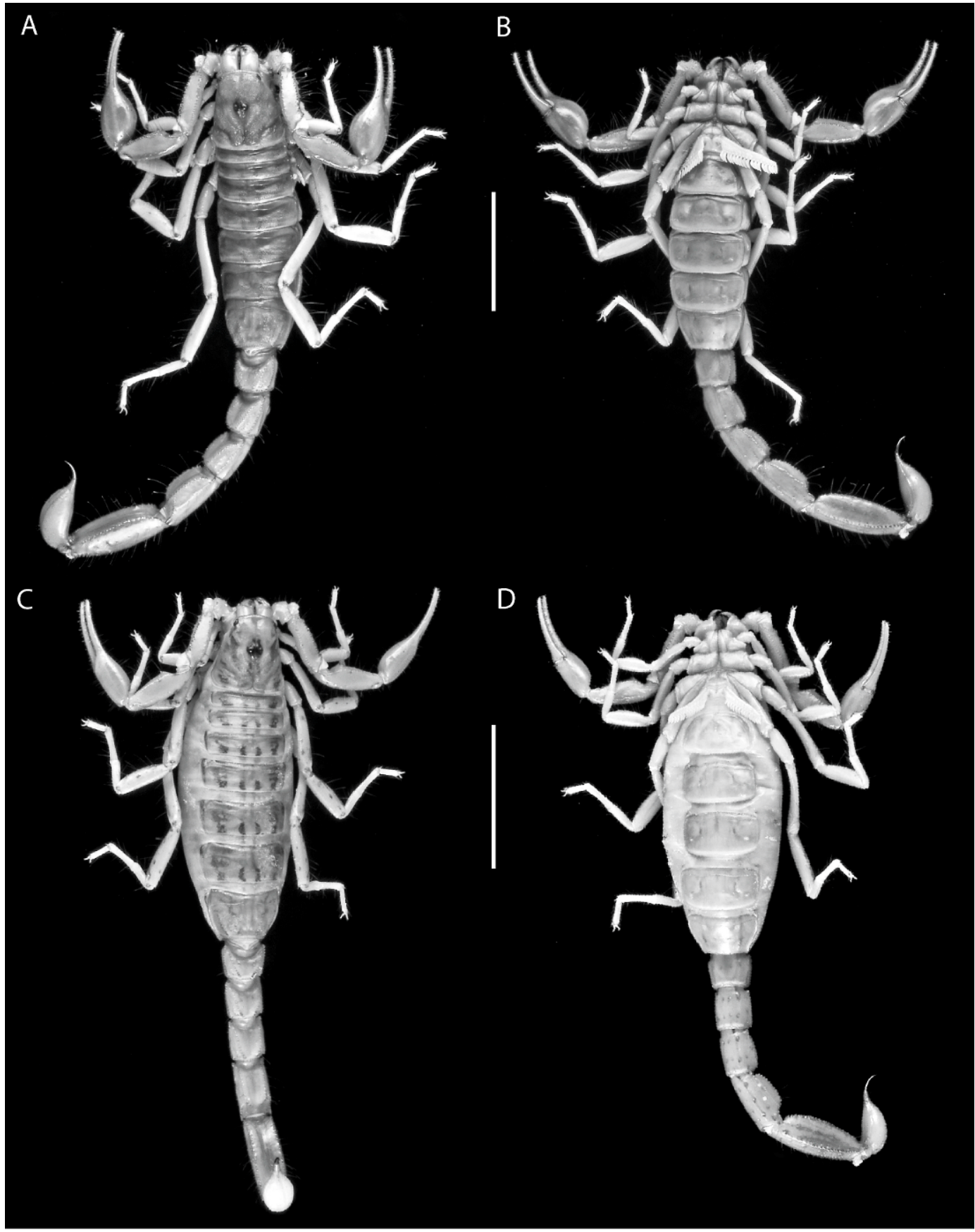

Fig. 22. Hadruroides tishqu, n. sp., habitus. A, B. Paratype $\hat{\delta}$ (AMNH). C, D. Subadult $q$ paratype (MHNC). A, C. Dorsal aspect. B, D. Ventral aspect. Scale bars $=1 \mathrm{~cm}$. 


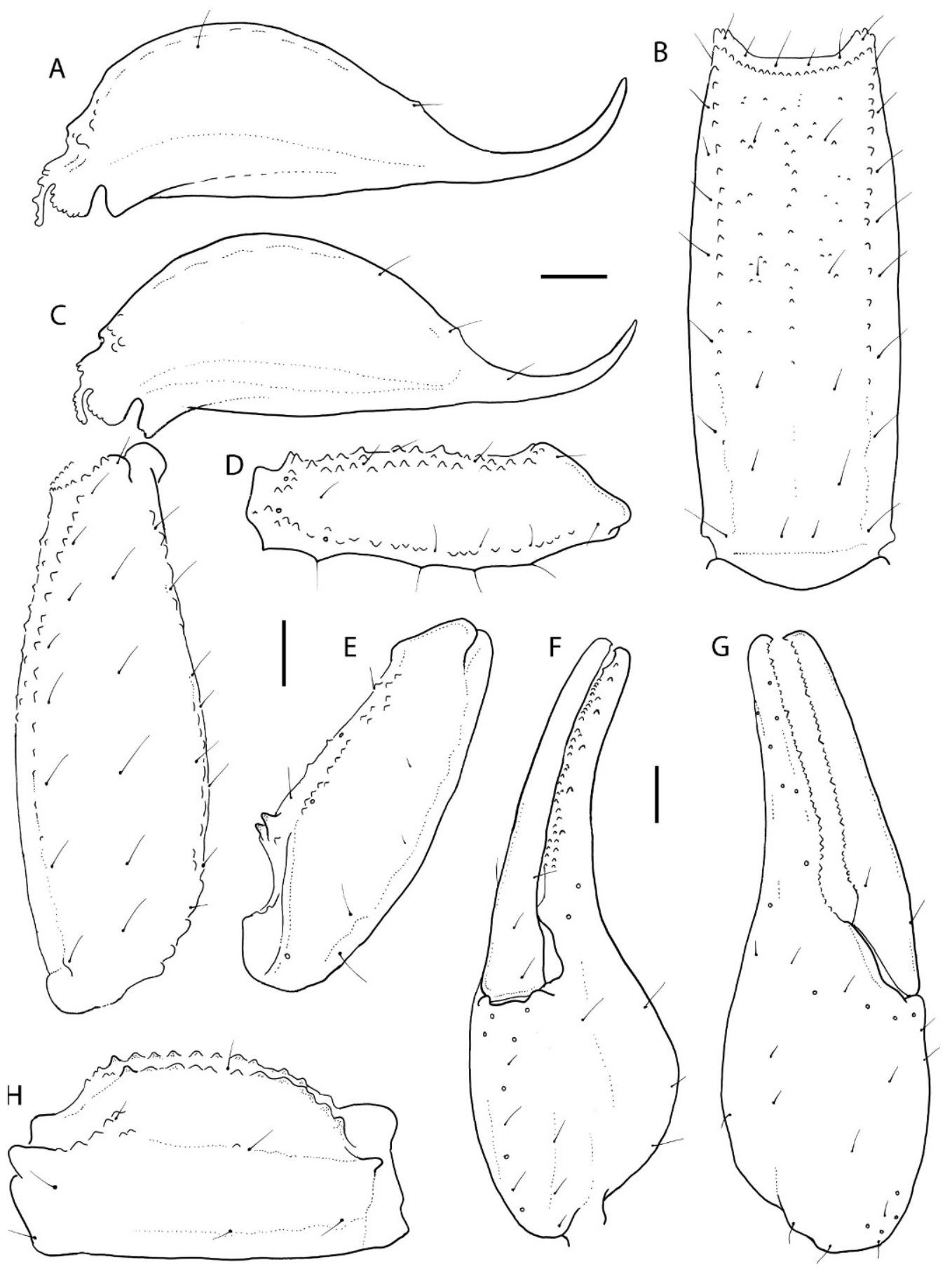

Fig. 23. Hadruroides tishqu, n. sp., diagnostic characters. A. Paratype $q$ (AMNH), telson, lateral aspect. B-H. Holotype $\hat{\delta}$ (MHNC). B. Metasomal segment V, ventral aspect. C. Metasomal segment V and telson, lateral aspect. D. Dextral pedipalp femur, dorsal aspect. E. Dextral pedipalp patella, dorsal aspect. F. Dextral pedipalp chela, ventrointernal aspect. G. Dextral pedipalp chela, external aspect. H. Metasomal segment IV, lateral aspect. Scale bars $=1 \mathrm{~mm}$. 

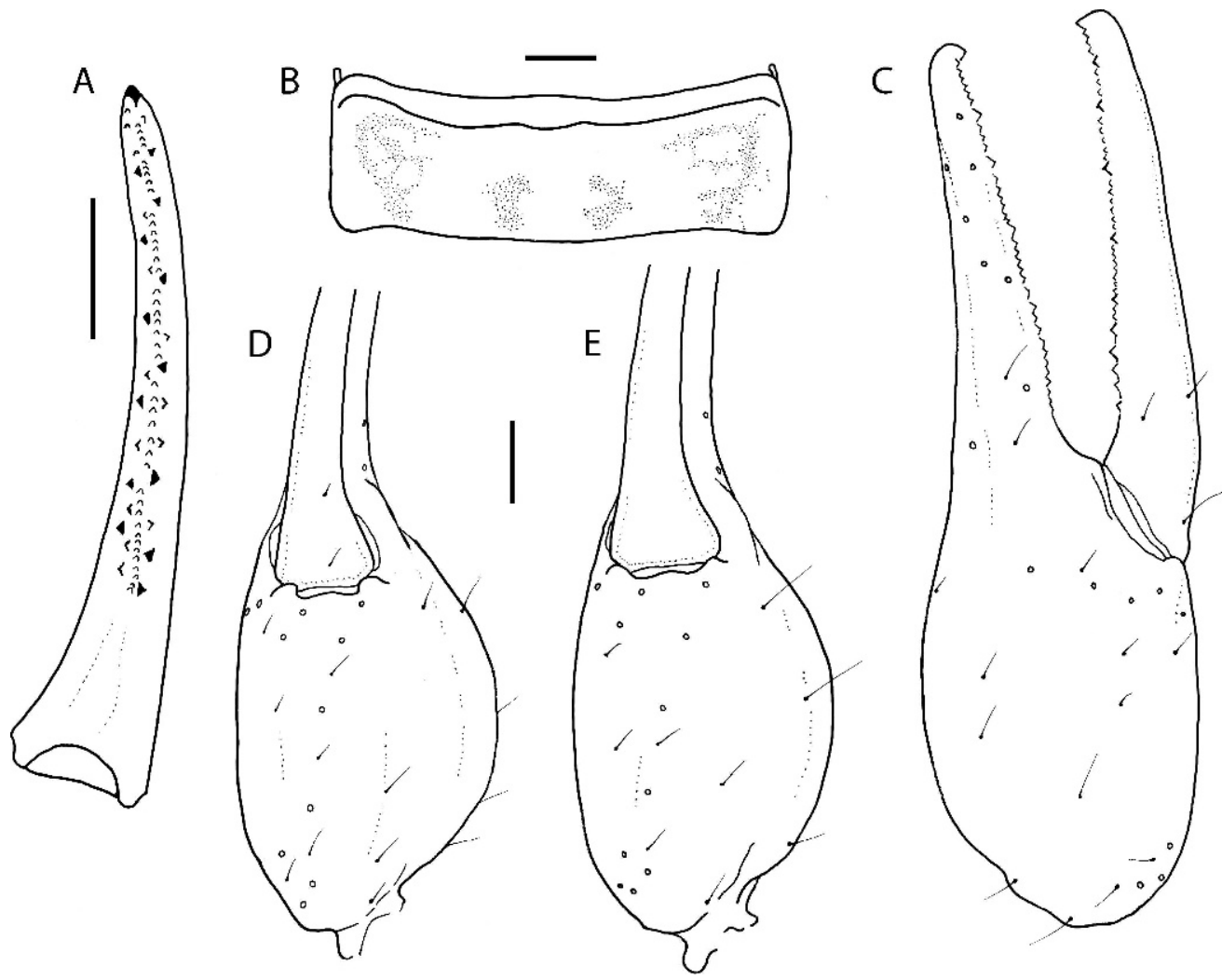

Fig. 24. Hadruroides tishqu, n. sp., diagnostic characters. A. Subadult $\delta$ paratype (MHNC), dextral pedipalp chela, movable finger, dorsal aspect showing dentition. B. Paratype $\hat{\delta}$ (MHNC), tergite IV, dorsal aspect showing pigmentation pattern. C. Paratype $+(\mathrm{AMNH})$, dextral pedipalp chela, external aspect. D. Holotype $\delta$ (MHNC). Dextral pedipalp chela, ventral aspect. E. Paratype $q$ (AMNH), dextral pedipalp chela, ventral aspect. Scale bars $=1 \mathrm{~mm}$.

longitudinal sulcus obsolete; posteromedian longitudinal and posterolateral sulci well developed; median ocular sulcus obsolete; ocular tubercle well developed.

Pedipalps: Femur with VI, DI, and DE carinae complete, granular; VM and VE vestigial (fig. 23D); dorsal surfaces smooth, internal surface with prominent granules in proximal half, ventral surfaces with few small granules proximally. Patella with DI and VI carinae complete, granular; DE and VE vestigial, smooth; DPP and VPP with prominent spiniform granules (fig. 23E). Chela robust; surfaces smooth; dorsomarginal carina vestigial, restricted to base of chela (figs. $23 \mathrm{~F}$, $\mathrm{G}, 24 \mathrm{C}-\mathrm{E})$; chela fixed finger curved, creating a distinct (f) or weakly developed (f) proximal gap with movable finger when the fingers are closed; movable finger, median denticle row comprising six subrows, 1-3 internal and external accessory denticles flanking subrows II and III, distal three subrows without external accessory denticles (fig. 24A).

Trichobothrial pattern: Typical of genus; femur with three trichobothria, patella with 20 , chela with 26; chelal trichobothrium $e b$ situated slightly distal to proximal gap between fixed and movable fingers $(\delta)$; trichobothrium $E t_{5}$ situated slightly distal to $E t_{4}$ (figs. 23G, 24C).

Legs: Prolateral surfaces granular; retrolateral surfaces smooth. Leg III, femur tetracarinate, VI and EM carinae well developed; 
A

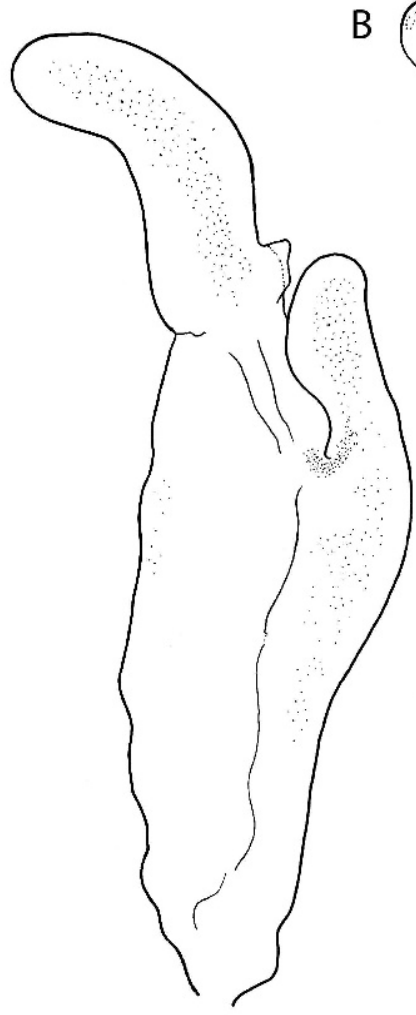

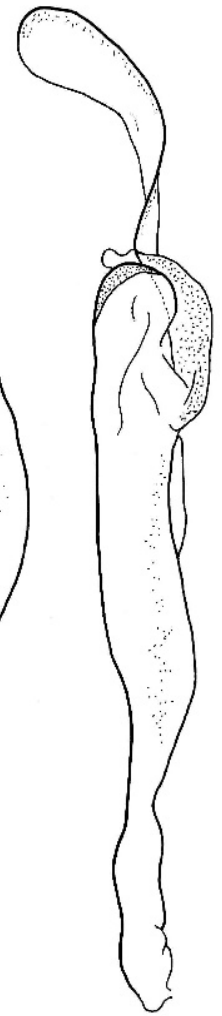
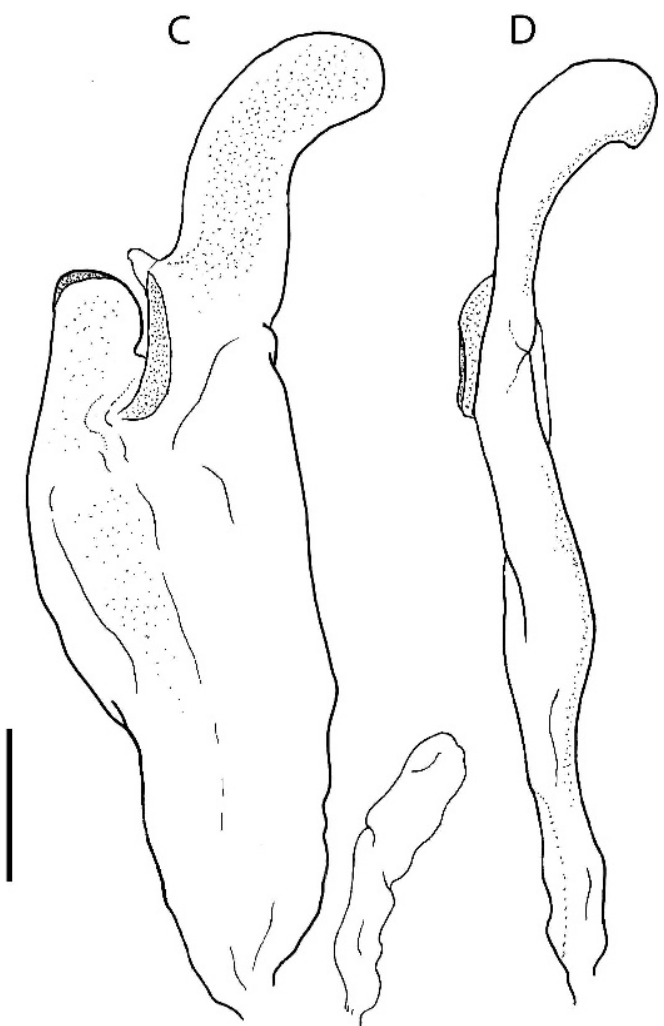

Fig. 25. Hadruroides tishqu, n. sp., paratype $\hat{\delta}$ (MHNC), sinistral hemispermatophore. A. Ental aspect. B. Dorsal aspect. C. Ectal aspect. D. Ventral aspect. Scale bar $=0.5 \mathrm{~mm}$.

patella DE carinae comprising few small granules in proximal half of segment, DI present in distal half, VI comprising few granules distally, EM obsolete. Telotarsus with $8-13$ ventromedian spinule clusters (setaceous tufts).

Tergites: Pretergites finely granular ( $\hat{\delta})$ or smooth ( + ). Post-tergites I-VI, surfaces finely granular, becoming more coarsely granular laterally and posteriorly, but weaker in $q$ and absent in juvenile; VII coarsely granular, with four well-developed longitudinal carinae.

Sternum: Subpentagonal; surface granular medially, with six macrosetae; posterolateral surfaces granular; median sulcus well developed.

Pectines: Pectinal tooth count: 16-18 (\$ิ), 13-14 (ㅇ).

Sternites: Sternites III-VI, surfaces slightly matte $(\hat{\delta})$ or smooth ( + ); spiracles narrow, situated in posterior half of segment; VII, surface smooth, acarinate, only a few small granules evident in position of VL carinae.

Metasoma: Segments I-IV, dorsal surfaces with scattered granules medially; DL carinae complete; ML carinae complete on segments I-III, obsolete on IV, comprising only few small granules posteriorly; LIM carinae complete on segment I, present in posterior half of II, and posterior third of III, absent on IV; surfaces between DL and ML carinae granular on segments I-III; VL carinae obsolete, smooth on segments I-IV (fig. 23H); VSM carinae absent on all segments. Segment V, DL carinae complete, comprising low granules (fig. 23C); VL and VM carinae present in posterior two-thirds of segment, obsolete in anterior third (fig. 23B); VL carinae occasionally complete but granules coarser in posterior two-thirds; VSM carinae comprising sparse 
granules in posterior half of segment; dorsal and lateral surfaces smooth. Segment I with two pairs of ventral setae; II and III each with three pairs; IV with five pairs, some specimens with additional setae along posteromedian margin of I-IV; V with 10-15 ventral setae and 4-7 additional setae along posterior margin.

Telson: Vesicle, surfaces sparsely setose, mostly smooth; ventral surface with scattered granules anteriorly (fig. 23A, C).

Hemispermatophore: Distal lamina strongly curved to ventral border in distal half; apex rounded; crest less than half lamina length (fig. 25).

Variation: Total length: $\hat{\delta}, 45.3-50.9$ (mean $=48.1, n=4)$; + , 49.1-57.9 $($ mean $=53.1, n$ $=3$ ). Pedipalp chela, length:width ratio: $\delta$, 2.98-3.34 (mean = 3.21, $n=4)$; + , 3.39-3.69 (mean $=3.52, n=3)$; length:height ratio: $\hat{\sigma}$, 2.73-3.06 $($ mean $=2.92, n=4)$; + , 3.03-3.21 (mean $=3.21, n=3$ ). Pedipalp femur, length:width ratio: $\hat{\delta}, 3.20-3.35$ (mean $=$ $3.29, n=4)$; + ,, $3.23-3.38$ (mean $=3.32, n=$ 3). Pectinal tooth count: of $(n=12), 16(n=$ 1), 17 (7), 18 (4); ㅇ ( $n=14), 13$ (11), 14 (3). Metasomal segment V, length:width ratio: $\delta$, 2.25-2.59 $($ mean $=2.43, n=4) ;$; , 2.28-2.55 (mean $=2.45, n=3$ ); length:height ratio: $\delta$, $2.48-2.78$ (mean $=2.62, n=4)$; + , 2.28-2.8 (mean $=2.56, n=3)$; number of setae: dorsolateral $(n=26)$ : $7(n=5), 8(11), 9(10)$; lateral $(n=26)$ : 5 (6), 6 (16), 7 (4); ventrolateral $(n=26): 7(2), 8(21), 9(1), 10$ (2); ventral $(n=13)$ : 10 (1), 11 (2), 12 (3), 13 (2), 14 (3), 15 (2). Telson, length:height ratio: o, 3.09-3.26 (mean $=3.17, n=4)$; ㅇ, 3.333.41 (mean $=3.37, n=3)$. Telotarsus, number of ventromedian spinule clusters (setaceous tufts): III $(n=24), 8(n=3), 9$ (9), 10 (9), 11 (2), 12 (1); IV $(n=22), 9$ (3), 10 (7), 11 (7), 12 (4), 13 (1).

Distribution: (fig. 1). This species is presently known from two localities: Isla Santa situated $5 \mathrm{~km}$ from the mainland, near Chimbote (fig. 3E), and Caleta Santa on the coastal mainland (fig. 1). Both localities occur in the Pacific desert ecoregion (Brack, 1986).

Ecology: The type locality is a rocky island (142.42 ha), bordered with cliffs on all sides (fig. 3E), and mostly covered by the nests and guano of many seabirds. Specimens of $H$. tishqu were collected at night with UV light detection in rocky areas, as well as under stones and bird nests during the day.

Hadruroides vichayitos, $\mathrm{n}$. $\mathrm{sp}$.

Figures 1, 3F, 5D, 12G, 20H, 26-28; table 2

Type Material: PerU: Piura Department: Talara Province: Holotype ô, 2 oे, 1 $q$ paratypes (MHNC), $2 \hat{\delta}, 1$ q paratypes (AMNH), Playa Vichayitos, $5 \mathrm{~km} \mathrm{~N}$ Los Órganos, near Mancora, $04^{\circ} 08^{\prime} 29^{\prime \prime} \mathrm{W}$ $81^{\circ} 05^{\prime} 30^{\prime \prime} \mathrm{W}, \quad 20-28 \mathrm{~m}, \quad 24 . x i .2004$, J.C. Chaparro and J.A. Ochoa.

ETYMology: The specific name is a noun in apposition taken from the type locality.

Diagnosis: Hadruroides vichayitos may be distinguished from other species of the genus by means of the pigmentation pattern. This species is almost completely depigmented, except for very small, faint spots on the carapace and tergites (fig. 12G). It may be related to $H$. carinatus, $H$. chinchaysuyu, and $H$. geckoi based on the similar development of the ventral carinae on sternite VII and the metasomal segments in these species. It differs from them based on the weaker lobe on the fixed finger on the pedipalp chela of the adult male and smaller proximal gap created when the fixed and movable fingers are closed (fig. $27 \mathrm{H}$ ). The proximal gap is well developed in $H$. geckoi (fig. $11 \mathrm{H}$ ) and $H$. carinatus and, although not as pronounced as in $H$. chinchaysuyu, is always more so than in $H$. vichayitos (figs. 8C, 27H). Hadruroides vichayitos differs further from $H$. geckoi in the following respects: lower count of accessory denticles on the pedipalp chela fingers (fig. $20 \mathrm{G}, \mathrm{H}$ ); shorter metasomal segments: the length:width ratio of segment $\mathrm{V}$ is $1.91-2.26$ in $H$. vichayitos, compared with 2.40-2.89 in $H$. geckoi; less granular metasomal segment V (figs. 11B, 27D); patella DI carina comprising only a few distal granules (fig. 27E), compared with $H$. geckoi, in which it is complete and granular (fig. 11C); deeper telson. Hadruroides vichayitos may be further distinguished from $H$. carinatus by means of the less-developed VSM carinae on sternite VII. Additional characters separating $H$. vichayitos from $H$. carinatus, $H$. chinchaysuyu, and $H$. geckoi, are as follows: the VSM carinae are present on 


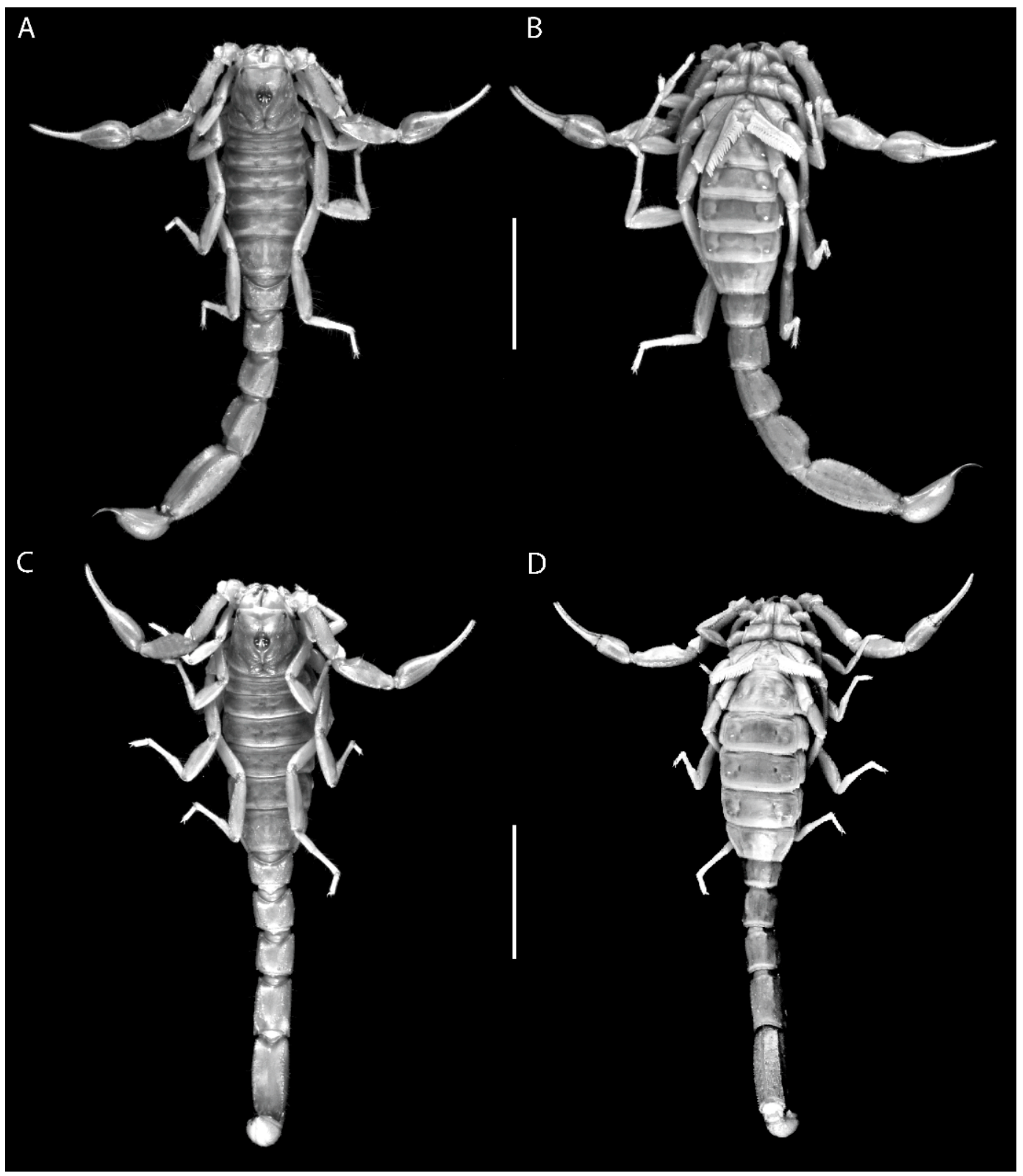

Fig. 26. Hadruroides vichayitos, n. sp., habitus. A, B. Paratype $\delta$ (AMNH). C, D. Paratype $q$ (AMNH). A, C. Dorsal aspect. B, D. Ventral aspect. Scale bars $=1 \mathrm{~cm}$.

metasomal segments I-III in $H$. carinatus and $H$. chinchaysuyu, but obsolete on segment I and absent on segments II and III in $H$. vichayitos; the lamina of the hemispermatophore is strongly curved in $H$. carinatus and $H$. geckoi, but shorter and slightly curved in
$H$. vichayitos; the apex of the lamina is acuminate in $H$. chinchaysuyu and H. geckoi, but rounded in $H$. vichayitos.

DESCRIPTION: Based on the holotype and paratypes. Measurements of the holotype $\hat{\sigma}$ and a paratype $q$ are recorded in table 2 . 


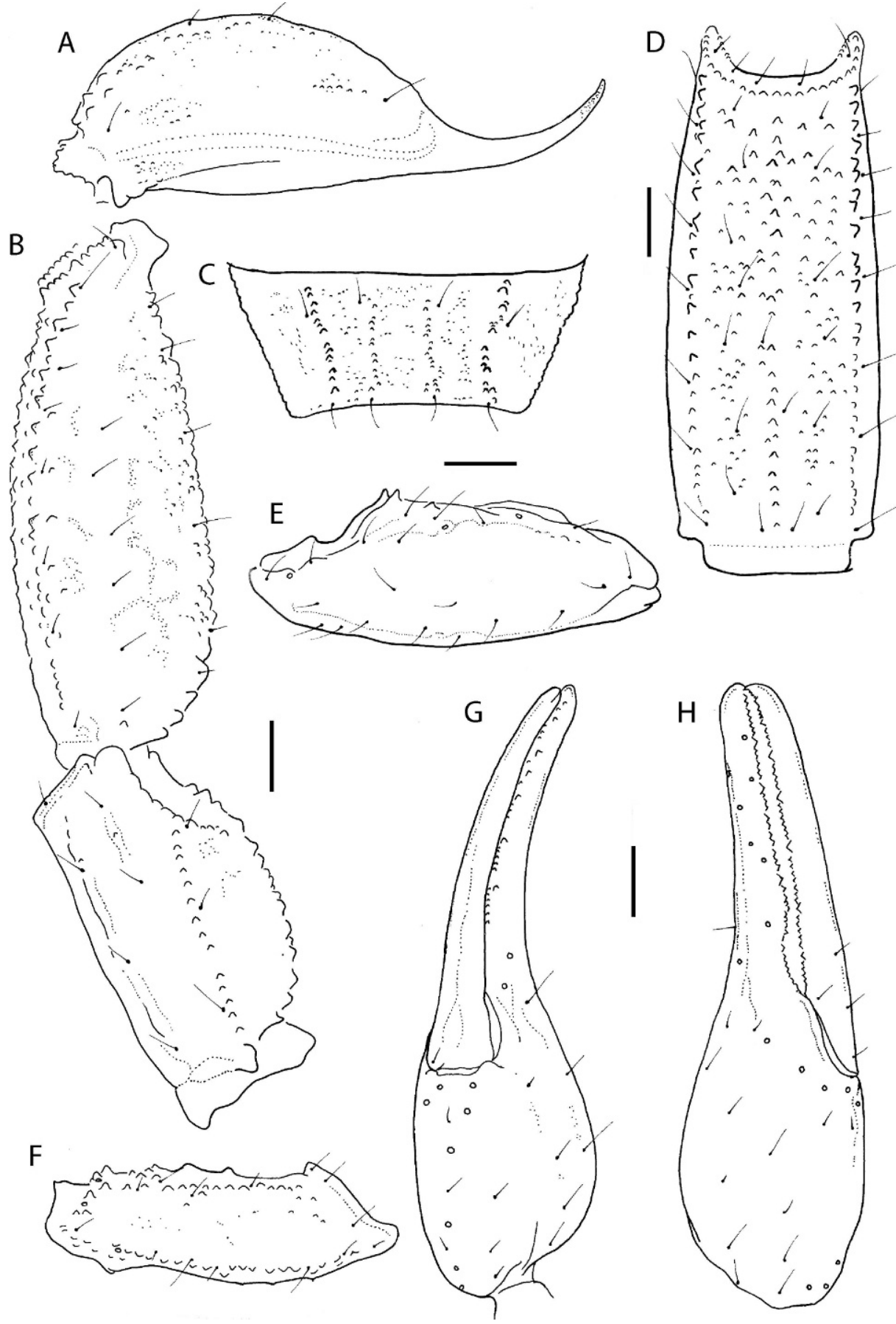

Fig. 27. Hadruroides vichayitos, n. sp., holotype $\delta$ (MHNC). A. Telson, lateral aspect. B. Metasomal segments IV and V, lateral aspect. C. Sternite VII, ventral aspect. D. Metasomal segment V, ventral aspect. E. Dextral pedipalp patella, dorsal aspect. F. Dextral pedipalp femur, dorsal aspect. G. Dextral pedipalp chela, ventrointernal aspect. H. Dextral pedipalp chela, external aspect. Scale bars $=1 \mathrm{~mm}$. 

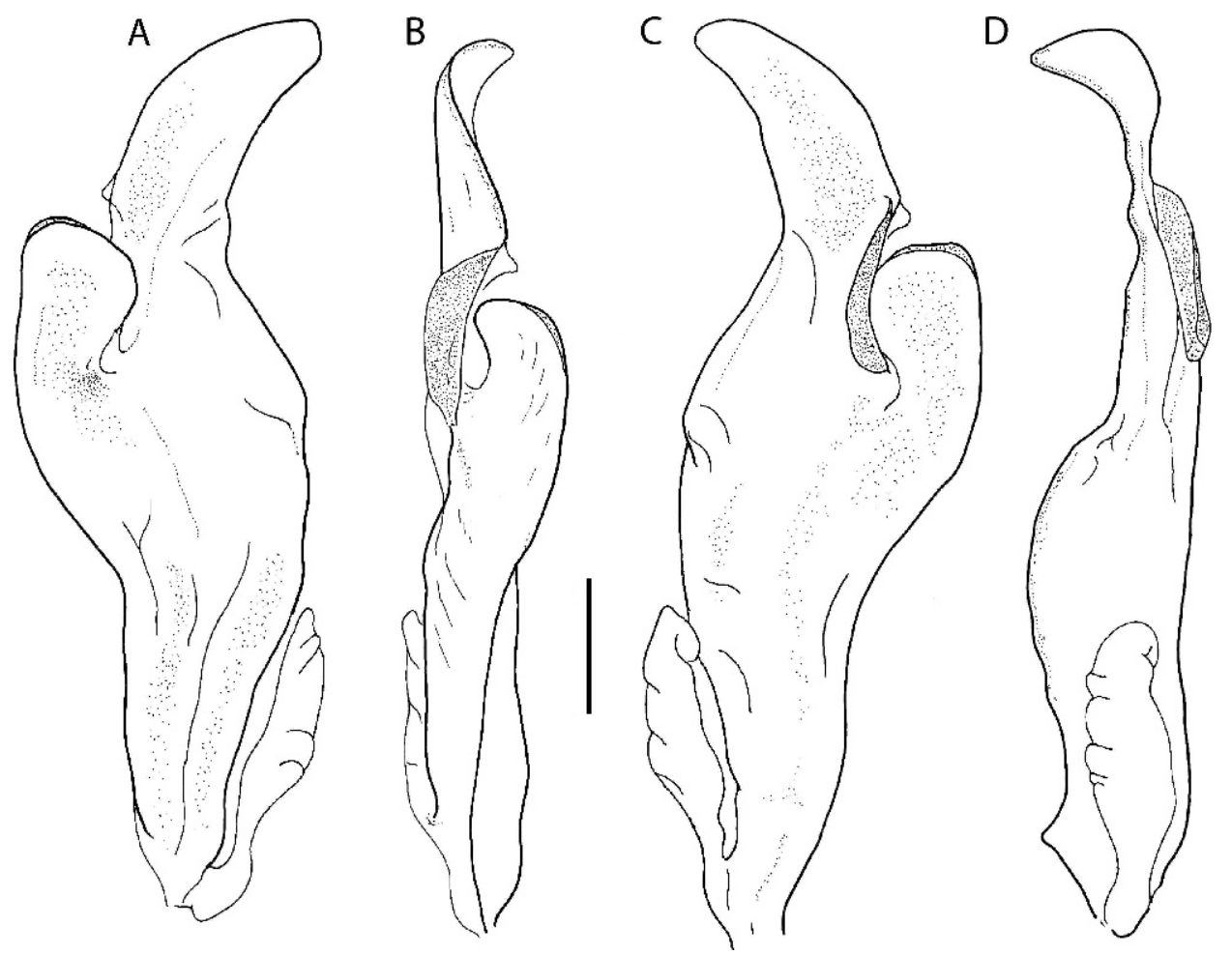

Fig. 28. Hadruroides vichayitos, n. sp., paratype $\delta$ (MHNC), dextral hemispermatophore. A. Ental aspect. B. Dorsal aspect. C. Ectal aspect. D. Ventral aspect. Scale bar $=0.5 \mathrm{~mm}$.

Color: Base color yellowish with small, faint spots. Carapace faintly spotted laterally and posterolaterally; ocular tubercle blackish. Tergites I-VI with six small, faint spots, four situated near posterior margin, and two situated on anterior margin; VII with faint spots along carinae only (fig. 12G). Metasomal segments depigmented dorsally; ventral surfaces occasionally with very faint pigmentation along anterior third of VL carinae; other surfaces depigmented. Sternites, chelicerae, pedipalps, and legs depigmented.

Chelicerae: Typical of genus; surfaces smooth; dorsal surface with two macrosetae situated near base of fingers.

Carapace: Anterior margin with weak median projection and eight macrosetae; surfaces granular, densely so laterally, except for anterior third which is smooth; anteromedian longitudinal sulcus obsolete, with few fine granules bordering posterior half; posteromedian longitudinal sulcus obsolete in anterior half, becoming more developed in posterior half; posterolateral sulci well developed; median ocular sulcus obsolete; ocular tubercle well developed.

Pedipalps: Femur with VI, DI, and DE carinae complete, granular; VM vestigial; dorsal surface with few scattered granules (fig. 27F); internal surface with few granules medially; ventral surface smooth. Patella with DI carinae complete but obsolete, comprising only three or four granules distally; DPP and VPP with prominent spiniform granules; VI carinae complete, granular (fig. 27E); all other surfaces smooth. Chela robust; fingers relatively elongated; fixed finger lobed and weakly curved, creating shallow proximal gap with movable finger when fingers closed (fig. 27G, $\mathrm{H})$; movable finger, median denticle row comprising six subrows, internal and external accessory denticles flanking first subrow only, subrows II-VI without external accessory denticles (fig. 20H).

Trichobothrial pattern: Typical of genus; femur with three trichobothria, patella with 
20, chela with 26; chelal trichobothium dst situated slightly distal to est (absent in two specimens); chelal trichobothrium $e b$ situated slightly distal to proximal gap between fixed and movable fingers (fig. 27H).

Legs: Prolateral surfaces granular; retrolateral surfaces smooth and markedly setose on patella, tibia, and tarsus. Leg III, femur tetracarinate with DI, DE, VI, and EM carinae complete, VI and EM more strongly developed; patella, dorsal surface with few fine granules medially, DM carinae present in proximal half of segment, DI comprising few small granules in distal third, IM and VI well developed, DE restricted to proximal twothirds of segment, EM complete. Telotarsus with 7-11 ventromedian spinule clusters (setaceous tufts).

Tergites: Pretergites smooth. Post-tergites I-VI, surfaces finely granular, becoming more coarsely granular laterally and posteriorly; VII coarsely granular, with four well-developed longitudinal carinae.

Sternum: Subpentagonal; surface granular medially, with six macrosetae; posterolateral surfaces granular; median sulcus well developed.

Pectines: Pectinal tooth count: 17-19 (đ)), 15-17 (ㅇ).

Sternites: Sternites III-VI, surfaces finely granular ( $\delta$ ) or smooth ( $q$ ); spiracles narrow, situated in posterior half of segment; VII, surface granular, VL carinae well developed, VSM present but obsolete (fig. 27C).

Metasoma: Segments I-IV, DL and ML carinae complete, granular on segments I-III, with posterior granule slightly larger; dorsal surface and surfaces between DL and ML carinae granular near DL carinae, more so on segment I, granulation decreasing towards segment IV; LIM carinae well developed on segment I, present in posterior half of II and III, but less granular on III, absent or obsolete on IV (fig. 27B); surfaces between ML and LIM carinae granular on segment I, sparsely granular on II and III, smooth on IV; VL carinae complete, granular on segment I, obsolete, comprising and three or four small granules posteriorly on II-IV; surfaces between LIM and VL carinae finely granular on segment I, all other segments smooth; VSM carinae obsolete on segment I, absent on IIIV. Segment V, dorsal surface finely granular;
DL carinae complete, granular medially; lateral surfaces with scattered granulation; VL and VM carinae complete, granular; VSM carinae present in anterior third of segment only, posterior two-thirds obscured by granulation of ventral surface (fig. 27B, D). Segment I with two pairs of ventral setae; II and III each with three pairs, occasionally with additional setae along posteromedian margin of III; IV with five pairs and additional setae along posteromedian margin; $\mathrm{V}$ with 16-18 ventral setae and 5-6 additional setae along posterior margin.

Telson: Vesicle, surfaces sparsely setose, ventral surface sparsely granular anteriorly, smooth $(\hat{\delta})$ or densely granular ( + ) posteriorly; aculeus short (fig. 27A).

Hemispermatophore: Distal lamina short, slightly curved in distal half; crest more than half lamina length; basal portion more than twice lamina length (fig. 28).

Variation: Total length: ô, 34.4-43.7 (mean $=40.5, n=5)$; ㅇ, 40.3-40.8 $(n=2)$. Pedipalp chela, length:width ratio: of, 3.68-4.00 (mean $=3.81, n=5)$; $9,4.11-4.38$ (mean $=4.25, n$ $=2$ ); length:height ratio: of, 3.42-3.67 (mean $=3.54, n=5) ;$ \% , 3.90-3.95 (mean $=3.92, n$ $=2$ ). Pedipalp femur, length:width ratio: $\hat{\delta}$, 3.16-3.31 (mean $=3.21, n=5)$; ㅇ, 3.10-3.22 $($ mean $=3.16, n=2)$. Pectinal tooth count: $\hat{\sigma}$ $(n=10), 17(n=1), 18(6), 19(3)$; ㅇ $(n=4)$, $15(n=1), 16(1), 17(2)$. Metasomal segment $\mathrm{V}$, length:width ratio: $\delta, 1.91-2.26$ (mean $=$ $2.15, n=5)$; ㅇ, $2.07-2.14$ (mean $=2.11, n=$ 2); length:height ratio: $\delta, 2.10-2.44$ (mean $=$ 2.30, $n=5)$; + , $2.14-2.22($ mean $=2.18, n=$ $2)$; number of setae: dorsolateral $(n=12): 5(n$ $=2), 6(5), 7(3), 8(2)$; lateral $(n=12): 6(7), 7$ (4), 8 (1); ventrolateral $(n=12): 6$ (1), 7 (1), 8 (3), 9 (3), 10 (4); ventral $(n=6)$ : 15 (1), 16 (1), 17 (2), 18 (2). Telson, length:height ratio: $\delta$, 2.92-3.14 (mean $=3.04, n=5)$; + , 3.14-3.19 (mean $=3.16, n=2)$. Telotarsus, number of ventromedian spinule clusters (setaceous tufts): III $(n=12), 7(n=1), 8$ (4), 9 (6), 10 (1); IV $(n=9), 9$ (2), 10 (4), 11 (5).

Distribution: This species in known only from the type locality, an area representing the last remnant of Pacific Desert in northern Peru (fig. 1).

ECOLOGY: All specimens were collected at night with UV light detection, under shrubs 
near a sand dune formation, surrounded by equatorial dry forest (fig. 3F).

\section{ACKNOWLEDGMENTS}

The first author was supported by a Kalbfleisch Postdoctoral Fellowship at the AMNH. Fieldwork in Peru was funded in part by the Kalbfleisch fellowship and in part by National Science Foundation grant DEB 0228699 to the second author. We are grateful to Dany Apaza, Emiliano Carrillo, Pedro Castillo, Juan Carlos Chaparro, Reynaldo Elizarde, Roberto Gutiérrez, Fernando Mejía, Luis Nizama, Jano Nuñez, Aarón Quiroz, and Joyce Vitorino Villegas for assisting the first author in the field; A. Catennazzi for providing additional specimens from Isla Santa; Pedro Castillo (Universidad Nacional de Tumbes) for logistical support with fieldwork in Tumbes; Wilfredo Medonza (MUSM) for providing data on the vegetation; the Dirección de Conservación de la Biodiversidad, Instituto Nacional de Recursos Naturales de Peru (INRENA) for permits 061-2004-INRENA-IFFS-DCB，0022008-INRENA-IFFS-DCB, 106-2008-INRENAIFFS-DCB, to collect scorpions in Peru; Karina Ramírez and Rosa Vento (IFFS-DCB) for assistance with the collecting permits; Proyecto Especial de Promoción del Aprovechamiento de Abonos Provenientes de Aves Marinas (PROABONOS), Ministerio de Agricultura of Peru, for entry permits to the Guano islands; the following for loaning material and/or providing data from collections: Camilo Mattoni (CDA), Petra Sierwald, and Alfred Newton (FMNH), Andres Ojanguren Affilastro (MACN), Olintho Aguilar (MHNC), Evaristo Lopez (MUSA), Gerardo Lamas and Diana Silva (MUSM), Jonathan Coddington and Scott Larcher (USNM), Jason Dunlop and Anja Friederichs (ZMB). We thank Steve Thurston (AMNH) for assistance with preparing the plates for this contribution and Camilo I. Mattoni and Andres A. Ojanguren Affilastro for comments on a previous version of the manuscript.

\section{REFERENCES}

Acosta, L.E., and J.A. Ochoa. 2002. Lista de los escorpiones bolivianos (Chelicerata: Scorpiones), con notas sobre su distribución.
Revista de la Sociedad Argentina de Entomología 61 (3-4): 15-23.

Aguilar, P.G. 1968. Notas sobre escorpiones de Lima. Anales Científicos de la Universidad Nacional Agraria La Molina 6: 165-172.

Aguilar, P.G. 1977. Fauna desertico-costera peruana. IV: Artropodos del tillandsial de Punta Hermosa, Lima. Revista Peruana de Entomología 20: 87-92.

Aguilar, P.G., and O. Meneses. 1970. Escorpiones y escorpionismo en el Perú I: Nota preliminar sobre los Scorpionida peruanos. Anales Científicos de la Universidad Nacional Agraria La Molina 8: 1-5.

Aguilar, P.G., and J.A. Türkowsky. 1977. Fauna desertico-costera peruana. III: Observaciones en el tillandsial de Cajamarquilla, Lima. Revista Peruana de Entomología 20: 81-84.

Armas, L.F. de. 1984. Identidad taxonómica de Hadrurus parvulus Karsch 1879 (Scorpiones: Iuridae). Miscelánea Zoológica 22: 1.

Banks, N. 1924. Arachnida of the Williams Galapagos Expedition. Zoologica (New York) 5 (9): 93-99.

Boeris, G. 1889. Aracnidi raccolti nel Sud-America dal Dott. Vincenzo Ragazzi. Atti della Società dei Naturalisti di Modena Memorie Ser. 3(8): 123-135.

Brack, A. 1986. Ecología de un país complejo. In Gran Geografía del Perú: Naturaleza y Hombre. Barcelona: Manfer-Juan Mejía Baca, 2: $175-319$.

Bücherl, W. 1964. Distribução geográfica dos Aracnóides peçonhentos temíveis. Memórias do Instituto de Butantan 31: 55-66.

Bücherl, W. 1967. Escorpiões, aranhas e escolopendromorfos da Amazônia. In: H. Lent (editor), Atas do Simposio sôbre a Biota Amazônica 5 (Zoologia): 111-125.

Bücherl, W. 1969. Giftige Arthropoden. In: E.J. Fittkau et al. (editors), Biogeography and Ecology in South America, vol. 2: 764-793. Monographiae Biologicae. Dordrecht: W. Junk, 19.

Bücherl, W. 1971. Classification, biology and venom extraction of scorpions. In: W. Bücherl and E. Buckley (editors), Venomous Animals and Their Venoms. New York: Academic Press, 3: 317-348.

Byalynitskii-Birulya, A.A. [Birula, A.A.] 1917a. Arachnoidea Arthrogastra Caucasica. Pars I. Scorpiones. Zapiski Kavkazskogo Muzeya (Mémoires du Musée du Caucase) A (5): 1-253. Tiflis [Tbilisi, Georgia]: Imprimerie de la Chancellerie du Comité pour la Transcaucasie. [in Russian, English translation: Byalynitskii-Birulya, A.A. 1964. Arthrogastric Arachnids of Caucasia. 1. Scorpions. Jerusa- 
lem: Israel Program for Scientific Translations, 170 pp.]

Byalynitskii-Birulya, A.A. [Birula, A.A.] 1917b.

Faune de la Russie et des pays limitrophes. Fondée principalement sur les collections du Musée Zoologique de l'Académie des Sciences de Russie. Arachnides (Arachnoidea). Petrograd: Russian Academy of Sciences: 1 (1): xx, 227 pp. [in Russian, English translation: Byalynitskii-Birulya, A.A. 1965. Fauna of Russia and Adjacent Countries. Arachnoidea. Vol. 1. Scorpions. Jerusalem: Israel Program for Scientific Translations, xix, $154 \mathrm{pp}$.]

Ceballos Bendezú, I. 1976. Nuevo esquema biogeográfico del Perú. Revista Universitaria Universidad Nacional del Cusco 130: 19-44.

Cekalovic, K.T. 1966. Contribución al conocimiento de los escorpiones chilenos. Museo Nacional de Historia Natural Noticiario Mensual (Santiago) 10 (118): 1-8.

Cekalovic, K.T. 1983. Catálogo de los escorpiones de Chile (Chelicerata, Scorpiones). Boletín de la Sociedad Biológica de Concepción 54: 43-70.

Chamberlin, R.V. 1920. South American Arachnida, chiefly from the Guano Islands of Peru. Science Bulletin of the Museum of the Brooklyn Institute of Arts and Sciences 3: 35-44.

Dupré, G. 2007. Conspectus Genericus Scorpionorum 1758-2006. Euscorpius 50: 1-31.

Escobar, E., C. Rivera, and L. Tincopa. 2003. Acción de la toxina H13 sobre músculo esquelético. Revista Peruana de Biología 10 (1): 88-92.

Escobar, E., C. Rivera, L. Tincopa, and D. Rivera. 2002. Purificación parcial de las toxinas H11, H12 y H13 del veneno del escorpión Hadruroides lunatus KOCH, 1867 (Scorpionida: Vejovidae). Revista Peruana de Biología 9 (1): 3-10.

Esquivel de Verde, M.A. 1968. Notas sobre Scorpionidae de Venezuela. 1. Nuevos registros y comentarios sobre la distribución de algunos grupos en Venezuela. Acta Biologica Venezuelica 6 (2): 66-70.

Ferreyra, R. 1983. Los tipos de vegetación de la costa peruana. Anales Jardín Botánico de Madrid 40 (1): 241-256.

Fet, V., M.S. Brewer, M.E. Soleglad, and D.P.A. Neff. 2006. Constellation array: A new sensory structure in scorpions (Arachnida: Scorpiones). Boletín de la Sociedad Entomológica Aragonesa 38: 269-278.

Fet, V., and M.E. Soleglad. 2005. Contributions to scorpion systematics. 1. On recent changes in high-level taxonomy. Euscorpius 31: 1-13.

Fet, V., and M.E. Soleglad. 2008. Cladistic analysis of superfamily Iuroidea, with emphasis on subfamily Hadrurinae (Scorpiones: Iurida). Boletín de la Sociedad Entomológica Aragonesa 43: 255-281.
Fet, V., M.E. Soleglad, D.P.A. Neff, and I. Stathi. 2004. Tarsal armature in the superfamily Iuroidea (Scorpiones: Iurida). Revista Ibérica de Aracnología 10: 17-40.

Flórez, E. 1990. Escorpiones de Colombia: Catálogo de especies. Cespedesia 16-17 (5758): 117-127.

Francke, O.F. 1977. Escorpiones y escorpionismo en el Perú VI: Lista de especies y claves para identificar las familias y los géneros. Revista Peruana de Entomología 20: 73-76.

Francke, O.F. 1985. Conspectus Genericus Scorpionorum 1758-1982 (Arachnida: Scorpiones). Occasional Papers of the Museum, Texas Tech University 98: 1-32.

Francke, O.F., and L. Prendini. 2008. Phylogeny and classification of the giant hairy scorpions, Hadrurus Thorell (Iuridae Thorell): A reappraisal. Systematics and Biodiversity 6 (2): 205-223.

Francke, O.F., and M.E. Soleglad. 1980. Two new Hadruroides Pocock from Peru (Scorpiones, Vaejovidae). Occasional Papers of the $\mathrm{Mu}-$ seum, Texas Tech University 69: 1-13.

Francke, O.F., and M.E. Soleglad. 1981. The family Iuridae Thorell (Arachnida, Scorpiones). Journal of Arachnology 9: 233-258.

González-Sponga, M.A. 1984. Escorpiones de Venezuela. Cuadernos Lagoven. Caracas: Editorial Cromotip, 128 pp.

González-Sponga, M.A. 1996. Guía para Identificar Escorpiones de Venezuela. Cuadernos Lagoven. Caracas: Editorial Artes, 204 pp.

Iannacone, J. 2003. Artropofauna de importancia forense en un cadáver de cerdo en el Callao, Perú. Revista Brasileira de Zoología 20 (1): 85-90.

Kamenz, C., and L. Prendini. 2008. An atlas of book lung fine structure in the order Scorpiones (Arachnida). Bulletin of the American Museum of Natural History 316: $1-359$.

Karsch, F. 1879. Scorpionologische Beiträge. Part II. Mitteilungen des Münchener Entomologischen Vereins 3: 97-136.

Karsch, F. 1881. Ein neuer amerikanischer Skorpion. Berliner Entomologische Zeitschrift 25: 290.

Kinzelbach, R. 1973. Scorpions from the Galapagos Islands. In Galapagos, Studi e Ricerche. Spedizione "L. Mares - G.R.S.T.S.". Firenze: Museo Zoologico dell'Università di Firenze, 1-12.

Koch, L. 1867. Beschreibungen neuer Arachniden und Myriapoden. Verhandlungen der KaiserlichKöniglichen Zoologisch-Botanischen Gesellschaft in Wien 17: 173-250.

Kovařík, F. 1998. Štiři (Scorpions). Madagaskar, Jihlava, 175 pp. [in Czech] 
Kraepelin, K. 1894. Revision der Scorpione. II. Scorpionidae und Bothriuridae. Beiheft zum Jahrbuch der Hamburgischen Wissenschaftlichen Anstalten 11: 1-248.

Kraepelin, K. 1899. Scorpiones und Pedipalpi. In: F. Dahl (editor), Das Tierreich. 8 (Arachnoidea): 1-265. Herausgegeben von der Deutschen Zoologischen Gesellschaft. Berlin: Friedländer.

Kraepelin, K. 1901. Catalogue des scorpions des collections du Muséum d'Histoire Naturelle de Paris. Bulletin du Muséum National d'Histoire Naturelle 7: 265-274.

Laurie, M. 1896. Further notes on the anatomy and development of scorpions, and their bearing on the classification of the order. Annals and Magazine of Natural History 18 (6): 121-133.

Lourenço, W.R. 1994. Diversity and endemism in tropical versus temperate scorpion communities. Biogeographica 70 (3): 155-160.

Lourenço, W.R. 1995. Les scorpions (Chelicerata, Scorpiones) de l'Équateur avec quelques considérations sur la biogéographie et la diversité des espèces. Revue Suisse de Zoologie 102 (1): 61-88.

Lourenço, W.R. 1997a. Additions à la faune de scorpions neotropicaux. Revue Suisse de Zoologie 104 (3): 587-604.

Lourenço, W.R. 1997b. Synopsis de la faune de scorpions de Colombie, avec des considérations sur la systématique et la biogéographie des espèces. Revue Suisse de Zoologie 104 (1): 61-94.

Lourenço, W.R. 1998. Panbiogeographie: Les distributions disjontes et le concept de familie relictuelle chez les scorpions. Biogeographica 74 (3): 133-144.

Lourenço, W.R. 2000. Panbiogeographie, les familles des scorpions et leur repartition geographique. Biogeographica 76 (1): 21-39.

Lourenço, W.R., and H. Dastych. 2001. A contribution to the scorpion fauna of Peru, with a description of Chactas koepckei sp. nov. (Arachnida: Scorpiones). Mitteilungen aus dem Hamburgischen Zoologischen Museum und Institut 98: 51-62.

Marín Moreno, F. 1961. Panorama fitogeográfico del Perú. Revista Universitaria Universidad Nacional del Cusco 120: 9-68.

Maury, E.A. 1975. Escorpiones y escorpionismo en el Perú IV: Revisión del género Hadruroides Pocock, 1893 (Scorpiones, Vejovidae). Revista Peruana de Entomología 17 (1): 9-21.

Mello-Leitão, C. de. 1931. Divisão e distribução do gênero Tityus Koch. Annaes da Academia Brasileira de Ciências 3 (3): 119-150.
Mello-Leitão, C. de. 1942. Los alacranes y la zoogeografía de Sud Americana. Revista Argentina de Zoogeografía 2 (3): 125-131.

Mello-Leitão, C. de. 1945. Escorpiões sul-americanos. Arquivos do Museu Nacional Rio de Janeiro 40: 7-468.

Moritz, M., and S.-C. Fischer. 1980. Die Typen der Arachniden-Sammlung des Zoologischen $\mathrm{Mu}-$ seums Berlin. III. Scorpiones. Mitteilungen aus dem Zoologischen Museum in Berlin 2 (36): 309-326.

Nenilin, A.B., and V. Fet. 1992. Zoogeographical analysis of the world scorpion fauna (Arachnida: Scorpiones). Arthropoda Selecta 1 (2): 3-31. [in Russian, English summary].

Ochoa, J.A. 2005. Patrones de distribución de escorpiones de la región andina en el sur peruano. Revista Peruana de Biología 12 (1): $49-68$.

Ochoa, J.A., and J.C. Chaparro. 2008. Nueva especie de escorpión del género Hadruroides (Scorpiones: Caraboctoninae) de los valles interandinos de Perú. Revista Peruana de Biología 15 (1): 5-10.

Péfaur, J.E. 1981. Composition and phenology of epigeic animal communities in the Lomas of southern Peru. Journal of Arid Environments 4: $31-42$.

Pocock, R.I. 1893a. A contribution to the study of Neotropical scorpions. Annals and Magazine of Natural History 12 (6): 77-103.

Pocock, R.I. 1893b. Notes on the classification of scorpions, followed by some observations on synonymy, with descriptions of new genera and species. Annals and Magazine of Natural History 12 (6): 303-330.

Pocock, R.I. 1900. Some new or little-known Neotropical scorpions in the British Museum. Annals and Magazine of Natural History 5 (7): 469-478.

Prendini, L. 2000. Phylogeny and classification of the superfamily Scorpionoidea Latreille 1802 (Chelicerata, Scorpiones): An exemplar approach. Cladistics 16: 1-78.

Prendini, L. 2004. The systematics of southern African Parabuthus Pocock (Scorpiones, Buthidae): Revisions to the taxonomy and key to the species. Journal of Arachnology 32: 109-186.

Prendini, L., and W.C. Wheeler. 2005. Scorpion higher phylogeny and classification, taxonomic anarchy, and standards for peer review in online publishing. Cladistics 21: 446-494.

Rojas-Runjaic, F.J.M., and L. De Sousa. 2007. Catálogo de los escorpiones de Venezuela (Arachnida: Scorpiones). Boletín de la Sociedad Entomológica Aragonesa 40: 281-307. 
Sissom, W.D. 1990. Systematics, biogeography and paleontology. In: G.A. Polis (editor), The Biology of Scorpions. Stanford, CA: Stanford University Press, 64-160.

Sissom, W.D., and V. Fet. 2000. Family Iuridae Thorell, 1876. In V. Fet, W.D. Sissom, G. Lowe, and M.E. Braunwalder, Catalog of the Scorpions of the World (1758-1998). New York: New York Entomological Society, 409-420.

Soleglad, M.E., and V. Fet. 2003a. The scorpion sternum: Structure and phylogeny (Scorpiones: Orthosterni). Euscorpius 5: 1-34.

Soleglad, M.E., and V. Fet. 2003b. High-level systematics and phylogeny of the extant scorpions (Scorpiones: Orthosterni). Euscorpius 11: 1-172.

Soleglad, M.E., F. Kovaŕík, and V. Fet. 2009. Etudes on Iurids. 1. The orthobothriotaxic pattern of Iuridae, with observations on neobothriotaxy in genus Iurus (Scorpiones: Iuroidea). Euscorpius 79: 1-21.

Soleglad, M.E., and W.D. Sissom. 2001. Phylogeny of the family Euscorpiidae Laurie, 1896: A major revision. In: V. Fet and P.A. Selden (editors), Scorpions 2001. In memoriam Gary A. Polis. Burnham Beeches, Bucks, UK: British Arachnological Society, 25-111.

Stahnke, H.L. 1972. U.V. light, a useful field tool. BioScience 22 (10): 604-607.

Stahnke, H.L. 1970. Scorpion nomenclature and mensuration. Entomological News 81: 297-316.

Stahnke, H.L. 1974. Revision and keys to the higher categories of Vejovidae. Journal of Arachnology 1 (2): 107-141.
Teruel, R. 2003. Nuevos casos de anomalías morfológicas en escorpiones (Scorpiones: Bothriuridae, Buthidae, Chactidae, Chaerilidae, Diplocentridae, Euscorpiidae, Hemiscorpiidae, Ischnuridae, Iuridae, Scorpionidae). Revista Ibérica de Aracnología 7: 235-238.

Thorell, T. 1876. Etudes scorpiologiques. Atti della Società Italiana di Scienze Naturali 19: 75-272.

Vachon, M. 1952. Étude sur les Scorpions Alger: Institut Pasteur d'Algérie, 482 pp.

Vachon, M. 1973 [1974]. Étude des caractères utilisés pour classer les familles et les genres de scorpions (Arachnides). 1. La trichobothriotaxie en arachnologie: Sigles trichobothriaux et types de trichobothriotaxie chez les scorpions. Bulletin du Muséum National d'Histoire Naturelle Ser. 3 140: 857-958.

Volschenk, E.S., C.I. Mattoni, and L. Prendini. 2008. Comparative anatomy of the mesosomal organs of scorpions (Chelicerata, Scorpiones), with implications for the phylogeny of the order. Zoological Journal of the Linnean Society 154: 651-675.

Weidner, H. 1959. Die Entomologischen Sammlungen des Zoologischen Staatsinstituts und Zoologischen Museums Hamburg. I. Teil. Pararthropoda und Chelicerata. I. Mitteilungen aus dem Hamburgischen Zoologischen Museum und Institut 57: 89-142.

Williams, S.C. 1970. A systematic revision of the giant hairy scorpion genus Hadrurus. Occasional Papers of the California Academy of Sciences 87: 1-62.

Complete lists of all issues of the Novitates and the Bulletin are available at World Wide Web site http://library.amnh.org/pubs. Inquire about ordering printed copies via e-mail from scipubs@amnh.org or via standard mail from: American Museum of Natural History, Library-Scientific Publications, Central Park West at 79th St., New York, NY 10024. TEL: (212) 769-5545. FAX: (212) 769-5009. 